Universidade de São Paulo

Instituto de Física e Química de São Carlos

\title{
Um Estudo Sobre Centros DX em $\mathrm{Al}_{x} \mathrm{Ga}_{1-x} \mathrm{As}$
}

Luis Vicente de Andrade Scalvi

Tese apresentada ao Instituto de Física e Química de São Carlos para obtenção do título de Doutor em Ciências (Física Aplicada)

Orientador Prof. Dr. Pierre Basmaji

Departamento de Física e Ciência dos Materiais

São Carlos

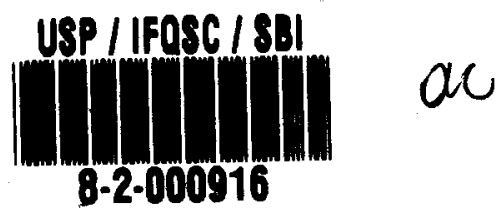

1991 


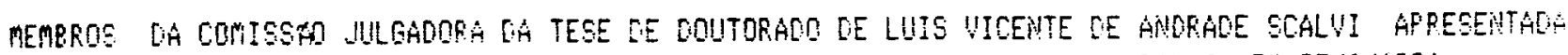
AO IHETTTUTO OE FISICA E RUIMICA DE SHO CARLOS. DA UNIUEREIDADE DE SHO PALLO, EM 27/3/1991

COMISSAO UUEGHOFA:

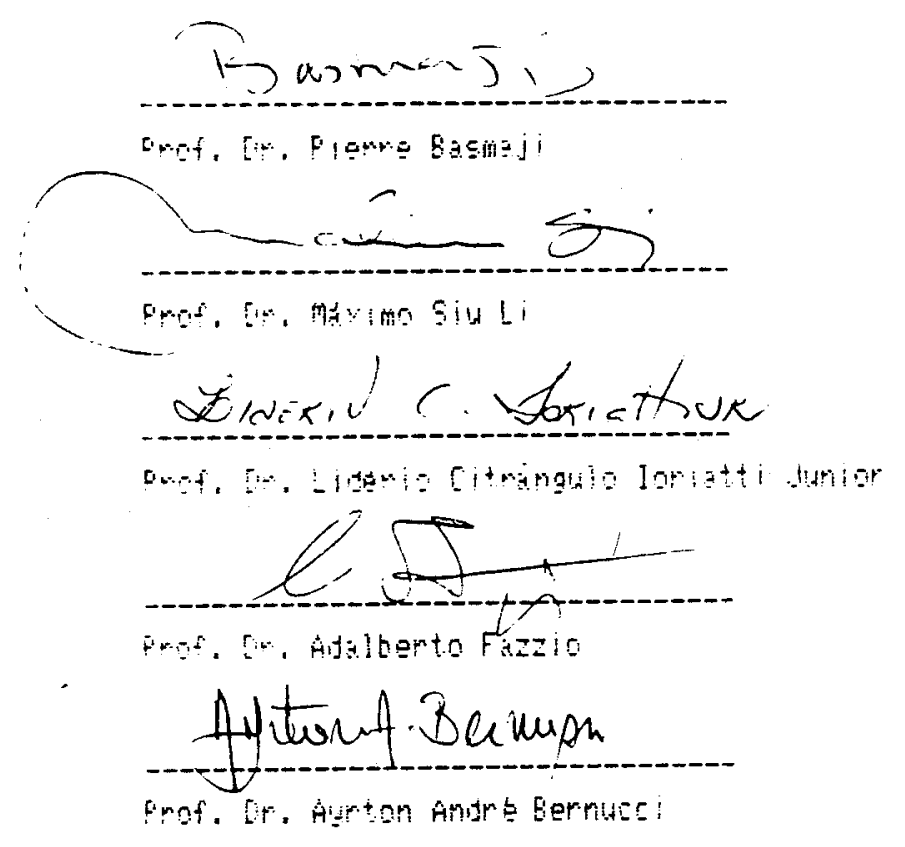

Cx. Postal, 369 - FONE (0162) 71-1016 - Fax (0162) 72-2218 - CEP 13560 - São Carlos - SP - Telex 162374 - FQSC - BR - BRASIL 


\section{AGRADECIMENTOS}

Este trabalho contém vários anos de aprendizado e dedicação que jamais poderiam ter acontecido não fosse a ajuda de muitas pessoas a quem eu serei eternamente grato. Antes de mais nada gostaria de agradecer ao Prof. Oscar Hipólito pela oportunidade de estagiar por 2 anos nos Estados Unidos.

Nesse lado "americano" do meu trabalho, agradeço ao Prof. John Arthur, um dos pioneiros de M.B.E. no mundo, um exemplo de simpatia e disposição, que me acolheu nos laboratórios da Oregon State University e sempre me incentivou muito. Ao Prof. John Wager, meu orientador efetivo nos Estados Unidos cujos ensinamentos e visão crítica influenciaram de forma altamente positiva meu trabalho e minha carreira futura. Ao Dr. Seung-Bae Kim, meu companheiro de trabalho, que dividiu comigo duras horas de trabalho e discussões fundamentais. A Thomas Dobson que me deu o empurrão inicial na técnica de TDPPC. Aos Drs. John Ebner, Yong-Mo Yoo e Jenifer Lary e ao Prof. Stephen Goodnick que muito me ensinaram. Ao técnico Leon Ungier que me pagou o primeiro café em Corvallis e sem o qual eu não teria feito absolutamente nada.

Pelo lado brasileiro eu agradeço ao meu orientador Prof. Pierre Basmaji, por muito boas discussões e o incentivo na conclusão de meu trabalho. Aos Prof. Lidério Ioriatti e Máximo Siu Li por boas discussões. A Eduardo Minami, com quem eu dividi as últimas horas de trabalho experimental. Aos amigos Airton, Newton, Rossi e Washington, companheiros de trabalho. A André Maeda pela discussão sobre contatos ôhmicos. Agradeço principalmente a Carlos Alberto de Souza, responsável pela maioria das ilustrações nesse texto e Haroldo Arakaki, sem os quais essa tese não seria concluída.

Gostaria de mencionar também meus companheiros de moradia Nagib e Wilson, que respeitaram minhas horas de sono e aguentaram os momentos de mau humor.

A CAPES e CNPq pelo apoio financeiro.

Finalizando, eu naturaimente agradeço a minha familia que sempre segurou a barra, mesmo nos momentos em que ela foi muito pesada. 


\section{ÍNDICE}

página

Lista de Tabelas e Ilustrações

Notação

.$i$

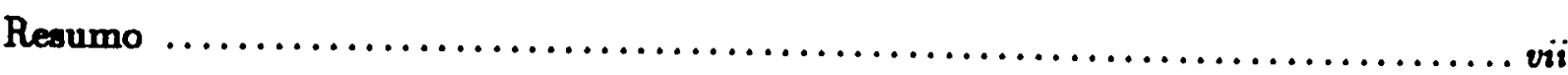

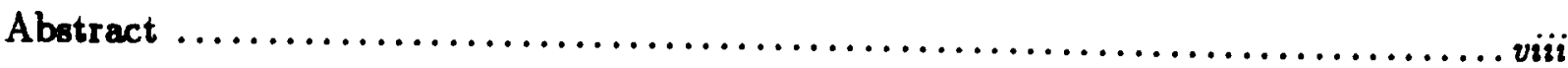

Introdução

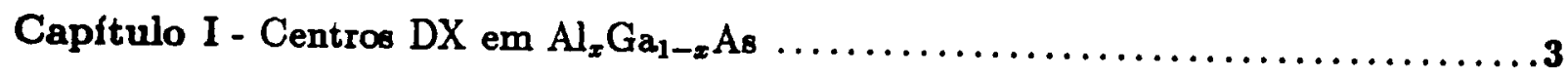

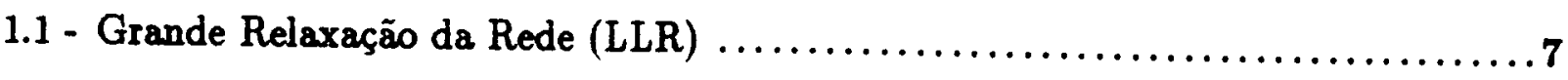

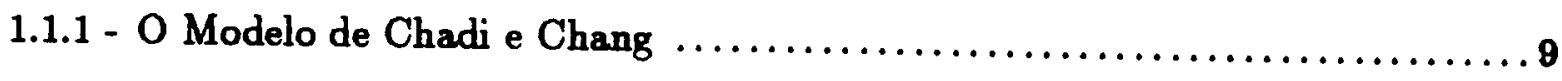

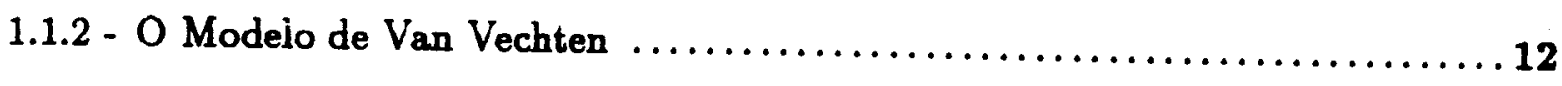

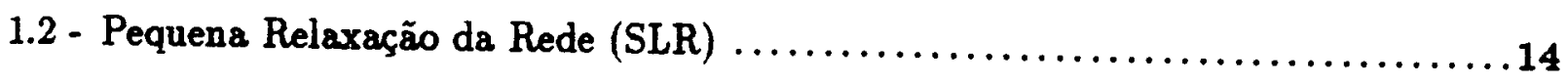

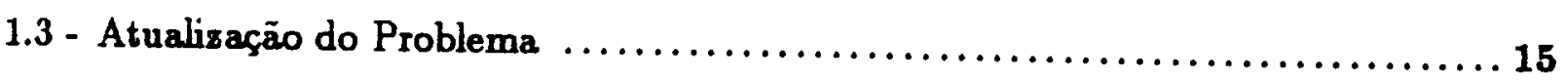

Capítulo II - Tecnologia da Obtenção de Amostras $\ldots . \ldots \ldots \ldots \ldots \ldots \ldots \ldots \ldots . \ldots 20$

2.1 - Crescimento por Epitaxia por Feixes Moleculares (MBE) $\ldots \ldots \ldots \ldots \ldots \ldots \ldots . \ldots 20$

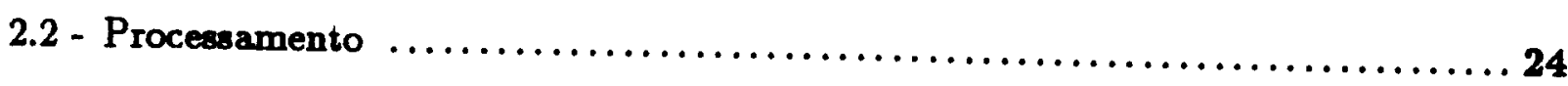

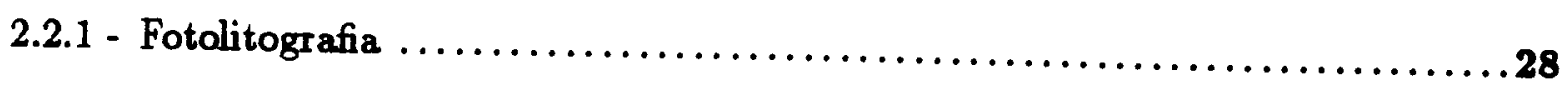

2.2.2 - Confecção das Máscaras .................................. 30 
Capítulo III - Decaimento d $\mathrm{z}$ Fotocondutividade Persistente (TDPPC) 38

3.1 - O Experimento de TDPPC 40

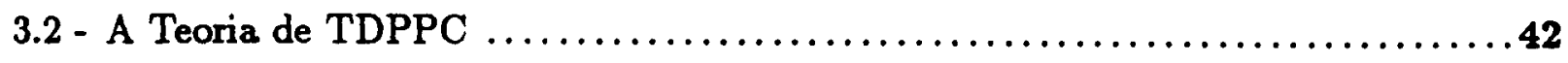

3.2.1 - Concentração de Eletrons Livres $\ldots \ldots \ldots \ldots \ldots \ldots \ldots \ldots \ldots \ldots \ldots \ldots \ldots \ldots \ldots \ldots \ldots \ldots \ldots$

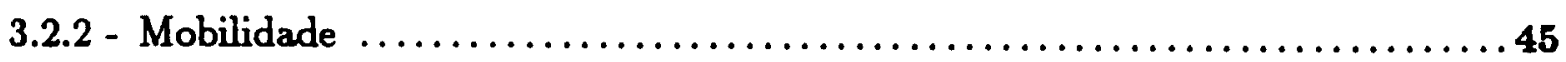

3.3 - Modelos de Centros DX para a Simulação Numérica ...................49

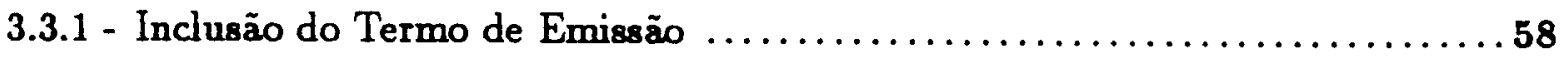

Capitulo IV - O Problema dos Contatos Ôhmicos a Baixa Temperatura .........60 60

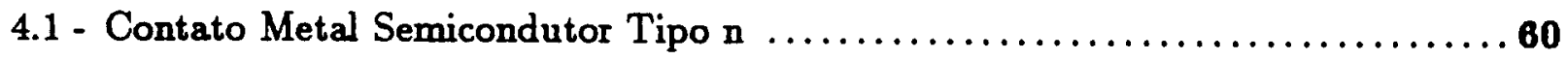

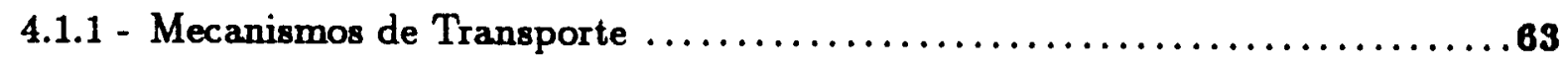

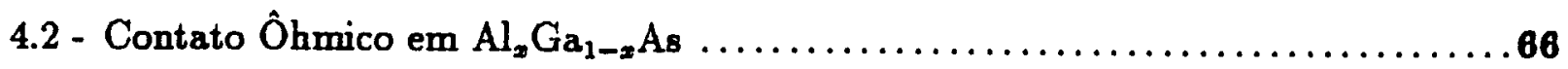

4.2.1 - Características Corrente-Voltagem da Liga Au/Ge/Ni como um Contato

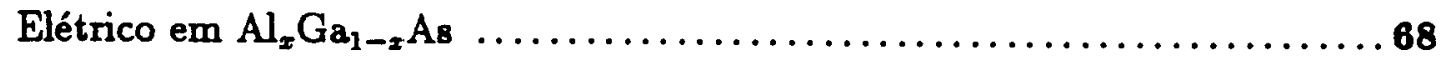

4.2.2 - Discussão dos Resultados Obtidos a Baixa Temperatura ...............74

Capitulo V - Outros Resultados Envolvendo Centros DX .................80

5.1 - Existência de Centros $\mathrm{DX}$ em $\mathrm{Al}_{x} \mathrm{Ga}_{1-x} \mathrm{As}$ dopado com $\mathrm{Pb} \ldots \ldots \ldots \ldots \ldots . \ldots 80$

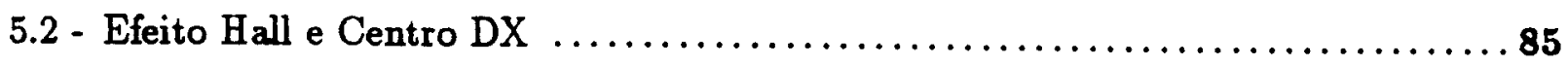

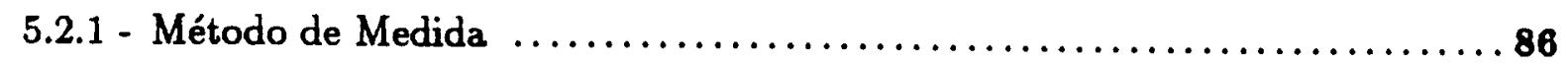




\section{LISTA DE TABELAS}

página

III.1 - Resumo da Simulação Numérica para todos os modelos

III.2 - Parâmetros usados na simulação de TDPPC para o modelo de Chadi e Chang em conjunção com o nível mais raso $\ldots \ldots \ldots \ldots \ldots \ldots \ldots \ldots \ldots \ldots \ldots$

III.3 - Parâmetros usados na simulação de TDPPC baseada no modelo de Van Vechten mais um termo $\mathrm{N}_{S D}$

III.4 - Parâmetros usados na simulação de TDPPC para o modelo de Chadi e Chang em conjunto com o nível mais raso para $\mathrm{Al}_{0.34} \mathrm{Ga}_{0.68} \mathrm{As}$ .57

III.5 - Parâmetros para análise da influência do termo de emissão na cinética de captura do centro DX pelo modelo de Chadi e Chang

V.1 - Medidas de voltagens para determinação de resistividade e coeficiente Hall em AlGaAs:Si

V.2 - Valores de concentração de eletrons e mobilidade obtidos por efeito Hall 90

A.1 - Energia de captura a partir de dados de TDPPC .100

\section{LISTA DE FIGURAS}

1.1 - Energia de ligação $\left(\mathrm{E}_{d}\right)$ do nível doador dominante de $\mathrm{Si}$ em $\mathrm{Al}_{x} \mathrm{Ga}_{1-x} \mathrm{As}$ em função da composição de Al 
1.2 - Valores de energia mínimos nos vales $\Gamma, L$ e $X$ e posições relativas do centro DX

1.3 - Esquema de energias envolvidas nas transições de carga do centro DX e diagrama de coordenada configuracional

1.4 - Vista esquemática da distorção da rede em torno do átomo doador segundo o modelo de Chadi e Chang

1.5 - Diagrama esquemático do processo de captura de um eletron em um centro DX segundo o modelo de pequena relaxação da rede

2.1 - Espectro Auger pré crescimento de um substrato semi-isolante de GaAs

2.2 - Diagrama esquemático da estrutura das amostras crescidas por M.B.E.

2.3 - Oscilações na intensidade do feixe especular RHEED para 0.6 monocamadas por segundo de GaAs (001)

2.4 - Espectro Auger de uma amostra com camada ativa de $\mathrm{Al}_{0.4} \mathrm{Ga}_{0.8} \mathrm{As}$ .26

2.5 - Diagrama esquemático das amostras processadas para experimentos de TDPPC e Foto-Hall

2.6 - Diagrama de um passo do processamento fotolitográfico das amostras usadas

2.7 - Máscaras usadas no processamento de amostras para o experimento de TDPPC

2.8 - Máscaras usadas no processamento de amostras para o experimento de Foto-Hall

2.9 - Princípio de funcionamento do sistema de vácuo da evaporadora VEECO

2.10 - Princípio básico de funcionamento do sistema VEECO de sputtering 37

3.1 - TDPPC de uma amostra de $\mathrm{Al}_{0.3} \mathrm{Ga}_{0.7} \mathrm{As}$ a $60 \mathrm{~K}$ 39

3.2 - Esquema de montagem do experimento de TDPPC .40

3.3 - TDPPC de uma amostra de $\mathrm{Al}_{0.5} \mathrm{Ga}_{0.5} \mathrm{As}$ a temperaturas de 80 e $90 \mathrm{~K}$ .41 
3.4 - TDPPC de uma amostra de $\mathrm{Al}_{0.3} \mathrm{Ga}_{0.7} \mathrm{As}$ a $85 \mathrm{~K}$

3.5 - Dependência com a temperatura da mobilidade devida a diferentes tipos de espalhamento

3.6 - Mobilidade x concentração de $\mathrm{Al}$ para $\mathrm{Al}_{x} \mathrm{Ga}_{1-x} \mathrm{As}$, segundo os potenciais de Brooks-Herring e Takimoto

3.7 - Mobilidade x temperatura para $\mathrm{Al}_{0.5} \mathrm{Ga}_{0.5} \mathrm{As}$, segundo os potenciais de Brooks-Herring e Takimoto

3.8 - Simulação numérica do modelo do aceptor simples com uma concentração líquida de doadores rasos

3.9 - Simulação do modelo de Chadi e Chang

3.10 - Simulação baseada no modelo de Chadi e Chang mais doador mais raso .56

4.1 - Formação da barreira entre metal e semicondutor

4.2 - Processos de transporte numa barreira Schottky com polarização direta

4.3 - Comportamento típico corrente-tensão de uma barreira Schottky

4.4 - Curvas I-V para uma amostra de $\mathrm{Al}_{0.3} \mathrm{Ga}_{0.7} \mathrm{As}$ em função da temperatura

4.5 - Curvas I-V para $\mathrm{Al}_{0.3} \mathrm{Ga}_{0.7} \mathrm{As}$ em função da temperatura .70

4.6 - Curvas I-V para $\mathrm{Al}_{0.5} \mathrm{Ga}_{0.5} \mathrm{As}$ em função da temperatura .71

4.7 - Curvas I-V para $\mathrm{Al}_{0.5} \mathrm{G}_{2_{2} .5} \mathrm{As}$ em função do tempo de recozimento 72

4.8 - Curvas I-V para $\mathrm{Al}_{0.4} \mathrm{G}_{4_{0.8}} \mathrm{As}$ em função do tempo de recozimento 73

4.9 - Curvas $\mathrm{I}-\mathrm{V}$ para $\mathrm{Al}_{0.5}$ Gío.5 $\mathrm{As}$ a $75 \mathrm{~K}$

4.10 - Diagrama de bandas qualitativo das amostras estudadas sem a aplicação de potencial

4.11 - Diagrama de bandas qualitativo com aplicação de uma diferença de potencial .. 78

4.12 - Características corrente-voltagem calculadas e normalizadas em função do fator de idealidade 
5.1 - Espectro de Fotocondutividade de $\mathrm{Al}_{0.24} \mathrm{Ga}_{0.76} \mathrm{As}$ a $77 \mathrm{~K}$

5.2 - Resistência $\times$ Temperatura para $\mathrm{Al}_{0.24} \mathrm{Ga}_{0.76} \mathrm{As}$ dopado com $\mathrm{Pb}$ 84

5.3 - Nomenclatura dos contatos para medidas do efeito Hall .87

5.4 - Concentração de eletrons em função da temperatura medido por efeito Hall ....91

5.5 - Mobilidade em função da temperatura medido por efeito Hall 82

A.1 - Gráfico de Arrhenius para se obter a energia de captura do centro DX. 101 


\section{NOTAÇÃO}

$c_{n}$ - taxa térmica de captura de eletrons

$d^{+}, d^{\circ}-$ estados de carga da impureza doadora

e - carga do eletron

$e_{n}$ - taxa térmica de emissão de eletrons

$\mathbf{g}$ - degenerescência

h - constante de Planck

$\mathbf{k}_{B}$ - constante de Boltzmann

$m_{e i}$ - massa efetiva no vale $i$

$m_{e}^{*}$ - massa efetiva para a condutividade

$n_{i}, n$ - concentração de eletrons no vale $i$ e total

$\mathrm{n}_{\mathbb{0}^{\circ}}, \mathrm{n}_{D X}{ }^{-}, \mathbf{n}_{d^{+}}-$concentração de estados $\mathrm{d}^{\circ}, \mathrm{DX}^{-}$e $\mathrm{d}^{+}$respectivamente

$\mathrm{I}$ - distância radial

$\mathbf{r}_{H}$ - fator do coeficiente Hall

$t$ - tempo

w - largura da camada de depleção

B - campo magnético

$E_{\text {cap }}$ - barreira de energia para captura pelo centro DX

$E_{\text {emiss }}$ - barreira de energia para emissão pelo centro DX

$E_{d}$ - energia de ligação

$E_{p}$ - nível de Fermi

$\Delta E_{t}$ - diferença de energia entre nível profundo e mínimo da banda de condução

$\mathrm{E}_{B C}$ - mínimo da banda de condução

$E_{C V}$ - gap de energia

G - condutância

I - corrente

$\mathrm{K}_{S}$ - constante de proporcionalidade entre condutividade e condutância

$\mathrm{M}_{A s}$ - átomo de metal em posição anti-sítio ( no lugar do átomo de arsênio) 
$\mathrm{N}$ - número de mínimos equivalentes (banda de condução)

$\mathrm{N}_{S D}, \mathrm{~N}_{S A}$ - concentração de doadores rasos e aceitadores rasos respectivamente

$\mathrm{N}_{i i}$ - concentração de impurezas ionizadas

$\mathrm{N}_{c i}$ - densidade de estados no vale $\mathrm{i}$

$R$ - resistência

$\mathrm{R}_{H}$ - coeficiente Hall

$\mathrm{V}$ - voltagem

$V_{A \text { A - vacância de Arsênio }}$

$V_{\text {th }}$ - velocidade térmica dos eletrons

$T$ - temperatura

Z - carga da impureza

$\gamma_{n}$ - secção transversal de captura

$\gamma_{\infty}$ - secção transversal de captura a alta temperatura

$\varepsilon$ - constante dielétrica

$\varepsilon_{0}$ - permissividade elétrica no vácuo

$\mu$ - mobilidade

$\mu_{H}$ - mobilidade Hall

$\nu_{n}$ - seç̧ão transversal para emissão

$\rho$ - reaistividade

$\sigma-$ condutividade

$\tau$ - tempo de relaxação

$\phi_{b}$ - altura da barreira no contato metal-semicondutor

$\phi_{m}$ - função de trabalho do metal

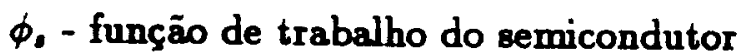

$\Phi$ - função de onda do doador substitucional

$\Psi_{c}^{\circ}$ - funções de Bloch do cristal não perturbado

$\chi_{e}$ - afinidade eletrônica

$\Omega$ - volume do cristal

$f$ - fator para o cálculo de resistência (efeito Hall)

$f_{I}$ - fator de idealidade

$F_{i}$ - integral de Fermi-Dirac de ordem i 


\section{RESUMO}

É feito um resumo dos principais modelos criados para se explicar as intrigantes propriedades do centro DX e atualizar o problema. O decaimento da fotocondutividade persistente (PPC) é medido em $\mathrm{Al}_{x} \mathrm{Ga}_{1-x}$ As dopado com Si e se discute a validade dos modelos em função da cinética de captura dos eletrons pelos centros DX. Boa concordância com o modelo de Chadi e Cnang é encontrada desde que se postule a existência de um nível doador mais raso. O crescimento por MBE assim como todo o processamento de amostras para os experimentos realizados é descrito sinteticamente.

É discutido também o problema dos contatos a baixa temperatura e a possível influência dos centros DX nos desvios do comportamento ôhmico observados. Incluise também a descoberta da. fotocondutividade persistente em $\mathrm{Al}_{x} \mathrm{Ga}_{1-x} \mathrm{As}$ dopado com $\mathrm{Pb}$, que também é relacionado à existência dos centros $\mathrm{DX}$ 


\section{ABSTRACT}

A short discussion about the main models created to explain the striking properties cf the DX center is done in order to bring the problem up-to-date. The decay of persistent photoconductivity is measured and it is analysed as a function of the kinetics of electron trapping by $\mathrm{DX}$ centers in Si-doped $\mathrm{Al}_{x} \mathrm{Ga}_{1-x} \mathrm{As}$, according to these models. Good agreement with Chadi and Chang's model is found as long as we postulate the existence of a shallower donor. The M.B.E. growth as well as the whole sample processing is shortly described.

It is also discussed the problem of low temperature contacts and the possible influence of DX centers in the deviation from ohmic behavior. Persistent Photoconductivity has been found in $\mathrm{Pb}$-doped $\mathrm{Al}_{x} \mathrm{Ga}_{1-x} \mathrm{As}$ and it is also related to the $\mathrm{DX}$ center existence.

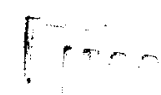




\section{INTRODUÇÃO}

Centro DX é um tópico que tem atraído a atenção de um grande número de pesquisadores no últimos anos e tem sido, de modo geral, associado com a concentração de impurezas doadoras presentes no material. Devido à inevitabilidade da presença desses defeitos em ligas semicondutoras de $\mathrm{Al}_{x} \mathrm{Ga}_{1-x} \mathrm{As}(0 \leq \mathrm{x} \leq 1)$ tem havido dúvidas sobre a real importância tecnológica de dispositivos baseados nessas ligas.

Desde o início das investigações, o semicondutor composto GaAs tem chamado a atenção devido ao gap proibido de energia ser direto, ou seja, o mínimo da banda de condução se dá exatamente no vale $\Gamma$, de mesmo momento de cristal que o máximo da banda de valência. No vale $\Gamma$ a mobilidade é muito maior que em outros vales. Um outro aspecto é a potencial importância do sistema $\mathrm{Al}_{x} \mathrm{Ga}_{1-x} \mathrm{As} / \mathrm{GaAs}$ devido à pequena diferença entre o parâmetro de rede de GaAs e AlAs, o que inibe a formação de uma concentração de estados adicionais indesejáveis. Essas características tornam essas ligas especialmente atraentes para dispositivos eletrônicos de alta velocidade e dispositivos optoeletrônicos.

Além dos aspectos negativos da presença do centro DX em termos do funcionamento de dispositivos, as particularidades desse defeito têm atraído a atenção de um número já grande e ainda crescente de pesquisadores em todo o mundo. Seria impossível falar sobre o assunto sem necessariamente ser injusto com um ou outro trabalho, já que o número de publicações é imenso. Apesar diseo ( e exatamente por isso) não existe um consenso a respeito de um modelo que conseguisse explicar totalmente os efeitos advindos do centro DX, entre os quais se encontra a surpreendente propriedade conhecida como fotocondutividade persistente (PPC) e que consiste basicamente no congelamento de eletrons num estado metaestável 
na banda de condução a baixas temperaturas, devido à presença de uma barreira térmica de ativação.

Existem duas tendências para se modelar o centro DX: uma que vê o centro DX como um estado ligado ao vale $\mathrm{L}$ e obtido naturalmente como consequência da teoria da massa efetiva e a outra linha de raciocínio atribui ao centro DX um caráter de grande relaxação da rede ligando diferentes estados de energia. $O$ potencial da impureza de um átomo doador substitucional pode ser escrito como a soma do potencial coulombiano de longo alcance mais um potencial da célula central de curto alcance. Os estados eletrônicos resultantes serão de dois tipos : rasos devido a potencial coulombiano e mais profundos relacionados com o potencial da célula central ${ }^{1,2}$. O estado a que se referem os partidários da teoria de pequena relaxação da rede para o centro DX, teria simetria $A_{1}$ (localizado). Trabalhos recentes têm demonstrado que o estado de simetria $A_{1}$, cuja energia depende fortemente da identidade química dos doadores, não pode ser o centro DX, pois a evidência experimental é de que o estado profundo envolvido não apresenta barreira à transferência de eletrons para o estado raso $1,3,4$. Exastem muitas evidências de que a captura de eletrons pelo centro DX se dá via relaxação da rede ${ }^{1,5}$.

Ense trabalho tem a intenção de também ser uma contribuição nesse sentido, ou seja, o trabalho é favorável à segunda linha de pensamento assim como o são a grande maioria dos peequisadores. Serão discutidas as possibilidades para o modelamento do centro DX e é proposto um experimento para tratar esses modelos sob o ponto de vista da cinética de captura. Esse experimento é aplicado para amostras de $\mathrm{Al}_{3} \mathrm{Ga}_{1-\infty} \mathrm{As}$ crescidas por epitaxia por feixes moleculares (M.B.E.). É também discutido o problema da formação de contatos ôhmicos nessas amostras e a possível influência dos centros DX no comportamento a baixa temperatura. São incluídos também experimentos adicionais que colaboram nas conclusões sobre o defeito.

Toda a tecnologia sobre o processamento de amostras é descrita em capítulo a parte. Isso é feito de modo a compartilhar o conhecimento prático adquirido nesses anos de trabalho e que eu espero, venha a ser bastante útil aos possíveis leitores. 


\section{CAPÍTULO I}

CENTROS DX EM Al $\mathrm{Ga}_{1-X}$ As

Centro DX é um defeito presente em ligas III-V tais como $\mathrm{Al}_{x} \mathrm{Ga}_{1-x} \mathrm{As}$ e que apresenta tal particularidade que tem sido enquadrado numa classe de defeitos totalmente nova. Devido à importância tecnológica das ligas III-V na fabricação de dispositivos tais como lasers semicondutores, diodos emissores de luz e varios tipos de transistores ${ }^{5-7}$, o conhecimento e prevenção dos efeitos detrimentais associados aos centros DX é de fundamental relevância ${ }^{8}$. Esses efeitos ocorrem principalmente a temperaturas baixas. Um exemplo desses dispositivos, o transistor de alta mobilidade eletrônica (HEMT) tem suas características I-V altamente melhoradas a temperaturas menores que $100 \mathrm{~K}^{6}$. Daí vem a importância prática do estudo de centros DX, que são responsčiveis por um dos mais intrigantes fenômenos da física de semicondutores, a chamada fotocondutividade persistente (PPC), que consiste basicamente num congelamento de eletrons num estado metaestável na banda de condução e que ocorre exatamente a baixa temperatura. Em outras palavras quando se ilumina a amostra os eletrons presos nos centros DX são excitados para a banda de condução e devido à existência de uma barreira de captura, eles permanecem no estado condutivo. Dependendo da temperatura (mais baixa) o tempo de captura pode ser infinitamente longo.

O nome centro DX foi proposto originalmente por Lang e colaboradores ${ }^{9}$ que constataram que as observaçōes experimentais desse defeito sempre apontavam para 
uma concentração proporcional à concentração dos dopantes doadores incorporados na amostra, daí a associação com a letra D. Além disso, havia fortes indicações de um comportamento não-hidrogênico, então a associação com um defeito desconhecido $\mathrm{X}$.

Centro DX tem sido encontrado em um grande número de cristais epitaxiais crescidos por diferentes técnicas tais como epitaxia em fase líquida (LPE), deposição em vapor químico (CVD) e epitaxia por feixes moleculares (MBE) ${ }^{10}$, técnicas que produzem filmes bastante homogêneos. Devido à qualidade dos filmes produxidos por diferentes técnicas, não é provável que o defeito seja originário de instabilidades microscópicas localizadas que ocorreriam durante o crescimento. Ainda que essas técnicas produzam filmes de altíssima qualidade, investigações experimentais invariavelmente revelam a existência de centros DX.

A figura 1.1 fornece a energia de ligação do átomo doador de $\mathrm{Si}$ numa rede de $\mathrm{Al}_{x} \mathrm{Ga}_{1-x} \mathrm{As}$, para níveis moderados de dopagem. A energia de ligação é a energia líquida para ionizar a impureza doadora. Esta energia corresponde a distância entre o nível do átomo doador e o mínimo da banda de condução. A partir de $x$ aproximadamente 0.22 esta energia passa a ser correspondente a um nível profundo, diferindo do nível raso que existe para $x<0.22$.

Experimentos em AlGaAs com aplicação de pressão hidrostática ${ }^{12,13}$ mostraram que DX também existe nas ligas com composição $x<0.22$, a diferença é que ele é localizado acima do mínimo da banda de condução, sendo portanto ressonante com o vale $\Gamma$. A variação dos mínimos dos vales $\Gamma, L$ e X em função da composição de alumínio é mostrado na figura 1.2. Também é mostrado a variação da energia de ligação de silício - DX. Os níveis referentes ao centro DX estão divididos em quatro linhas tracejadas devido a trabalhos recentes que reportam a existência de quatro níveis energéticos do centro DX ${ }^{14,15}$. Isso é facilmente interpretável ao se pensar que a vizinhança do átomo de Si pode ser ocupada por um número variável de átomos de Al. A existência de quatro níveis pode ser explicada com base no modelo de grande relaxação da rede (LLR) que será discutido na seç̧ão 1.1, aonde o centro DX, um átomo de $\mathrm{Si}$ deslocado para uma posição intersticial ao longo da direção <111> pode possuir um número de 0 a 3 átomos de alumínio como vizinhos próximos. A 


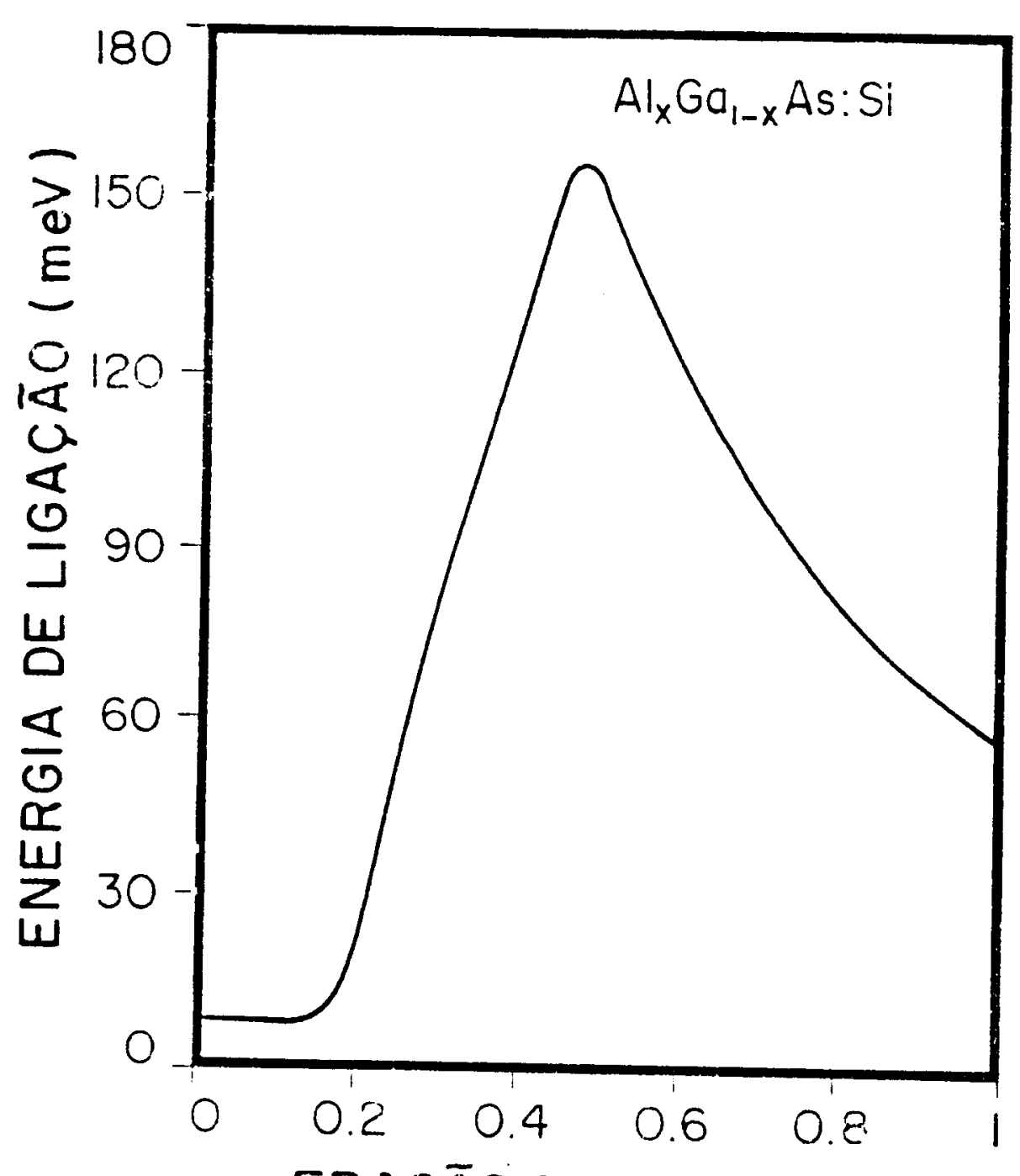

FRACĀO MOLAR DE. AI

Figura 1.1 - Energia de ligação $\left(E_{d}\right)$ do nível doador dominante de $\mathrm{Si}$ em $\mathrm{Al}_{3} \mathrm{Ga}_{a_{1-}, \mathrm{As}}$ em função dus comporiçäo de Al ${ }^{11}$ 


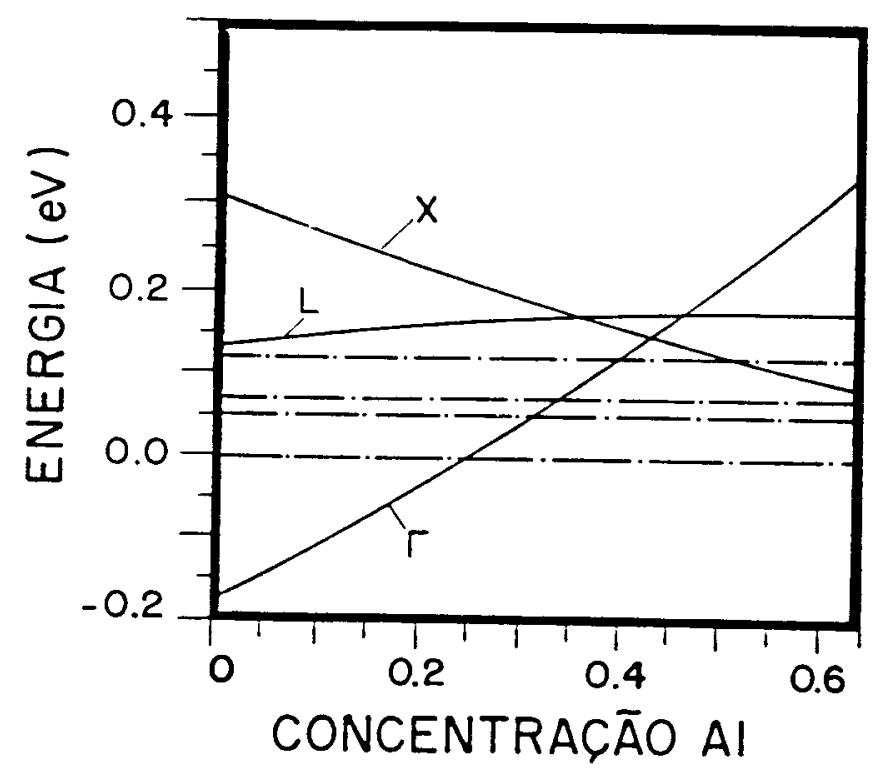

Figara 1.2 - Valores de energia do mínimo dos vales $\Gamma$, L e X e posiçöes relativas do centro $\mathrm{DX}^{14-16}$. O valor de energia de DX mais baixo é tomado como linha de referência (igal a zero)

transição direta-indireta de energia se dá em torno de $x$ aproximadamente $0.45 \mathrm{e}$ como pode ser verificado na figura 1.1 a energia de ligação possui um máximo em torno desse valor de composição de $\mathrm{Al}$.

Deve-se ressaltar que a figura 1.1 é válida para concentraçóes moderadas do dopante Si. Para amostras altamente dopadas (concentração $>2 \times 10^{19} \mathrm{~cm}^{-3}$ ) o centro DX é empurrado para cima ${ }^{17}$, ou seja, tende a ficar acima do mínimo da banda de condução, ressonante com o vale $\Gamma$ (ou X, dependendo da composição de Aluminio).

Apesar de muito trabalho realizado e artigos publicados nos últimos 20 anos, a física do centro DX ainda não é completamente conhecida. Na realidade existe ainda controvérsia a respeito do defeito apresentar pequena ou grande relaxação da rede, e mesmo dentro dessas correntes não há um consenso total a respeito de modelos. 


\section{1 - GRANDE RELAXAÇÃO DA REDE}

O primeiro modelo largemente aceito foi proposto por Lang et a ${ }^{9}$ que construíram o diagrama mostrado na figura 1.3, ainda largamente utilizado. $\mathrm{Na}$ figura 1.3(a) é mostrado um esquema das energias associadas ao centro DX com relação a mínimo da banda de condução, que seria a linha central. As elevações representam as barreiras de energia térmica (energias de ativação) entre dois estados distintos, ou seja : aonde o eletron está preso ao centro DX e onde está na banda de condução. A energia de ionização ótica é muito maior que a energia de ionização térmica o que sugere um deslocamento de Franck-Condon razoavelmente grande. A figura 1.3(b) representa um diagrama de coordenada configuracional onde a ordenada é uma representção da energia eletrônica mais a energia de distorção do defeito. Assim, para que o eletron preso ao centro DX possa ser emitido para a banda de condução termicamente, a temperatura tem que ser suficiente para que o defeito (eletron mais distorção da rede) possua energia maior que $E_{\text {emiss }}$ (energia de ativação para emissão). Do mesmo modo como o eletron preso metaestavelmente na banda de condução só poderá voltar ao estado localizado se a energia térmica for maior que $\mathrm{E}_{\text {cap }}$ (energia de ativação para captura). O centro DX é um dos casos de mais forte acoplamento com a rede que se conhece, onde as energias associadas à relaxação da rede são da ordem ou maiores que a energia de ligação, a qual é associada somente com a parte eletrônica da Hamiltoniana do defeito ${ }^{10}$. Esses efeitos da relaxação da rede são vistos na figura 1.3 e são manifestados pela captura de eletrons via emissão multifonon e deslocamentos de Stokes da energia de transição entre ionização ótica e ionizaçiso térmica. Desta forma a grande energia associada à ionização ótica é justificada por um modelo de grande relaxação da rede. Para explicar estas características observadas no centro DX, Lang et al propuseram um modelo no qual DX é da forma [ $\left[\mathrm{V}_{A \theta}\right.$ ] onde I significa o átomo da impureza doadora substitucional e $V_{A}$, é uma vacância de arsênio.

Existe um tipo comum de defeito que exibe todas as características qualitativas 


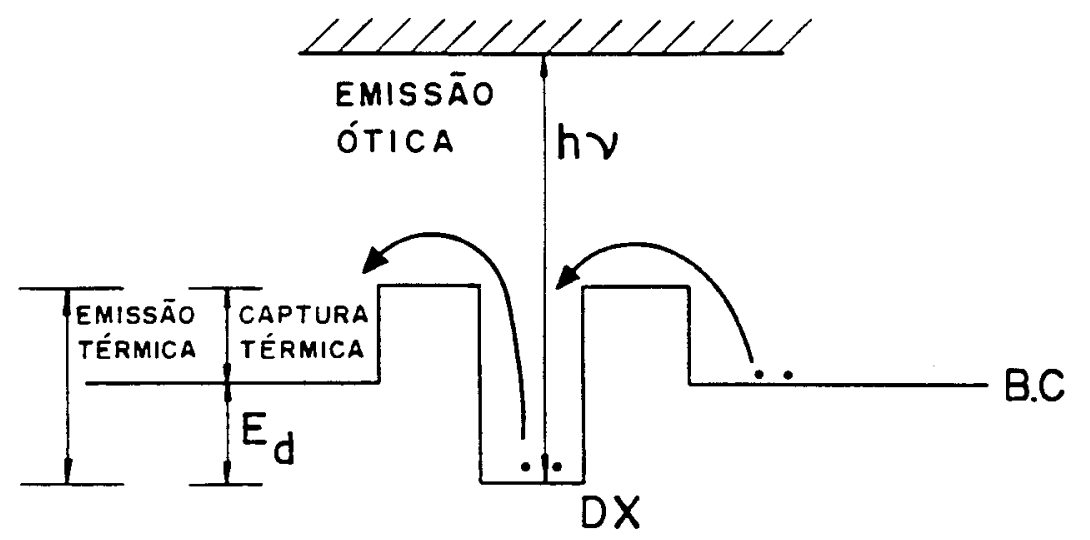

a)

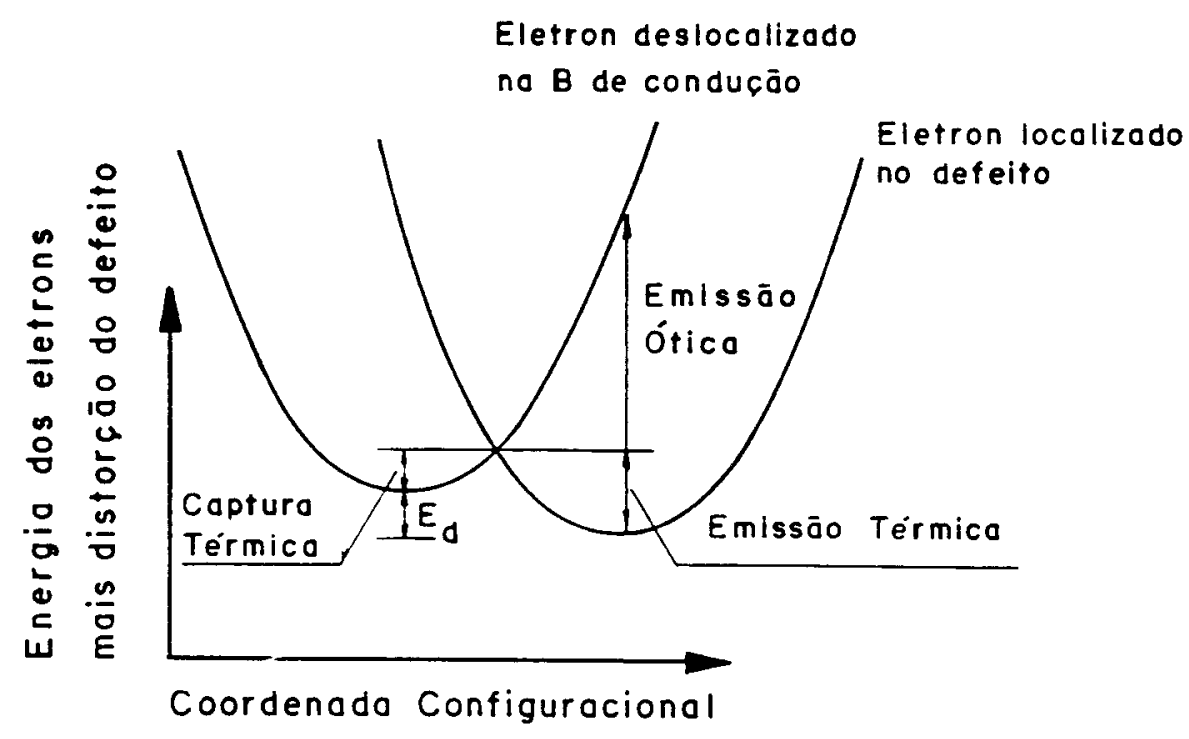

b)

Figara 1.3 - (a) - Esquema de energias envolvidas nas transições de carga do centro DX. (b) Diagrama de coordenada configaracional para explicar a localização do defeito 9 
do centro DX, sendo conhecidos como vacância-ânion doador. Qualquer complexo contendo uma vacância-ânion é dominado por esse defeito similarmente à vacância isolada. Lang et al associam esse complexo com o modelo proposto para o centro DX, ou seja uma vacância associada com uma impureza doadora. O potencial atrativo do átomo doador abaixará a simetria de $\mathrm{V}_{A \text { en }}$, separando estados degenerados cuja posição pode variar uns poucos décimos de um volt com diferentes elementos químicos doadores ou posição do átomo doador, porém as propriedades gerais do complexo serão dados por essa simetria resultante da vacância e pelo próprio potencial da vacância ${ }^{18}$. A vacância-ânion e seus complexos associados possuem estados profundos e estados ressonantes na banda de condução. É possível que o comportamento do centro DX esteja relacionado com a existência de um nível desocupado na banda de condução e um nível ocupado que relaxa para um estado ligado dentro do gap de energia. Para o caso aonde o próprio centro DX é ressonante na banda de condução (fração de alumínio < 0.22), diagramas similares ao da figura 1.3 seriam facilmente obtidos ${ }^{16,19}$.

\subsection{1 - O Modelo de Chadi e Chang}

Os estudos mais recentes têm demonstrado que independente da composição da liga, cada doador dá origem a 2 estados eletrônicos ${ }^{13,12,20-23}$. Um raso e deslocalizado, e um mais localizado, profundo no gap de energia, aparecendo de uma distorção da rede próxima do doador ou no próprio doador. Os experimentos com pressão ${ }^{12,13,24}$ têm demonstrado que a transição raso - profundo desses níveis é associada com o próprio átomo doador e que uma ligação dos doadores com outros defeitos tais como uma vacância de As não deve ocorrer.

Chadi e Chang ${ }^{19,23}$ propõe um modelo no qual o átomo doador se desloca ao longo da direção <111> ( no caso de dopante do grupo IV) para formar o defeito, conforme mostrado na figura 1.4. Conforme pode ser verificado, a relaxação da 
(a)

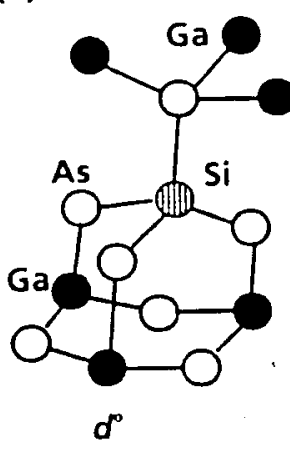

(c)

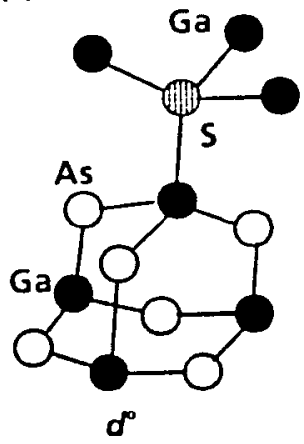

(b)

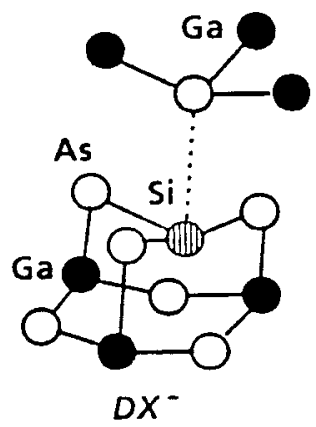

(d)

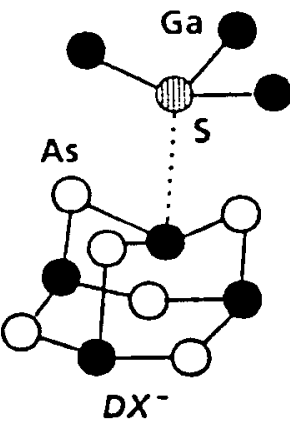

Figura 1.4 - Vista esquemática da distorção da rede em torno do átomo doador segando o modelo de Chadi e Chang ${ }^{19.23}$ (a) e (c) representam cristais de GaAs com dopagem de Si e S respectivamente. (b) e (d) representam as respectivas distorçöes. 
rede que leva à formação do centro DX depende da natureza química do dopante. A relaxação da rede devida ao dopante do grupo IV é devida ao deslocamento do próprio átomo doador, enquanto que no caso de grupo VI, é devida ao átomo de $\mathrm{Ga}$ (Al). Essa relaxação da rede seria responsável pelo grande deslocamento de Stokes verificado experimentalmente. Nesse modelo o centro DX tem comportamento com U-negativo. A idéia da interação com U-negativo foi primeiro utilizada por Anderson ${ }^{25}$ para modelar defeitos localizados em semicondutores amorfos. A interação efetiva é atrativa e pode ser vista como a soma da interação coulombiana repulsiva U mais a interação atrativa causada pelo pareamento de 2 elétrons na ligação. Isso implica num forte acoplamento elétron-fônon e o acioplamento resulta atrativo devido aos fônons compensarem o potencial repulsivo U. Desta forma o estado ocupado é um singlete com dois elétrons pareados, sendo portanto diamagnético. Falhas na obtenção de um sinal de ressonância paramagnética de elétron (EPR) justificam esse modelo já que espectros de EPR são observados apenas para estados de carga de níveis que são paramagnéticos. A reação global dando o centro DX é portanto :

$$
2 d^{\circ}=d^{+}+D X^{-}
$$

onde $\mathrm{d}^{\circ}$ é o estado do doador neutro, $\mathrm{d}^{+}$é o estado do doador que se ioniza liberando um eletron e $\mathrm{DX}^{-}$é o estado que capturou 2 eletrons e se relaxa para uma posição de nível profundo. Os cálculos de Chadi e Chang mostram que tanto o estado DX॰ como $\mathrm{DX}^{+}$são completamente instáveis em relação a $\mathrm{d}^{\circ} \mathrm{e}^{+}$. A equação 1.1 pode ser reescrita para uma amostra altamente dopada como :

$$
d^{+}+2 e^{-}=D X^{-}
$$

já que os elétrons formam um gás degenerado e estão aproximadamente todos ionizados. A relação entre as concentrações relativas do estado $d^{\circ}\left(n_{f^{\circ}}\right)$ e do estado $D^{-}\left(\mathbf{n}_{D X^{-}}\right)$é dada por ${ }^{18}$ :

$$
\frac{n_{d^{\bullet}}}{n_{D X-}}=\exp \frac{E_{d}\left(D X^{-}\right)}{k_{B} T}
$$

onde $E_{d}\left(\mathrm{DX}^{-}\right)$é a energia de ligação do centro $\mathrm{DX}$. Usando a energia de ligação dada pela figura 1.1, para uma amostra de $\mathrm{Al}_{0.9} \mathrm{Ga}_{0.7} \mathrm{As}$, nós teríamos $\mathrm{n}_{d^{\circ}} / \mathbf{n}_{D X}-=$ 
0.18 a $300 \mathrm{~K} \mathrm{e} \mathrm{n}_{d^{\circ}} / \mathrm{n}_{D X-}=0.0030$ a $90 \mathrm{~K}$. Desta forma à medida que a temperatura vai abaixando a concentração relativa de estados $d^{\circ}$ vai diminuindo e ocorre o congelamento dos elétrons que se prendem ao doador positivamente ionizado e relaxam a rede para a posição do nivel mais estável $\mathrm{DX}^{-}$. Se os elétrons fossem fotoionizados a baixa temperatura um bom modo de se representar a captura de retorno ao estado $\mathrm{DX}^{-}$seria, portanto, através da relação 1.2 .

$O$ modelo de Chadi e Chang tem sido o mais aceito atualmente pelos partidários dos modelos de grande relaxação da rede. Apesar disso existe ainda um ponto não muito claro a respeito desse modelo. Medidas de susceptibilidade magnética feitos por Khachaturyan et a $^{28}$ mostraram mudanças na susceptibilidade eletrônica com variação da temperatura, o que mostra que DX não poderia ser diamagnético e que possui um elétron não pareado, sendo portanto, paramagnético. Isso é contrastante com o modelo com interação de U-negativo como proposto por Chadi e Chang.

\subsection{2 - O Modelo de Van Vechten}

Na hipótese do modelo de Lang et al ${ }^{9}$, o X de DX é uma vacância de As, o qual tem 2 configurações separadas por uma larga relaxação da rede, cuja origem não é especificada por eles. Van Vechten ${ }^{8,27}$, argumenta que LLR é devido simplesmente ao salto do vizinho próximo, que pode ser exemplificado por :

$$
D^{+} V_{A_{1}}^{o}+3 e^{-}=D^{+} M_{A_{1}}^{2-} V_{G_{a}}^{-}
$$

onde $M$ pode ser tanto $A j$ ou $G a$, um dos vizinhos próximos da vacância de $A_{s}\left(V_{A s}\right)$ que saltou na reação.

A associação da presença de DX com vacâncias tem sido refutada em função 
da concentração de DX ser sempre suficiente para compensar uma larga fração dos dopantes independente do potencial químico de arsênio na superfície do cristal durante o crescimento, mesmo variando tanto a fração de arsênio como a pressão de vapor de As ou ainda o fluxo de arsênio durante o crescimento por MBE. Além disso os experimentos com pressão em GaAs que revelaram o estado ressonante do centro DX são consistentes com a observação de que DX é um estado profundo no gap de energia do próprio doador. Van Vechten acredita que isso seria válido somente se fosse provado que não existem vacâncias de arsênio suficientes em GaAs puro. Pelo contrário, estudos de aniquilação de pósitrons ${ }^{28}$, mostraram que existem vacâncias suficientes em qualquer tipo de GaAs e além disso Van Vechten afirma que o fato da concentração de DX ser independente do potencial químico na superfície de crescimento pode ser um bom contra-argumento ao se pensar em $D X$ associado a $V_{A}$, isoladas, porém a concentração de real interesse é $\mathrm{M}_{A_{0}}^{2-} \mathrm{V}_{\mathrm{G}_{a}}^{-}$. Em termodinâmica de níveis profundos em semicondutores a energia do gap pode ser vista como a diferença de energia livre entre o conjunto de elétrons na banda de condução e o conjunto de buracos na banda de valência. A condição para que o defeito seja estável é que a energia gasta para criar o defeito seja menor que a energia livre liberada na captura dos portadores livres, ou seja :

$$
\Delta E\left(M_{A_{0}}^{\circ} V_{G_{a}}^{\circ}\right)<3 \Delta E_{C V}-\Delta E\left(V_{G_{a}}^{-}\right)-\Delta E\left(M_{A_{0}}^{-}\right)-\Delta E\left(M_{A_{0}}^{2-}\right)
$$

onde $\Delta E\left(\mathrm{M}_{A,}^{\circ} \mathrm{V}_{\mathrm{G}_{a}}^{\circ}\right)$ é a energia livre necessária para formar o estado neutro, $\Delta \mathrm{E}_{C V}$ é o gap de energia e $\Delta E\left(X_{y}^{-}\right)$é a energia para a captura de um eletron (ionização).

$\mathrm{O}$ argumento de Van Vechten é que para o caso da reação 1.4, a relação 1.5 será obedecida e que custará menos energia fazer uma vacância do grupo $V\left(V_{V}\right)$ e transformá-la no complexo $\mathrm{V}_{I I I} \mathrm{III}_{V}$ (vacância do elemento do grupo III mais um átomo do elemento do grupo $\mathrm{V}$ em posição anti-sítio) que capturará 3 elétrons, do que formar 3 vacâncias do grupo V, que capturarão 1 elétron cada. Então a grande relaxação da rede observada está relacionada com o salto atômico que se verifica na reação 1.4 . 


\section{2 - PEQUENA RELAXAÇÃO DA REDE}

O problema de se resolver um átomo de hidrogênio num meio dielétrico homogêneo com uma cavidade esférica concêntrica dá origem, por analogia, ao estudo de um átomo de impureza numa posição intersticial num semicondutor ${ }^{20}$. Introduzindo um fator de renormalização espacial $|\Phi(0, r)|^{2}$ e também correções para as condições de contorno, Bourgoin e Maude ${ }^{30}$ estenderam este problema para o caso de uma impureza substitucional. Por um raciocínio advindo da solução deste problema, eles atribuem a origem do centro DX a uma instabilidade raso-profundo causada por uma mistura inter-vales.

Levando-se em conta essa mistura inter-vales, a equação de Schrödinger deve ser resolvida para um elétron em um potencial $|\Phi(0, r)|^{2} \mathrm{~V}(\mathrm{r})$ onde ${ }^{28}$ :

$$
\begin{gathered}
V(r)=\left[-\frac{e^{2}}{\varepsilon_{0} r}+\frac{e^{2}}{\varepsilon_{0} r_{0}}\left(1-\frac{\varepsilon_{0}}{\varepsilon}\right)\right] \text { para } r<r_{0} \\
V(r)=-\frac{e^{2}}{c r} \quad \text { para } r>r_{0}
\end{gathered}
$$

$r_{o}$ é o comprimento característico simples do problema, sendo da ordem de uma distância atômica. Para o caso de um doador substitucional de simetria cúbica, o estado estacionário tem simetria $A_{1}$, e a onda estacionária correspondente à banda de condução pode ser escrita como ${ }^{30}$ :

$$
\Phi(0, r)=\sum_{\mu=1}^{N} \frac{1}{N^{1 / 2}} \Psi_{c}^{o}\left(k_{\mu}, r\right)
$$

onde $\mathrm{N}$ é o número de mínimos equivalentes correspondentes a $\mathrm{k}_{\mu} . \Psi\left(\mathrm{k}_{\mu}, \mathrm{r}\right)$ - funções de Bloch do cristal não perturbado. A coerência de fase é perdida a uma distância $r$, ou seja $\left|k_{\mu}\right| r_{o} \approx 1 .|\Phi(0, r)|^{2}$ pode ser aproximado por 1 para $r$ maior que $r_{o}$ e por $N$ para $r$ menor que $r_{o}(N \neq 1)$. Para que se possa definir $r_{0}$ como um comprimento característico, isso fica restrito para o caso dos vales $\mathrm{L}(\mathrm{N}=4)$ e $\mathrm{X}(\mathrm{N}=3)$ na zona de Brillouin. Para o vale $\Gamma(\mathrm{N}=1),|\Phi(0, \mathrm{r})|^{2}$ vale 1 . 
Incluindo a dependência espacial da massa do elétron e da constante dielétrica, pode-se obter a solução da equação de Schrödinger correspondente (Bourgoin e Maude ${ }^{30}$ não incluem a dependência espacial da constante dielétrica na obtenção de seus resultados qualitativo 1 ). A instabilidade raso-profundo ocorre em torno de $\mathrm{r}_{0} \approx 1.6$ unidades atômicas e aparece primeiro para o vale $\mathrm{L}$ do que para o vale $\mathrm{X}$, enquanto o vale $\Gamma$ permanece raso. Assim a energia de ligação é sempre maior para o vale $L$ do que para o vale X. Em resumo, a impureza doadora introduz um nível raso associado com a banda $\Gamma$ e um nível profundo associado com a banda $L$.

A energia do estado profundo depende quantitativamente da vizinhança e da distorção local da rede para minimizar a energia eletrônica total. Ele é mais profundo que o estado raso relacionado à massa efetiva da mais baixa banda de condução ( $\Gamma$ ou X dependendo da composição de Al da liga) para composições de Al maiores que aproximadamente 0.22 e permanece ressonante na banda de condução para composições menores. A função de onda do elétron é construída de estados da banda e portanto deve seguir a banda $L$ conforme a composição de alumínio varia. A captura de um elétron situado na base da banda de condução em um centro DX ocorre através de um processo cascata, ou seja, o eletron atinge a banda L que é próxima dos estados excitados do centro DX, conforme mostrado na figura 1.5. Então existe uma barreira de captura aparente que é igual a distância entre os mínimos de $\Gamma(\mathrm{X})$ e L. É esta barreira que origina a fotocondutividade persistente que não é nada mais que a metaesbilidade do elétron no mínimo da banda de condução $(\Gamma \text { ou } \mathrm{X})^{31}$.

\subsection{ATUALIZAÇÃO DO PROBLEMA}

Os modelos discutidos neste capítulo são apenas os modelos nos quais o tra- 


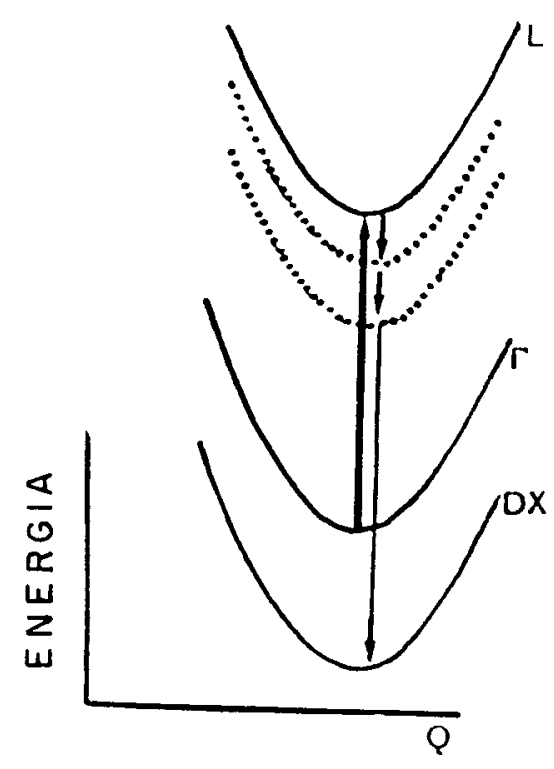

Figara 1.5 - Diagrams esquemático do processo de captura de um eletron em nm centro DX. AB curvas pontilhadas são hipóteses para os estados excitados do centro DX ${ }^{31}$

balho a ser descrito é baseado. Na realidade. existe uma infinidade de modelos e os argumentos usados pelos autores são quase irrefutáveis. Pequenas sutilezas ou experimentos complexos podem derrubar ou fortalecer determinados modelos.

Embora a argumentação de Van Vechten sobre a existência de vacâncias suficientes para participar do complexo DX, e também a argumentação termodinâmica de que o complexo $D^{+} M_{A_{s}}^{2-} V_{G_{a}}^{-}$tenha formação favorável, existe um experimento que parece descartar definitivamente a hipótese de participação de complexos além do próprio átomo doador. As medidas de modos locais de vibração (LVM) no infravermelho indicam que $90 \%$ do silício está presente como um doador substitucional e os $10 \%$ restantes ( que podem formar complexos) são muito menos que a concentração de centros DX na amostra ${ }^{1,17}$. A condição do centro DX como um estado advindo do próprio átomo doador está em excelente concordância com os experimentos realizados por Mizuta et al ${ }^{12}$ e Tachikawa et al ${ }^{13}$ que mostraram que em GaAs sob a aplicação de pressão hidrostática suficiente, o centro DX entra no gap e captura aproximadamente todos os eletrons de condução.

Um modo de se atacar o problema teoricamente é usar uma descriçạo loçạ- 
lisada na qual a parte coulombiana de longo alcance é truncada no espaço real. Essa é a base dos tratamentos por funções de Green ${ }^{32}$. Em GaAs puro tem-se orbitais ligantes e não ligantes. Quando um átomo de silício substitui um de Ga, os orbitais são destocados para uma posição de menor energia devido a maior eletronegatividade do átomo de Si. A interação entre os orbitais ligantes e não ligantes leva a uma separação entre um componente não degenerado de simetria $A_{1}$ e um componente triplamente degenerado de simetria $T_{2}$ que podem ser obtidos por um cálculo de ligações fortes ("tight binding") auto consistente com funções de Green ${ }^{32}$. O abaixamento na energia fas com que o estado antiligante $A_{1}$ seja o primeiro a cair no gap proibido, conforme se aumenta o alcance do potencial atrativo ${ }^{2}$. A separação entre os estados antiligantes $A_{1}$ e $T_{2}$ é da ordem de $1 \mathrm{eV}$, o que poderia ser uma interpretação para a transição ótica do centro DX.

Outro modo de se atacar o problema é a partir da teoria da massa efetiva. Pode-se obter estados $A_{1}[L]$ e $T_{2}[L]$ derivados dos quatro mínimos equivalentes da banda $L$ e que devem ser razoavelmente rasos, a menos que sofram uma instabilidade raso-profunda conforme já discutido, porém isso ajnda precisa ser quantitativamente provado. Considerando-se que $A_{1}[L]$ está no mesmo intervalo de energia de $A_{1}$ [antiligante], é possível que exista um estado fundamental que é uma mistura desses dois estados sendo estabilizado pela interação mútua. A transição ótica do centro DX seria $A_{1} \rightarrow T_{2}$ [anti-ligante] ${ }^{2}$. Esse estado $A_{1}$ resultante poderia seguir a banda $L$ conforme previsto pela teoria da massa efetiva.

Apesar de alguns pesquisadores ainda apostarem na possibilidade de pequena relaxação da rede, a grande maioria está de acordo com o modelo de Chadi e Chang 19,23. Trabalhos chaves na compreensão do porque o centro DX deve envolver uma distorção da rede e um deslocamento do átomo substitucional para uma posição intersticial são atriburdos a Mooney et al ${ }^{33}$ e Baba et al ${ }^{14}$ que mostraram que não pode haver mais do que quatro níveis de energia para o centro DX de silício, o que pode ser associado com a presença de $0,1,2$ ou 3 átomos de aluminio na vizinhança. A argumentação de Morgan ${ }^{34}$ sobre esse assunto é fundamental : se o átomo de Si está numa posição substitucional. Al seria segundo vizinho próximo e portanto seriam esperados treze valores para a energia de ligação do centro DX, já que esse 
que esse seria o número possível de segundos vizinhos. No entanto apenas quatro valores para a energia de ligação foram detectados, o que é bastante favorável à hipótese de posição intersticial, já que a interação com os átomos de alumínio passaria a ser direta (ver figura 1.4). Além disso, $\infty$ dados mostram que a mudança na energia de ligação do centro DX quando um átomo de Ga é substituido por um de Al é em torno de $100 \mathrm{meV}^{14}$, o que seria muito grande para uma interação entre segundos vizinhos próximos.

A idéia do deslocamento do átomo de impureza para uma posição intersticial que foi aqui atribuída a Chadi e Chang não é nova, Morgan 35 afirma que o estado $A_{1}$ derivado da banda de condução $\mathrm{L}$ não é profundo, porém o estado $\mathrm{T}_{2}$ que é triplamente degenerado é sujeito ao efeito de Jahn-Teller, que em linhas gerais afirma que para todo estado eletrônico orbitalmente degenerado, existe pelo menos um modo de distorção que ocorrerá espontâneamente e abaixará a energia total de vibração do sistema acoplado. Observações preliminares ${ }^{36}$ já afirmavam que o estado profundo no "gap" de energia parecia estar associado a uma grande distorção da rede. Segundo Morgan essa distorção é exatamente o deslocamento do átomo de impureza para a posição intersticial e o centro $\mathrm{DX}$ advém do estado $\mathrm{T}_{2}$, que possui um grande aumento na sua energia de ligação. A diferença fundamental entre o modelo inicialmente proposto por Morgan e o de Chadi e Chang é que no primeiro existe captura de apenas um elétron, tendo portanto U-positivo.

A característica do centro DX de seguir o vale $L$, tão aclamada pelos partidários da pequena relaxação da rede é tido por Chadi e Chang como mera coincidência. Segundo eles a energia do centro DX em função da composição de alumínio segue uma média na zona de Brillouin ${ }^{37}$ do mínimo da banda de condução $\left(\mathrm{E}_{B C}\right)$ e numa aproximação de ordem zero $\Delta \mathrm{E}_{B C} \approx \Delta \mathrm{E}(\mathrm{L})^{38}$. Uma aproximação mais precisa é obtida por ${ }^{19}$ :

$$
\Delta E_{B C} \approx \Delta[E(\Gamma)+3 E(X)+4 E(L)] / 8
$$

onde $E(i)$ representa o mínimo do vale i da condução.

Um trabalho amplamente favorável à hipótese da captura de 2 elétrons é o realizado por Fujisawa et al 39,40 que mostraram que numa amostra codopada com 
Ge e Si, o comportamento dos dados obtidos de concentração de elétrons só faz sentido se os centros DX capturarem dois elétrons, como no modelo de interação com U-negativo.

O estado da impureza substitucional com simetria $A_{1}$ foi detectado ${ }^{1,3,4}$ a partir de experiências no infravermelho. $O$ tempo de captura muito curto desse nível profundo a temperaturas da ordem de $10 \mathrm{~K}$ é um ponto fundamental para a diferenciação entre este estado e o centro DX, já que o tempo de captura para o centro DX é extremamente longo a essa temperatura. Em temperaturas mais altas ocorre o congelamento dos elétrons nos centros IXX, mas abaixo de um certo limite esse outro centro profundo passa a governar as propriedades de transporte. 


\section{CAPÍTULO II}

\section{TECNOLOGIA DA OBTENÇÃO DE AMOSTRAS}

\section{1 - CRESCIMENTO POR EPITAXIA POR FEIXES MOLECULARES}

As amostras utilizadas nos experimentos a serem descritos foram crescidas por epitaxia por feixes moleculares no Laboratório de Materiais Avançados da Universidade Estadual de Oregon. Os métodos quanto à preparação e tratamentos prévios do substrato diferem de um laboratório a outro, de forma que o que será discutido neste capítulo é o método por mim utilizado para o tratamento prévio de amostras naquele laboratório.

O sistema onde as amostras foram crescidas é um modelo Varian, projetado segundo um conceito de multi-câmaras. Este sistema inclui uma câmara de introdução da caixa multi-substrato, uma câmara de análise, pré aquecimento e estocagem e a câmara de crescimento propriamente dita. Cada uma das câmaras é isolada por meio de válvulas e cada uma contém sistemas adequados para a obtenção de ultra alto vácuo (UHV). Desta forma é possível desenvolver as funções de preparação do substrato, análise pré e pós crescimento e crescimento epitaxial independentemente e simultaneamente. A preparação do substrato envolve imersão por aproximadamente 
30 segundos em recipientes contendo TCE (tricloro etileno), acetona, metanol e água deionizada colocadas sobre o limpador ultrassônico. Em seguida o substrato é colocado em "choline" (revelador de fotoresiste positivo) por aproximadamente uma hora e deixada por alguns minutos sob água deionizada corrente. A amostra é seca em um aparelho girador ("spinner") com velocidade de 4000 rpm por 20 segundos, e finalmente soldada ao bloco de molibidênio usando índio. $O$ substrato pode então ser carregado na máquina de MBE, onde após a introdução na primeira câmara, seguindo um cuidadoso procedimento de levantamento e abaixamento de pressão, ele é conduzido para a câmara de análise onde deve permanecer durante toda a noite sob um pré aquecimento a $350 \mathrm{C}$.

Antes de se transferir o substrato para a câmara de crescimento, é medido o espectro Auger. A figura 2.1 mostra um exemplo típico do espectro Auger précrescimento de uma das amostras crescidas. O maior pico é o referente a uma transição característica de oxigênio, cuja presença é esperada desde que a exposição ao ar é inevitável. É provável que ocorra a formação de vários óxidos ${ }^{41,42}$. Medidas de morfologia de superfície indicam que a mesma fica livre desses óxidos quando se eleva a temperatura a $585 \mathrm{C}$ aproximadamente, que corresponde à temperatura de eliminação dos óxidos de gálio. Desta forma um bom modo de se calibrar o sensor de temperatura do substrato é identificando quando a superfície fica "limpa" e associar essa temperatura com 585 C. A presença de carbono na figura 2.1 indica que o procedimento de preparação não foi tão bom quanto o desejado. Apesar do pico referente à transição característica de carbono ser relativamente pequeno comparado com oxigênio, por exemplo, ainda é uma indicação da incorporação desse elemento negativamente na superfície do substrato durante a preparação. Acredita-se que com a eliminação dos óxidos, o conteúdo de carbono deva também ser reduzido.

As amostras crescidas por MBE apresentam todas a mesma estrutura, mostrada na figura 2.2, variando apenas a composição da camada ativa de $\mathrm{Al}_{x} \mathrm{Ga}_{1-x} \mathrm{As}$. A presença da camada de composição gradativa se deve a tentativa de evitar a presença de um gás bidimensional de elétrons (2DEG) na interface $\mathrm{GaAs} / \mathrm{Al}_{x} \mathrm{Ga}_{1-x} \mathrm{As}$ já que o nosso interesse é estudar as propriedades do volume de AlGaAs. A formação desse gás bidimensional de elétrons pode levar a inter- 


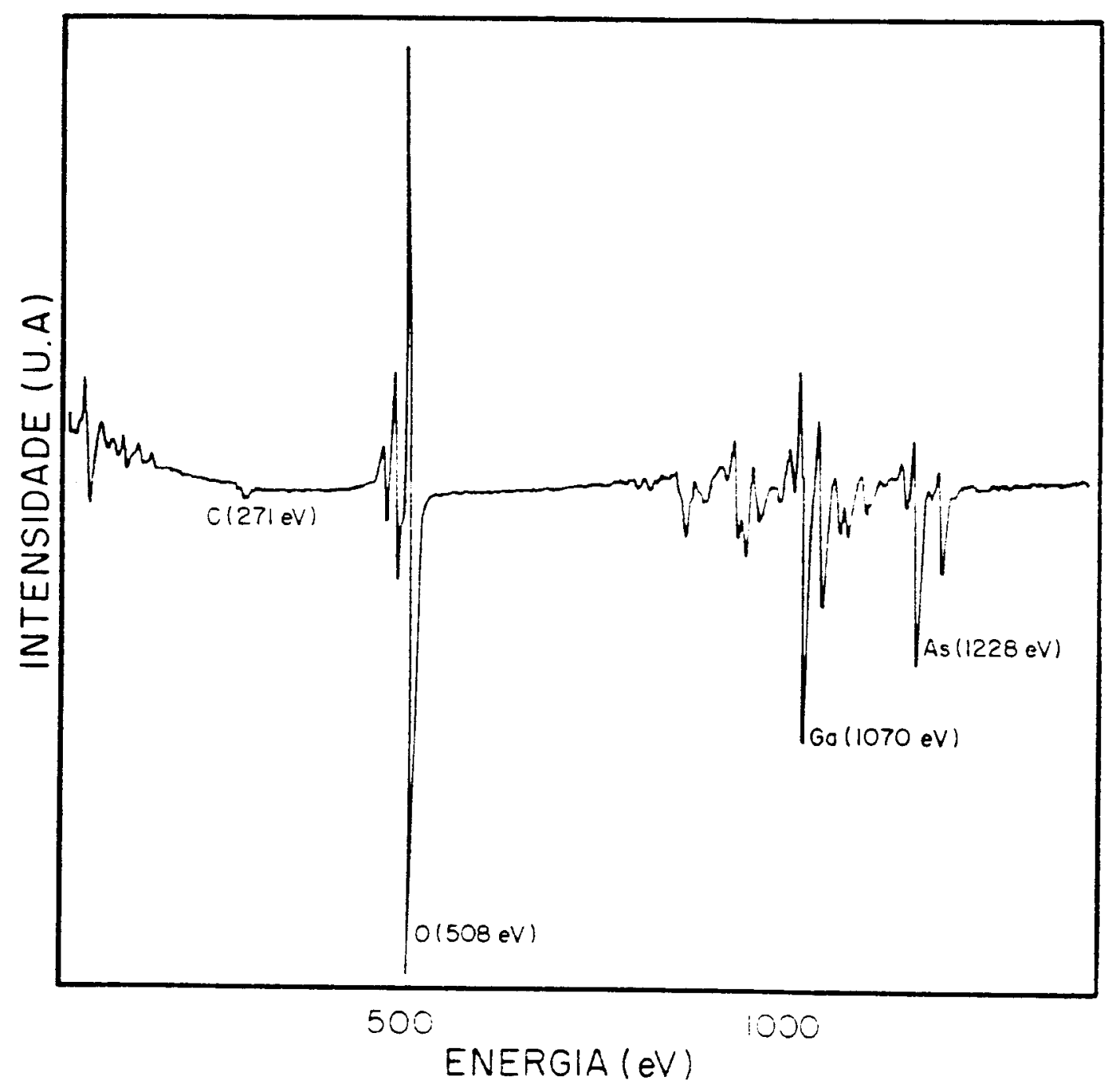

Figara 2.1 - Eepectro Auger pró-crescimento de um substrato semi-isolante de Gads 


\begin{tabular}{|c|}
\hline $50 \mathrm{~A}$ GoAs \\
\hline $1.75 \mu \mathrm{m} \mathrm{Al} \mathrm{Go}_{1-x}$ As dopodo com Si \\
\hline $0.25 \mu \mathrm{m} \mathrm{Al} \mathrm{Ga}_{1-x}$ As nōo dopodo \\
\hline $0.25 \mu \mathrm{m} \mathrm{Al} x \mathrm{Ga}_{1-x}$ As composição gradativa \\
\hline $0.25 \mu \mathrm{m}$ GaAs nāo dopado \\
\hline
\end{tabular}

Figura 2.2 - Diagrama esquemático da estratara das amostras crescidas por MBE

pretações errôneas de resultados de foto-Hall ${ }^{11,43,44}$ (capítulo V). Com o tipo de estrutura mostrado na figura 2.2, espera-se que esse problema tenha sido contornado. GaAs é crescido a $570 \mathrm{C}$ e $\mathrm{Al}_{x} \mathrm{Ga}_{1-x} \mathrm{As}$ a $680 \mathrm{C}$. A temperatura mais alta na liga ternária se dá em função de se reduzir a concentração de defeitos pontuais ${ }^{45}$. O aumento de temperatura do substrato aproxima o crescimento da amostra das condições de equilíbrio termodinâmico, evitando uma densidade adicional de defeitos em não equilíbrio ${ }^{46}$. Esse aumento de temperatura traz um novo problema : taxas menores de crescimento para as mesmas condições de deposição, o que implica que o sistema deva ser calibrado para o crescimento de cada amostra a partir da curva de incorporação de $\mathrm{AlGaAs}{ }^{47}$.

A maneira de se determinar a composição de alumínio na amostra a ser crescida é através de RHEED (difração de elétrons de alta energia). O feixe de elétrons emitido pelo canhão de RHEED atinge a amostra e se reflete sendo recebido numa tela fosforescente. Antes da amostra atingir a temperatura de $585 \mathrm{C}$ o que se vê na tela é uma imagem difusa. Ao atingir essa temperatura (expulsão dos óxidos) a imagem se torna clara, mostrando as linhas de difração. $O$ início do crescimento mostra que 
essas linhas de difração aumentam e diminuem em intensidade, devido a mudança de rugosidade na superfície. A superfície em equilíbrio existente antes de se iniciar o crescimento é lisa, correspondendo a alta refletividade do feixe especular (ordem zero). Ao se começar o crescimento, ilhas de nucleação se formarão em posições randômicas na superfície, levando a um decréscimo na refletividade. Estas ilhas crescerão e produzirão outra superfície lisa, e seria de se esperar que o mínimo de refletividade corresponda a $50 \%$ de recobrimento da superfície. Quando a imagem gerada na tela é captada por uma fotomultiplicadora e o sinal é enviado a um osciloscópio, pode-se observar as oscilações na intensidade e então calibrar a velocidade de crescimento bem como a composição de alumínio. A figura 2.3 mostra uma calibração típica de 0.6 monocamadas de GaAs por segundo. Calibrando-se em seguida 0.4 monocamadas de AlAs por segundo, pode-se então conseguir um crescimento de 1 monocamada por segundo de $\mathrm{Al}_{0.4} \mathrm{Ga}_{0.8} \mathrm{As}$, quando todas as tampas das células de efusão forem abertas simultaneamente. $O$ amortecimento observado nas oscilações é devido a nucleacão ocorrer sobre a camada em crescimento antes que a mesma se complete. As oscilações cessarão conforme o crescimento se torna distribuído em várias camadas atômicas incompletas ${ }^{48}$.

A figura 2.4 mostra o espectro Auger após o crescimento. Não há sinal de carbono ou oxigênio. A presença de alumínio também não é identificada devido à fina camada de topo, cuja função é evitar a oxidação de AlGaAs, já que o alumínio é bastante reativo com o oxigênio do ar. Considerando-se que os elétrons do canhão de Auger penetram apenas uns poucos ângstrons na superfície, não é de se esperar a presença de um pico correspondente a alumínio (1395 eV) no espectro.

\section{2 - PROCESSAMENTO}

As amostras utilizadas para as medidas de TDPPC (Decaimento da Fotocon-

SERVICO DE BIBLIOTECA E INFORMACAO - IFOSC

FISICA 


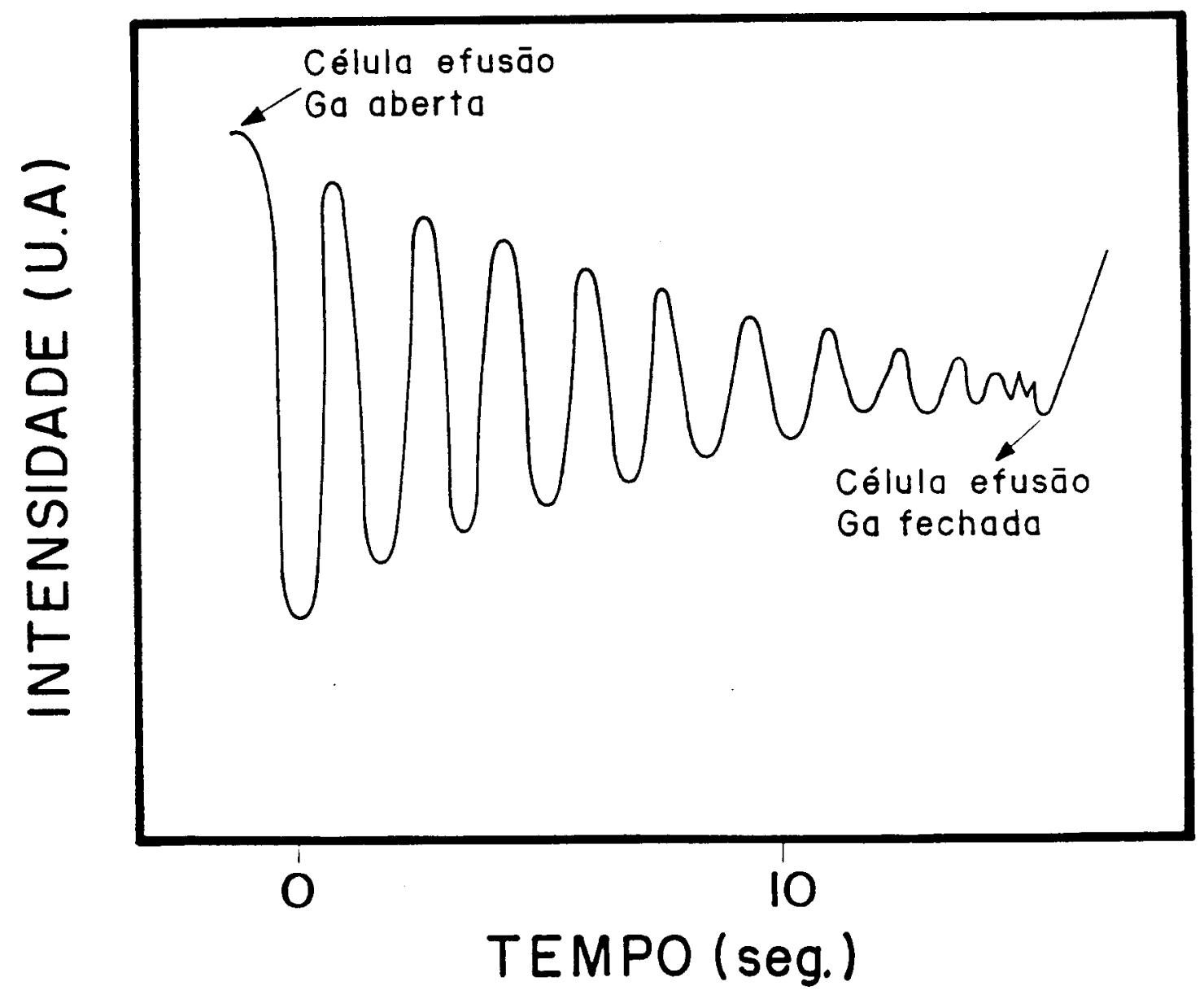

Figars 2.3 - Oscilaçöes ns intensidade do feixe especular RHEED para 0.6 monocamadas por segando de GaAs (001) 


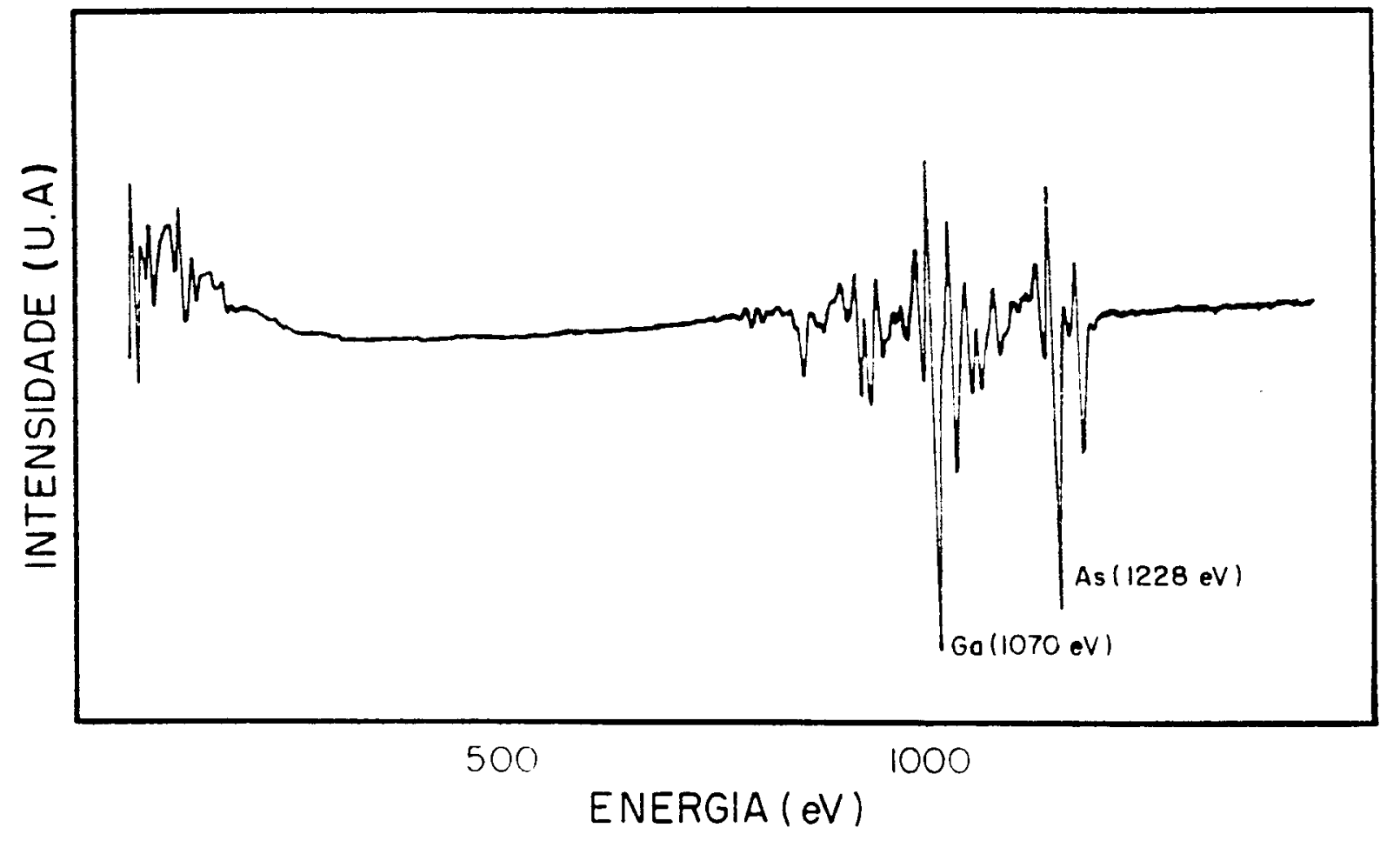

Figara 2.4 - Espectro Auger de ums amostra com camsda ativa de $\mathrm{Al}_{0.4} \mathrm{Ga}_{0.6} \mathrm{As}$ 
dutividade Persistente - capitulo III) eram iniciaimente obtidas de uma maneira simples, onde contatos de $\mathrm{Au} / \mathrm{Ge} / \mathrm{Ni}$ eram evaporados através de uma máscara de sombra posicionadas sobre a amostra, sendo então encapsulados pela utilização de fios de ouro e epoxy de prata para ligar cápsulas e contatos. O problema dos contatos tornarem-se não ôhmicos a baixas temperaturas e também a não reprodutibilidade de resultados sugeriu que as amostras devessem passar por um processamente mais sofisticado, que garantisse a perfeita estabilidade mecânica, de modo a se ter resultados reprodutíveis asaim como um comportamento perfeitamente ôhmico a baixa temperatura. Conforme será discutido no capítulo IV o comportamento não ôhmico a baixa temperatura é um problema ben mais complexo do que o advindo da ligação precária com epoxy de prata, porém o problema da estabilidade mecânica foi resolvido pelo processamento fotolitográfico. Assim sendo as amostras para outros experimentos foram também geradas por processamentos similares. A figura 2.5(a) e 2.5(b) mostram diagramas esquemáticos dos processamentos utilizados nos experimentos de TDPPC (e também curvas de corrente-tensão) e Foto-Hall respectivamente. O processamento da amostra para TDPPC consiste de duas máscaras e quatro passos de processamento fotolitográfico que são : evaporação do contato ôhmico (e posterior tratamento térmico), deposição por "sputtering" de uma camada de $\mathrm{SiO}_{2}$, ataque químico da camada óxida na região do contato e evaporação das bases de ligação ("bonding pads"), onde serão ligados os fios de ouro por soldagem ultrassônica. Já o processamento das amostras para medidas Hall consiste de três máscaras e cinco passos, a saber : evaporação dos contatos ôhmicos (e tratamento térmico), ataque químico do material em torno dos contatos, de forma a se ter um quadrado com contatos ôhmicos nos cantos, deposição de uma camada de $\mathrm{SiO}_{2}$, ataque químico do $\mathrm{SiO}_{2}$ na região dos contatos e deposição das bases de ligação. As bases de ligação, que consistem de uma camada de Ti e uma de Au, se fasem necessárias para a soldagem com ultra-som, uma vez que o Ti possui uma boa aderência. Se fosse feita diretamente sobre o contato ôhmico, este poderia ser arrancado. Além disso, a presença das bases de ligação aumenta a área para a soldagem, facilitando consideravelmente $o$ trabalho. Isto se torna particularmente relevante no caso de circuitos integrados de dimensões bastante pequenas, onde a ligação dos fios 
acs contatos ôhmicos ou barreiras Schottky seria praticamente impossível do ponto de vista operacional.

Todo esse procedimento envolve conhecimento das reações químicas e fotoquímicas envolvidas no processo, assim como a operação de diversos equipamentos. Desta forma, os principios básicos envolvidos serão descritos nas seccões que se seguem.

\subsection{1 - Fotolitografia}

O processo fotolitográfico é usado na fabricação de circuitos integrados de dimensões que se tornam cada vez mais reduzidas. Também assegura uma boa reprodutibilidade de resultados, quando o problema não são as dimensões, mas sim a confiabilidade nos dados experimentais. A fotolitografia engioba todos os passos envolvidos na transferência de uma estrutura de uma ou mais máscaras para a superficie do semicondutor. Existem basicamente dois modos de se conduzir a litografia : o processo subtrativo e o processo aditivo ("lift off") que se baseiam no fato que o reagente químico conhecido como fotoresiste é sensivel à presença de luz. Um diagrama simplificado do processo aditivo que foi utilizado é montado na figura 2.6, mostrando a técnica de transferência da estrutura de uma única máscara para a superfície do material crescido por MBE. A diferença para o processo subtrativo é que a camada do material seria depositada primeiro e a seguir é feito um ataque químico nas regiōes em torno do metal, mantendo a estrutura proposta. Com a técnica de lift off, o material que foi depositado sobre o fotoresiste é removido conjuntamente com o fotoresiste, de modo que o ataque químico não se faz necessário. Um fotoresiste agindo da maneira descrita é conhecido como fotoresiste positivo. Fotoresiste negativo também pode ser usado e ele age de maneira inversa, ou seja 
a)
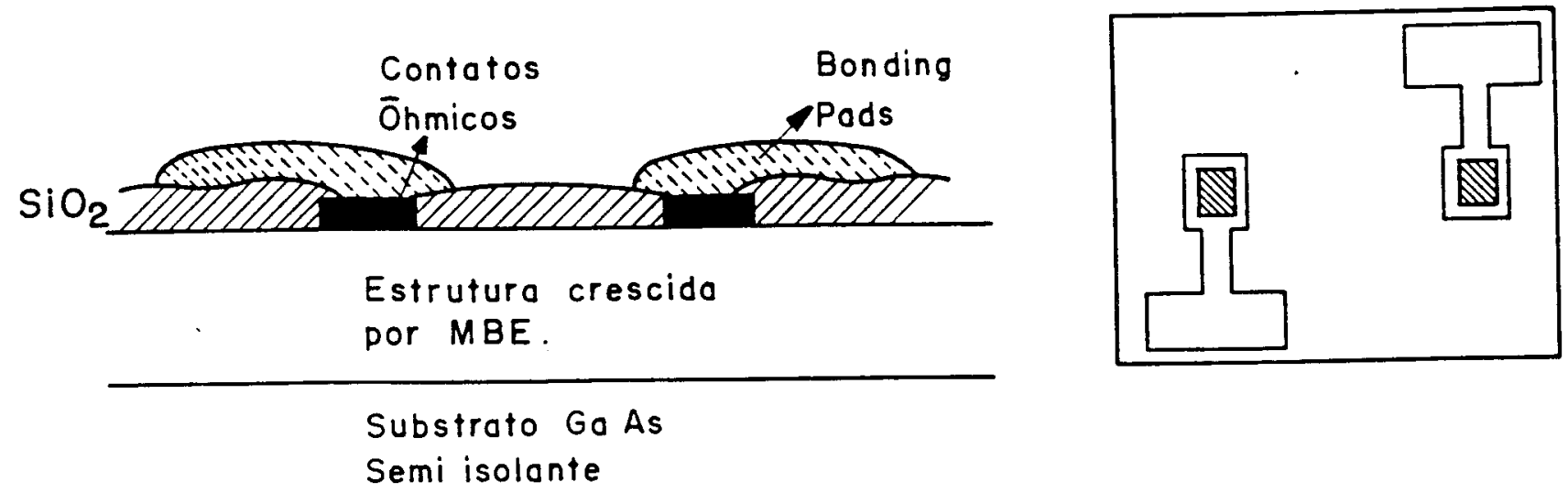

Substrato Ga As

b)
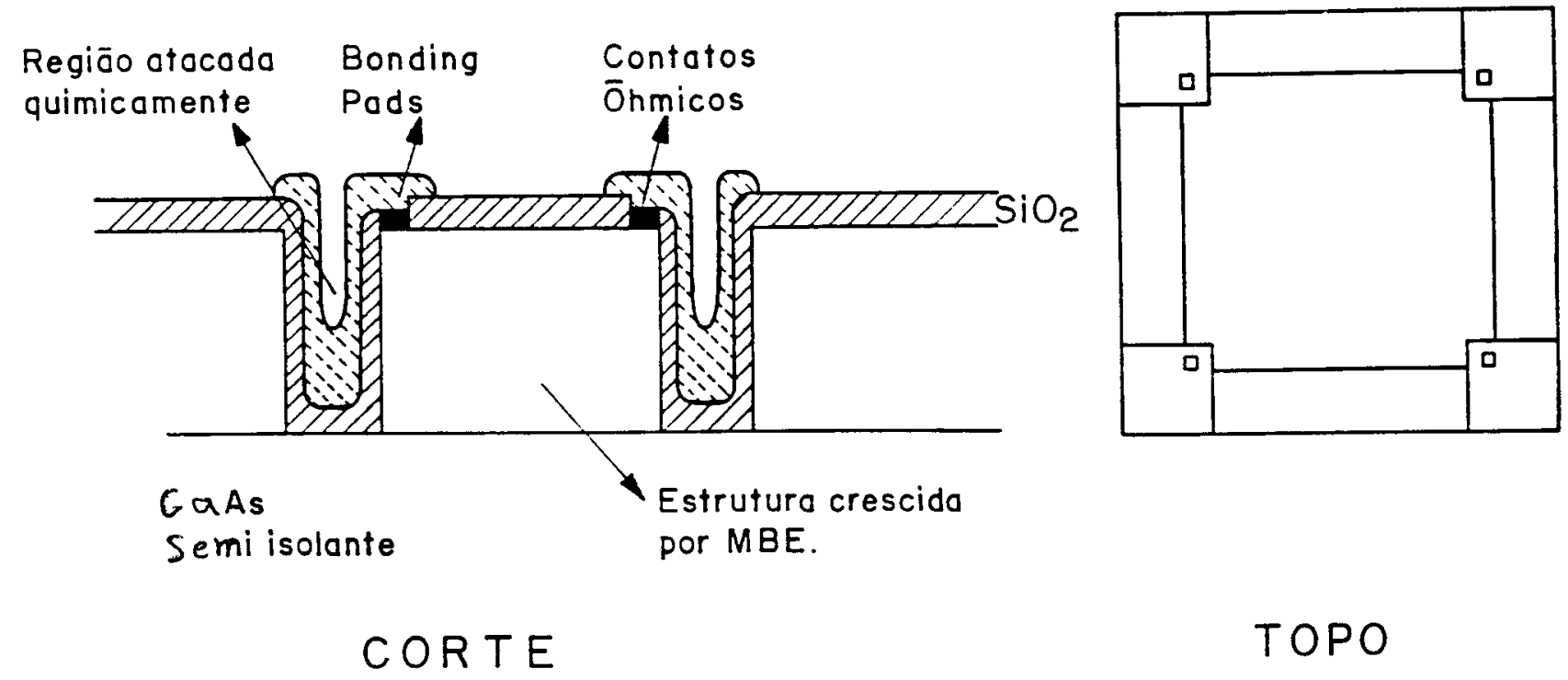

Figura 2.5 - Diagrama esquemático da amostras procesadad para experimentos de TDPPC (a) e Foto-Hall (b) 


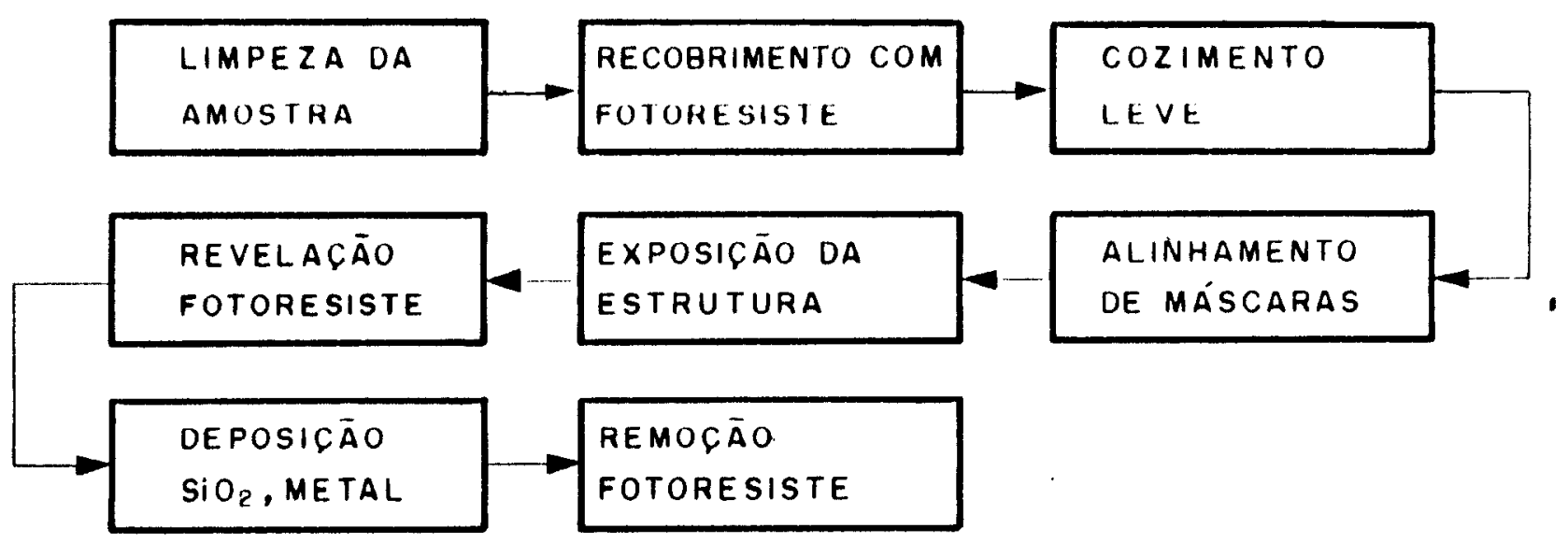

Figura 2.6 - Diagrama de um paseo do processamento fotolitografico das amostras usadas

permanece nos locais da superfície nos quais foi exposto a presença de luz ${ }^{49}$.

A limpera da amostra antes de se iniciar a fotolitografia é feita com acetona, metanol e água deionizada. Fotoresiste é revelado com revelador fotográfico convencional, a menos que se trate de preparação para a evaporação de bases de ligação, quando se usa "choline" para se ter uma melhor limpesa, o que garante uma melhor aderência da camada metálica, de forma a ajudar a mesma a não ser arrancada quando da soldagem com ultra-som.

\subsection{2 - Confecção das Máscaras}

Este processo envolve basicamente quatro etapas : a) projeto da estrutura desejada e do número de passos e máscaras a serem utilizados. b) desenho das máscaras em papel de acordo com a redução desejada para o tamanho final do dispositivo. Existem alguns programas de computador que fazem este tipo de projeto. 
c) corte de rubilita nas formas da máscara. Em casos de projetos complexos, existem equipamentos que farem este tipo de trabalho, funcionando como um plotador de gráficos, sendo que ao invés de canetas utilizam pequenas facas. d) gravação da máscara para a placa de vidro, que possui uma das faces foto-sensível. A partir daí as placas de vidro são reveladas como em processos fotográficos convencionais.

As máscaras usadas para a fabricação das amostras usadas no experimento de TDPPC e medidas de I-V estão mostradas na figura 2.7 e aquelas usadas para amostras Hall estão na figura 2.8. As marcas laterais são usadas para o alinhamento na Alinhadora de Máscaras. Na figura 2.7(a) vê-se a máscara usada para evaporação dos contatos ôhmicos (Au/Ge/Ni) e também para o ataque químico do dióxido de silício na região do contato. Para esse ataque químico usa-se uma solução de $\mathrm{HF}$ enfraquecida que consiste de 1 parte de $\mathrm{HF}(48 \%)$ e 4 partes de solução de $\mathrm{NH}_{4} \mathrm{~F}$. A máscara usada para a deposição das bases de ligação está na figura $2.7(b)$. Na figura 2.8(a) vê-se a máscara para contato ôhmico e posterior ataque químico do $\mathrm{SiO}_{2}$. A máscara da fig. 2.8(b) é usada para o ataque químico do material crescido por MBE e a da figura 2.8(c) é usada para deposição das bases de ligação.

\subsection{3 - Metalização}

A deposição de camadas metálicas é um processo indispensável para a produção de qualquer amostra ou dispositivo, pois todos os experimentos ou funções são baseados em contatos ôhmicos ou barreiras Schottky. Em nosso caso foram utilizados contatos ôhmicos de $\mathrm{Au} / \mathrm{Ge} / \mathrm{Ni}(0.01 \mathrm{~g} \mathrm{Ni}, 0.2 \mathrm{~g} \mathrm{Au} / \mathrm{Ge}$ - composição eutética- $12 \%$ Ge e $0.15 \mathrm{~g} \mathrm{Au}$ ) e bases de ligação de Ti e Au (0.015 g Ti e $0.2 \mathrm{~g} \mathrm{Au})$. As espessuras correspondentes são (aproximadamente) : $80 \mathrm{~A} \mathrm{Ni}, 1200 \mathrm{~A} \mathrm{Au} / \mathrm{Ge}$ e $1200 \mathrm{~A} \mathrm{Au}$, no caso dos contatos ôhmicos e $200 \mathrm{~A}$ Ti e $1600 \mathrm{~A}$ Au para o caso das bases de ligação. 


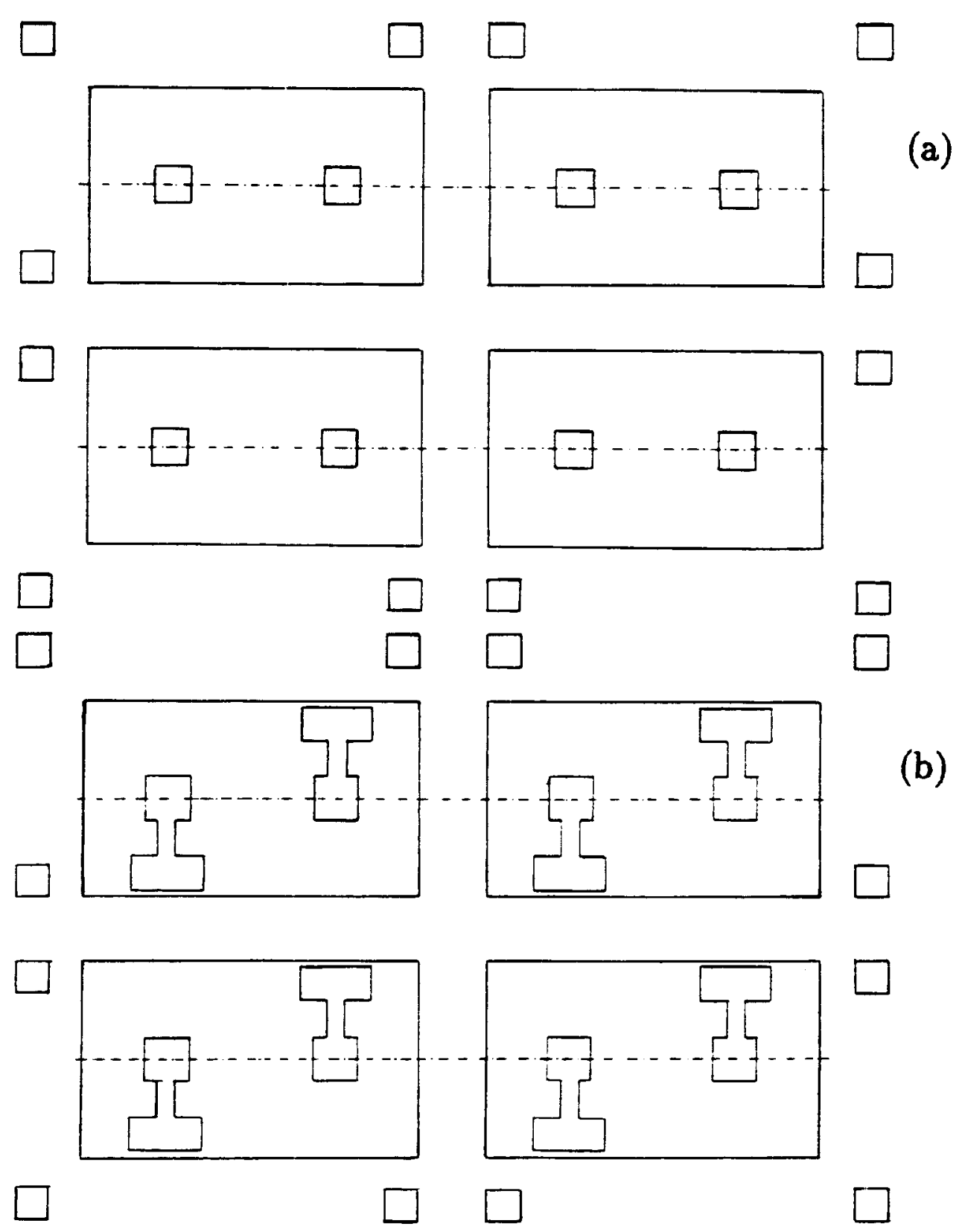

Figara 2.7 - Mbacaras usadas no processamento de amostras pars o experimento de TDPPC 


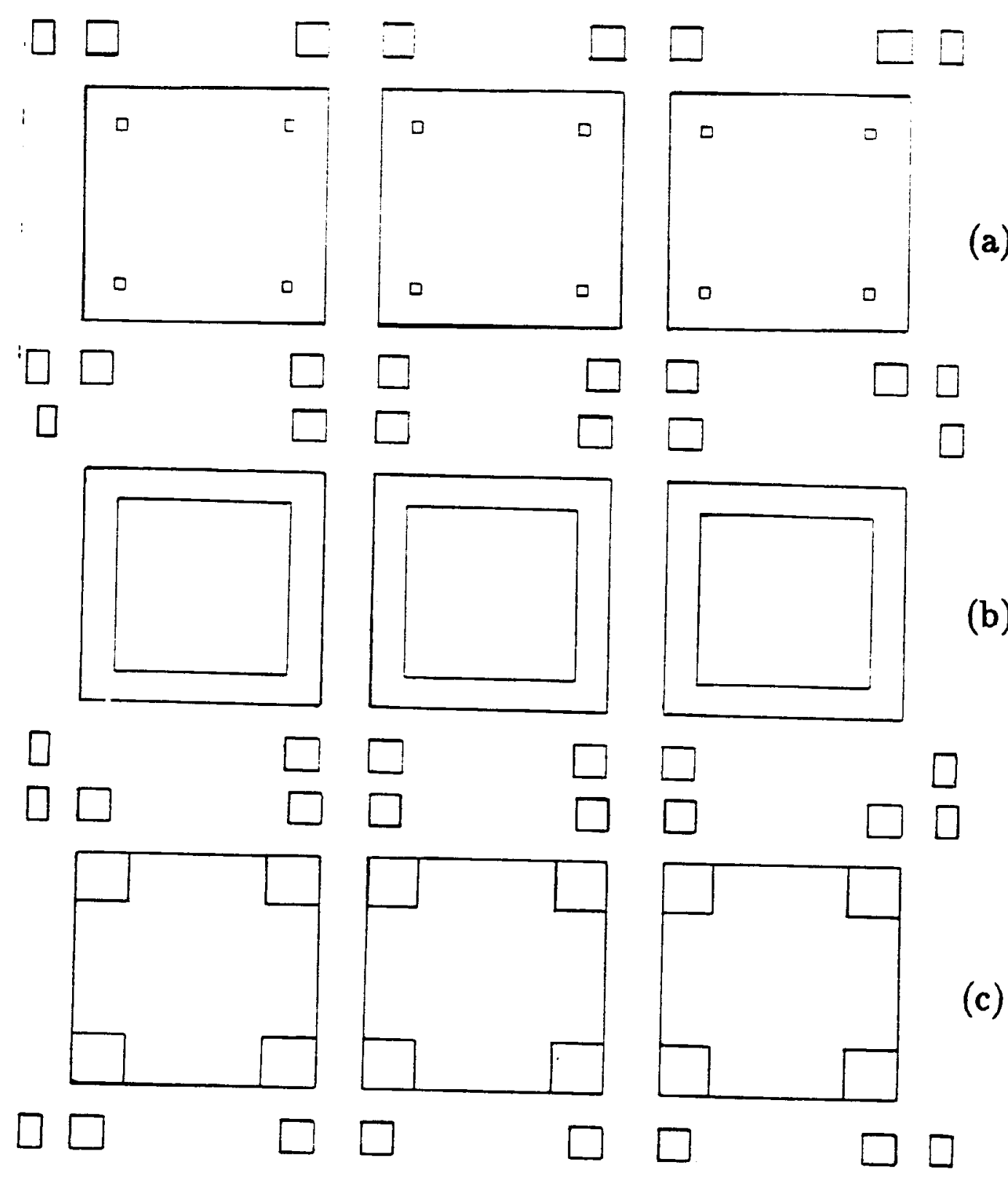

Figura 2.8 - Mtscaras usadas no processamento de amostras para o experimento de Foto-Hall 
A deposição é feita num sistema de evaporação VEECO, onde o metal a ser evaporado é colocado em cadinhos metálicos. Pela passagem de correntes altíssimas (da ordem de 100 a $200 \mathrm{Amp}$ ) consegue-se a fundição e posterior evaporação, quando a pressão de vapor iguala-se à pressão dentro da câmara de evaporação. Desta forma a presença de alto-vácuo faz com que essa condição termodinâmica seja mais facilmente atingida. Um bom vácuo também previne a incorporação de impurezas advinda da reação química entre o evaporante e o gás residual e além disso, aumenta o caminho livre das partículas do evaporante, melhorando a eficiência da evaporação. Os cadinhos utilizados são de molibdênio com $1 \mathrm{~mm}$ de espessura para evaporação do eutético Au/Ge e de Au. Para evaporação de Ni são usados cadinhos de Mo de $0.5 \mathrm{~mm}$ de espessura e para evaporação de Ti são usados cadinhos de Tungstênio também com $1 \mathrm{~mm}$ de espessura. A pressão da câmara na qual se processa a evaporação é em torno de $2 \times 10^{-6}$ Torr.

O sistema de vácuo da evaporadora VEECO é mostrado na figura 2.9, consistindo basicamente de bombas mecânica e difusora. $\mathrm{O}$ princípio da bomba de difusão ${ }^{\text {so }}$ é a evaporação de óleo na base do sistema, criando uma região de alta pressão de vapor de óleo que injeta o mesmo direcionado para baixo conforme pode ser verificado na figura. Esse jato de vapor captura as partículas de impurezas presentes no sistema. A refrigeração a água em torno da bomba condensa esse vapor de óleo, tornando-o líquido outra vez. A fuga do vapor é prevenida pelas chicanas ("bafte") também refrigeradas a água e pela armadilha fria, que é um reservatório de nitrogênio líquido. Essa armadilha fria também tem a função de ajudar a obtenção de vácuo, pela adsorção de partículas na parede. Devido a problemas ligados à saturação de óleo, não é conveniente iniciar a operação da bomba de difusão com o sistema a pressões maiores que $50 \mathrm{mTorr}$. Assim a bomba mecânica é usada para abaixar a pressão na câmara de evaporação até esse valor, quando então a porta que liga a bomba de difusão à câmara de evaporação pode ser aberta. A bomba mecânica também é usada para evacuar a bomba difusora, quando o sistema não está sendo usado. 


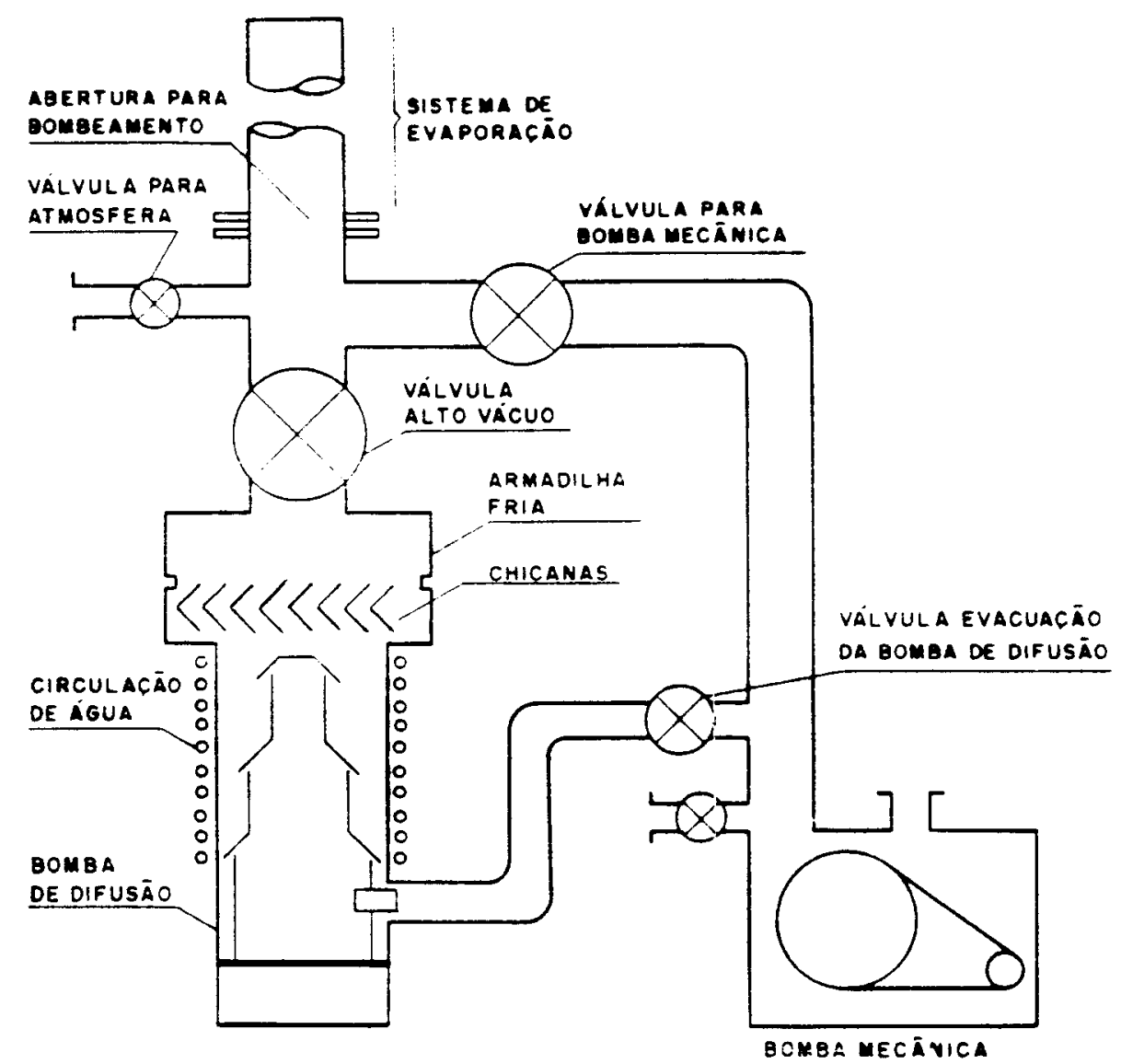

Figara 2.9 - Princípio de funcionamento do sistema de vácuo da evaporadora VEECO

\subsection{4 - Deposição de $\mathrm{SiO}_{2}$}

No processamento de amostras, foram utilizadas várias vezes camadas de dióxido de silício. A função dessa camada (geralmente em torno de $1000 \mathrm{~A}$ ) é servir de separação entre bases de ligação e a camada do material a ser analisado. Se a camada $\mathrm{Ti} / \mathrm{Au}$ fosse depositada diretamente sobre a amostra, seria criada uma barreira Schottky em toda a volta do contato ôhmico, o que alteraria o diagrama de energia perpendicularmente a direção de passajzem de corrente na camada ativa, dificultando a análise dos dados experimentais. Devido à transparência e alto gap de energia do dióxido de silício, não há influência desıa camada nos resultados obtidos. 
A deposição de $\mathrm{SiO}_{2}$ é feita por um sistema VEECO de "Sputtering". que é baseado no prinćpio de se arrancar moléculas de uma superfície (alvo) pelo bombardeamento de íons ${ }^{51}$. Acima do alvo existe uma câmara cilíndrica onde ocorre a formação de um plasma de íons que serão acelerados em direção ao alvo. Gás argônio é alimentado ao sistema e a presença de um filamento quente emite elétrons que ionizarão os átomos de argônio. Em volta deste filamento sxiste um cilindro de molibidênio que fornece um campo elétrico radial e serve como anodo para a descarga gasosa (arco). Um solenóide montado do lado de fora da câmara produz um campo magnético perpendicular ao campo elétrico, para defletir os elétrons em trajetorias cicloidais. As restrições finais do escoamento gasoso são dadas por uma malha metálica na saída do cilindro. Isto pode ser visto na figura 2.10. O feixe iônico homogêneo resultante, colimado e monoenergético, bombardeia a superfície do alvo, retirando moléculas de $\mathrm{SiO}_{2}$ que irão se depositar na superfície (fria) do substrato. $O$ alvo é normalmente colocado formando um ângulo de 45 graus com o feixe iônico e o substrato é colocado praticamente paralelo ao alvo, de forma a se ter maior eficiência na evaporação. O princípio de funcionamento do sistema de vácuo é idêntico ao sistema VEECO de evaporação descrito na secção anterior.

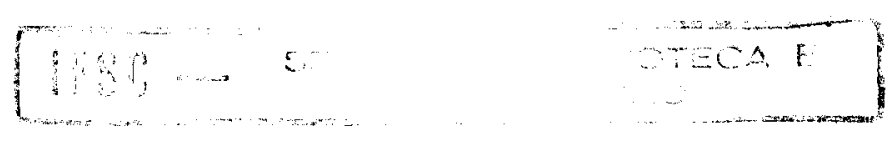




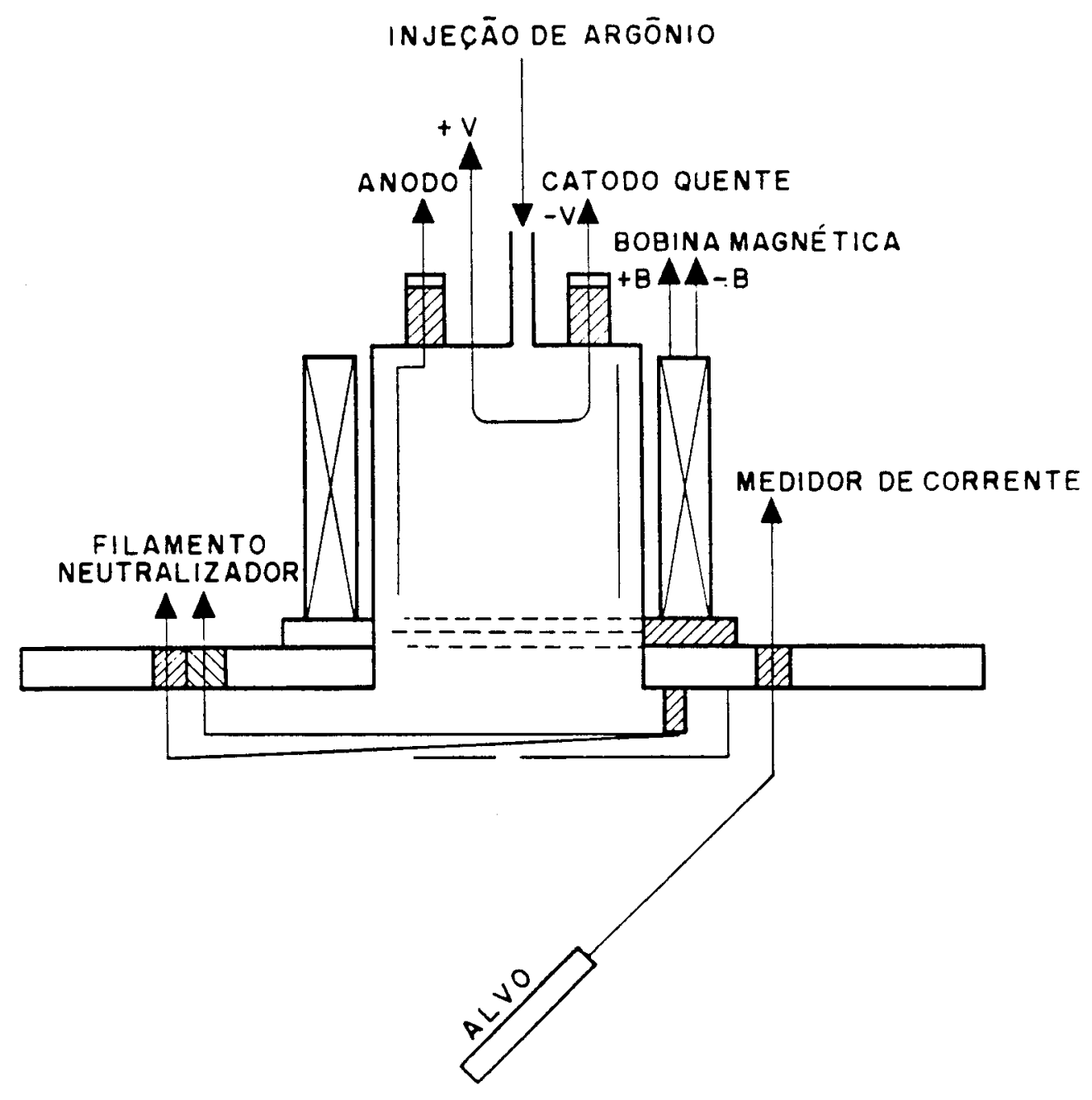

Figura 2.10 - Prinćpio básico de funcionamento do sistems VEECO de sputtering 


\section{CAPÍTULO III}

\section{DECAIMEN'TO DA FOTOCONDUTIVIDADE PERSISTENTE (TDPPC)}

Ao se retirar o sistema de um estado de equilíbrio térmico, por exemplo pela incidência de luz, cria-se um estado de metaestabilidade (fotocondutividade persistente). A investigação experimental da cinética de retorno a esse estado de equilibrio fornece importantes parâmetros na compreensão desse fenômeno. Um equacionamento do processo de decaimento só é possível à medida que sejam utilizados modelos para o centro DX. Esse é o objetivo de TDPPC ("Transient Decay of Persistent Photoconductivity"): medir o decaimento da fotocondutividade persistente e fazer a simulação numérica de modo a se decidir sobre os mais prováveis processos de captura.

Quando elétrons são excitados oticamente de um nível profundo a temperaturas muito baixas, eles tendem a ficar presos metaestavelmente na banda de condução, não possuindo energia térmica suficiente para retornar ao estado localizado de nível profundo no gap de energia. De acordo com Theis et al ${ }^{52}$ a temperaturas menores que aproximadamente $80 \mathrm{~K}$, o processo de captura dominante é puramente atérmico, ou seja, independe da temperatura da rede. $O$ que deve ocorrer é o tunelamento de um estado intermediário $d^{o}$ para DX. Conforme será discutido, a existência de um estado intermediário não se faz necessária para a simulação de 


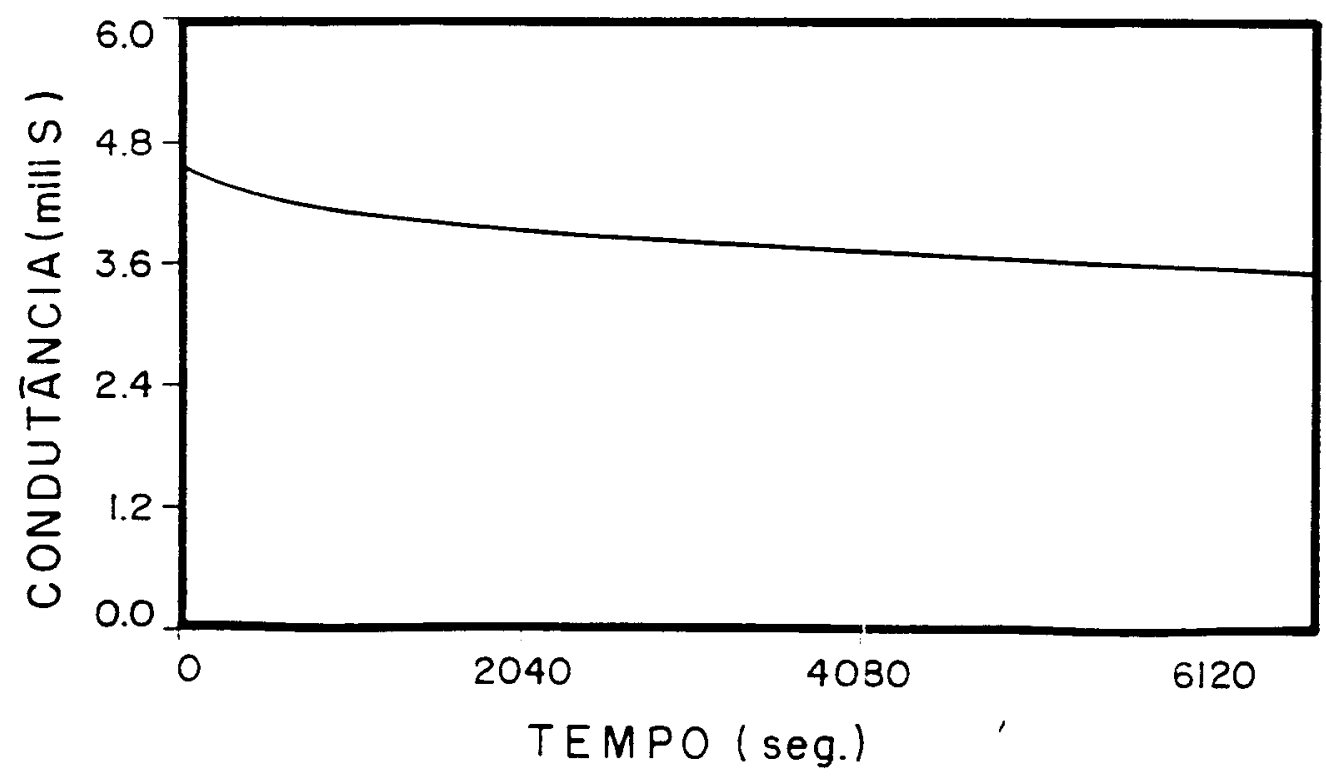

Figura 3.1 - TDPPC de ums amostra de $\mathrm{Al}_{0.3} \mathrm{Ga} 0.7 \mathrm{As}$ a $60 \mathrm{~K}$

nossos dados experimentais, porém a hipótese da captura é bastante conveniente quando se observa um decaimento como mostrado na figura 3.1, onde a condutância é fotoexcitada a um valor muito maior que à temperatura ambiente $(0.66 \mathrm{mS})$. A figura 3.1 é uma medida do decaimento da fotocondutividade persistente e mostra que a uma temperatura baixa o retorno ao estado de condutividade no escuro (praticamente zero, quando a temperatura é abaixada com a amostra no escuro) custaria um tempo impossível de ser medido. Além disso, nenhum equacionamento cinético que levasse em conta apenas o processo térmico de captura conseguiria explicar os dados obtidos com experimentos realizados a temperaturas menores que $80 \mathrm{~K}$. O experimento de TDPPC, que será discutido a seguir, é realizado no intervalo 80$100 \mathrm{~K}$. O limite superior do intervalo é escolhido pela razão de que a temperaturas maiores que $100 \mathrm{~K}$ o decaimento é extremamente rápido, de difícil medida e análise, e onde os processos térmicos de emissão começam a ter importância. 


\section{1 - O EXPERIMENTO DE TDPPC}

TDPPC é realizado da seguinte forma : a amostra é inicialmente esfriada no escuro para a temperatura desejada (80-100 K), sendo então iluminada com luz monocromática de comprimento de onda menor que o gap de energia, até que a fotocondutância atinja estado estacionário. A fonte de luz é desligada a $t=0$ e $o$ transiente é monitorado com um medidor de condutância. A aparelhagem usada no experimento é esquematizada na figura 3.2. O sistema é automatizado a partir de um computador de mesa modelo 9336 em conjunção com um medidor de capacitância/condutância 4280A I Mhz, ambos da Hewlett-Packard.

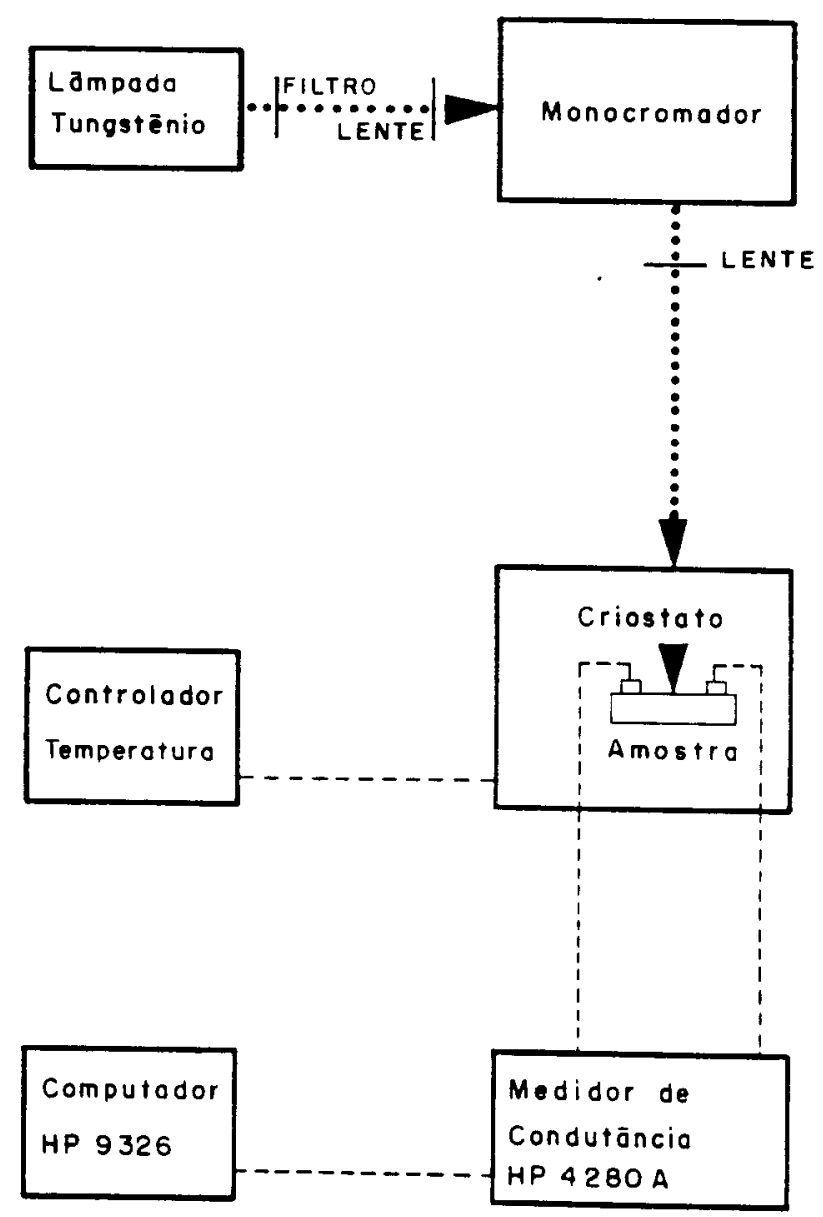

Figara 3.2 - Esquema de montagem do experimento de TDPPC 


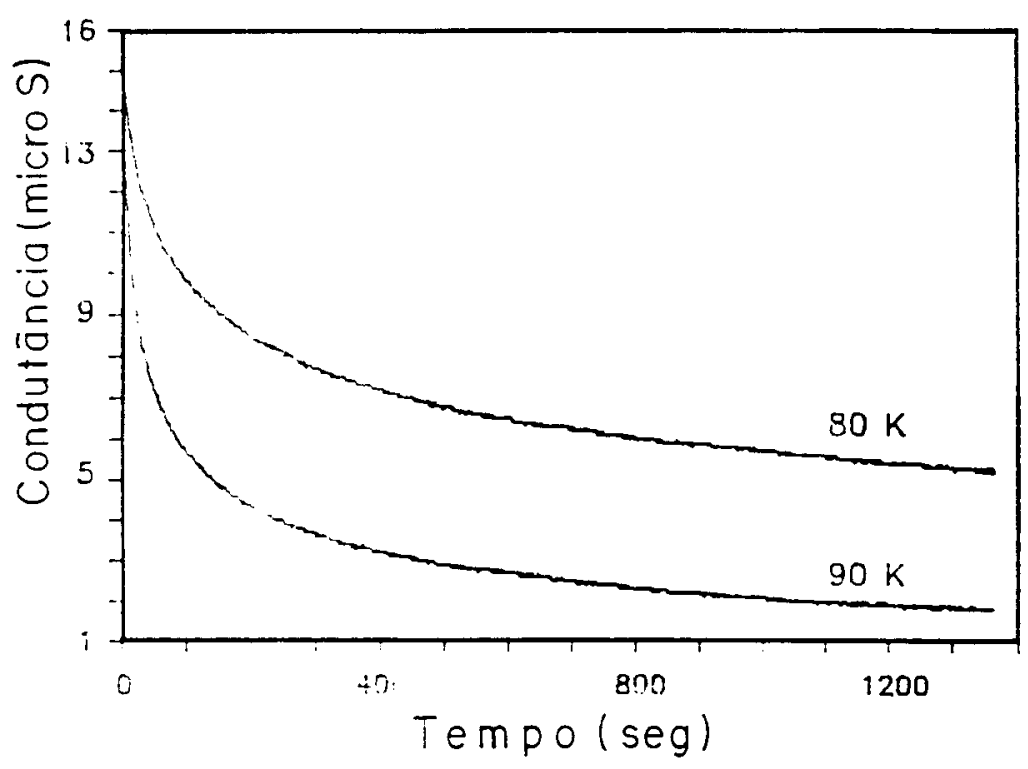

Figara 3.3 - TDPPC para ums amostra $\mathrm{Al}_{0.8} \mathrm{Ga}_{0.8} \mathrm{As}$ a temperaturas de $80 \mathrm{~K}$ (curva superior) e $90 \mathrm{~K}$ (curva inferior)

A temperatura é controlada com um criostato com circuito fechado de Hélio da Air Products e um controlador de temperatura da Scientific Instruments. A fonte de luz consistiu de uma lâmpada de tungstênio, um monocromador Jarrel-Ash e filtros e lentes apropriados conforme mostrado na figura 3.2.

A secção transversal de captura termicamente ativada dos centros DX faz com que o transiente seja uma função da temperatura da amostra. Na figura 3.3 é mostrado o decaimento para uma amostra de $\mathrm{Al}_{0.5} \mathrm{Ga}_{0.5} \mathrm{As}$, a diferentes temperaturas, mostrando que a velocidade de retorno à condição de equilibrio é maior para temperaturas mais altas ${ }^{33}$. Quando comparada com a figura 3.1 vê-se que os valores de condutância àquela temperatura são muito maiores. Além da razão óbvia de que a temperatura é menor, a altura da barreira para a captura é uma função da composição de alumínio na amostra. Apesar dessa dependência não estar ainda completamente explicada, nossos resultados ${ }^{54}$ mostrados no apêndice $A$ e que estão em concordância com a literatur $\mathrm{a}^{5,55}$ indicam que a energia de captura é maior numa amostra com $30 \%$ de alumínio do que naquela com $50 \%$ de alumínio. Assim para efeito de comparação é mostrada na figura 3.4 o experimento de TDPPC para uma amostra de AlGaAs com $30 \%$ de aluminio a uma temperatura de $85 \mathrm{~K}$.

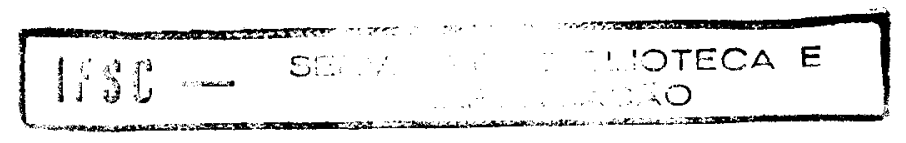




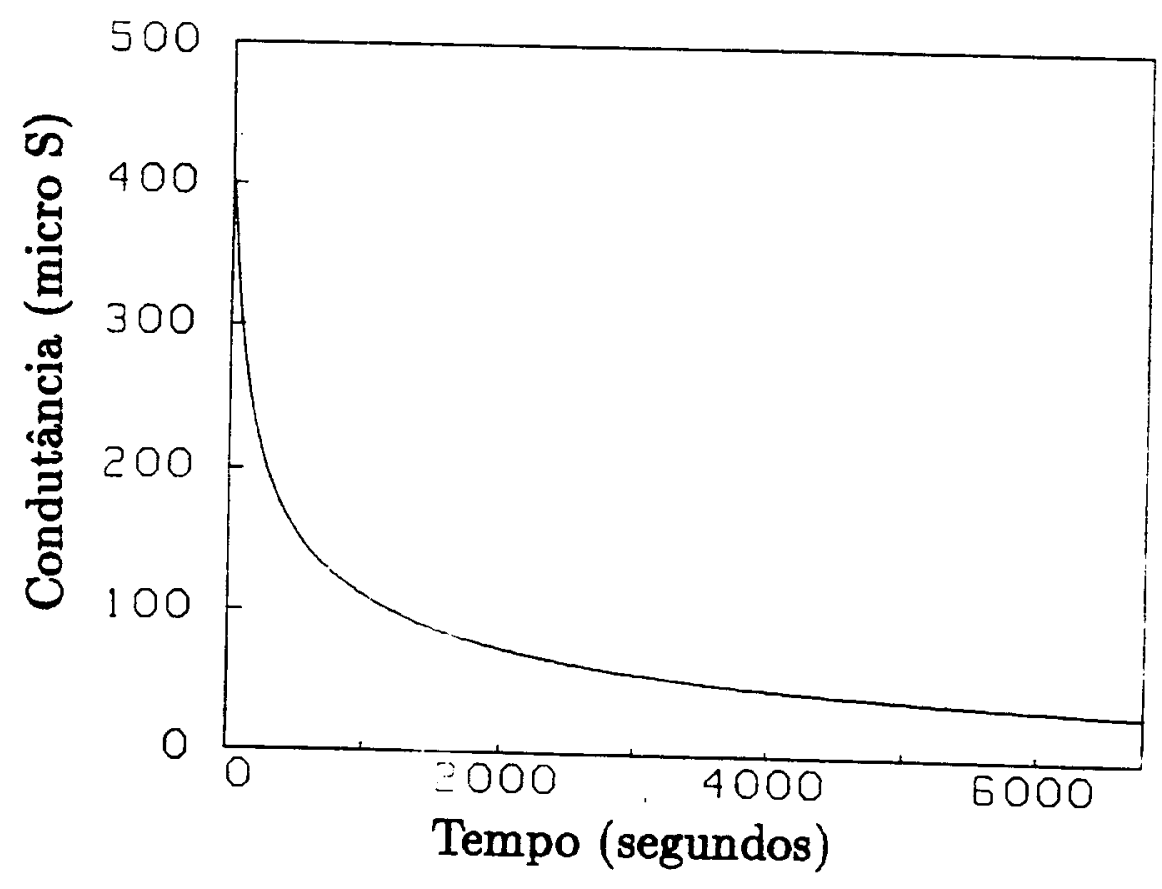

Figara 3.4 - TDPPC pare uma amostre de $\mathrm{Al}_{0.3} \mathrm{Ga}_{0.7} \mathrm{As}$ a $85 \mathrm{~K}$

\section{2 - A TEORIA DE TDPPC}

Para compreender os decaimentos experimentais discutidos na secção anterior, deve-se equacionar os princípios físicos envolvidos no fenômeno em termos da cinética de captura dos elétrons. A variação da condutividade $(\sigma)$ da amostra no tempo é uma função das variações temporais da mobilidade $(\mu)$ e concentração de elétrons livres (n), assim :

$$
\sigma(t)=e n(t) \mu(t)
$$

A condutância (G) pode ser vista como :

$$
G(t)=K_{S} \sigma(t)
$$

onde $\mathrm{K}_{S}$ é uma constante. A princípio, $\mathrm{K}_{S}$ é uma função das dimensões da amostra : área da secção transversal e distância entre contatos. Na prática esta relação simples torna-se complicada pelo fato de que é praticamente impossível determinar a 
área efetiva aonde a condução reaimente ocorre. Assim sendo, a constante $\mathrm{K}_{S}$ é determinada dividindo-se $o$ valor medido da condutância a $t=0$ pelo valor calculado da condutividade.

\subsection{1 - Concentração de Elétrons Livres}

Quando a luz é desligada a equação que governa o decaimento dos elétrons fotoionizados é dado por :

$$
\frac{d n}{d t}=-c_{n}\left[N_{D X}(\text { vazio })\right]+e_{n}\left[N_{D X}(\text { ocupado })\right]
$$

onde $N_{D X}$ (vazio) e $N_{D X}$ (ocupado) referem-se a concentração de centros DX ocupados ou não com elétrons. $c_{n}$ é a taxa térmica de captura de elétrons pelos centros DX e e é a taxa térmica de emissão de elétrons dos centros DX. A taxa de captura é dada por :

$$
c_{n}=V_{t h} \gamma_{n} n
$$

onde $V_{\text {th }}$ é a velocidade térmica dos eletrons ${ }^{36}$ :

$$
V_{t h}=\sqrt{\frac{3 k_{B} T}{m_{e i}}}
$$

$\gamma_{n}$ é a secção transversal de captura, $k_{B}$ é a constante de Boltzmann, $T$ é a temperatura e $m_{e i}$ é a massa efetiva no vale $i(\Gamma, L$ ou $X) \cdot \gamma_{n}$ é termicamente ativada é é dada por :

$$
\gamma_{n}=\gamma_{\infty} \exp \left[-\frac{\left(E_{c a p}-E_{F}\right)}{k_{D} T}\right]
$$

$\gamma_{\infty}$ é a secção transversal de captura a alta temperatura (constante para um determinado material), $E_{c a p}$ é a energia de captura e $E_{F}$ é a energia de Fermi. A 
relação entre o nível de Fermi e a concentração de elétrons livres depende da fração de alumínio na amostra e é dada por :

$$
n_{i}=N_{c i} F_{1 / 2}\left(\eta_{i}\right)
$$

onde $\mathrm{n}_{i}$ é a concentração de elétrons no vale $\mathrm{i}(\Gamma, \mathrm{L}$ ou $\mathrm{X})$. $\mathrm{N}_{a i}$ é a densidade de estados do vale i como dada por Casey e Panish ${ }^{57}$ e $F_{1 / 2}$ é a integral de Fermi-Dirac de ordem $1 / 2$ em relação ao mínimo do vale $i^{58}$, desde que :

$$
\eta_{i}=\frac{\left(E_{F}-E_{a i}\right)}{k_{B} T}
$$

onde $E_{c i}$ é o mínimo do vale $i$. É óbvio que a soma de eletrons nos vales $\Gamma, L$ e X fornece a concentração total de eletrons livres, ou seja :

$$
n=n_{\Gamma}+n_{L}+n_{X}
$$

É possível então se obter a fração no vale $i\left(\hat{f}_{i}=n_{i} / n\right)^{11}$. Por exemplo no vale $\mathrm{X}$, ela é dada por :

$$
f_{X}=\left\{1+\left(\frac{m_{e} \Gamma}{m_{e X}}\right)^{3 / 2} \exp \left[-\frac{\Delta E^{\Gamma-x}}{k_{B} T}\right]+\left(\frac{m_{e L}}{m_{e X}}\right)^{3 / 2} \exp \left[-\frac{\Delta E^{L-X}}{k_{B} T}\right]\right\}^{(-1)}
$$

onde $\Delta E^{i-X}$ significa a diferença de energia entre o mínimo do vale $i$ e o mínimo do vale X. Apesar de fundamental a temperatura ambiente, Chand et al ${ }^{11}$ mostraram que a baixa temperatura, a distribuição fracional é relevante apenas em concentrações de alumínio próximas da transição gap direto-indireto (entre 0.4 e $0.5 \mathrm{de} \mathrm{Al}$ ). Desta forma, à temperaturas no intervalo $80-100 \mathrm{~K}$, desde que a concentração seja menor que aproximadamente 0.4 ou maior que aproximadamente 0.5 a contribuição dos demais vales pode ser desprezada e considera-se apenas aquele que representa o mínimo da banda de condução, simplificando a relação 3.9 e não necessitando da relaçãa 3.10 . 


\subsection{2 - Mobilidade}

A figura 3.5 mostra a dependência da mobilidade com a temperatura devida aos diversos tipos de espalhamento, segundo Saxena et al ${ }^{59}$. Um dos processos dominantes em todo o intervalo de temperatura é aquele denominado espalhamento devido aos espaços de carga. Este espalhamento foi primeiro tratado por Weisberg ${ }^{60}$ para explicar efeitos anômalos na mobilidade em semicondutores. Em linhas gerais este espalhamento pode ser descrito como devido a uma distribuição não homogênea de defeitos que podem causar regiōes localizadas com cargas contrárias a do cristal matriz. Quando isso ocorre, um espaço de carga circunda esta região em ordem a se ter neutralidade elétrica. A mobilidade é diretamente proporcional a concentração desses espaços de carga ( $\mathrm{N}_{S}$ na figura 3.5) e área efetiva para espalhamento (Q). Dada a impossibilidade de se determinar tanto $\mathrm{N}_{S}$ como $\mathrm{Q}$, Saxena et al assumem um número para o produto dessas quantidades para encaixar os dados experimentais. Por se tratar de um efeito anômalo, esse espalhamento não é mencionado em livro de física de semicondutores (veja por exemplo Ridley ${ }^{61}$ ), além disso, a necessidade de se assumir valores para $\mathrm{N}_{S}$ e $\mathrm{Q}$ faz com que a mobilidade devida aos centros de carga possa assumir qualquer importância em qualquer temperatura. Portanto é preferível desprezar a possibilidade da ocorrência deste tipo de espalhamento, lembrando ainda a alta qualidade das amostras crescidas por MBE, que produz filmes bastante homogêneos. Não podemos esquecer porém, que a existência de uma distribuicão não homogênea de complexos pode ser explicação importante para resultados não esperados em ligas semicondutoras.

A mobilidade devido ao espalhamento de liga não é tão relevante como seria de se esperar, principalmente a baixa temperatura. $O$ espalhamento de liga cresce em importância para concentrações de alumínio em torno de $50 \%{ }^{62}$, porém a mobilidade devida ao espalhamento de liga é ainda muito maior que a mobilidade devido às impurezas ionizadas. Assim, para se tratar quantitativamente os resultados de TDPPC, assumimos que o espalhamento dominante a baixa temperatura é devido às impurezas ionizadas. A fórmula de Brooks-Herring é largamente usada para o 


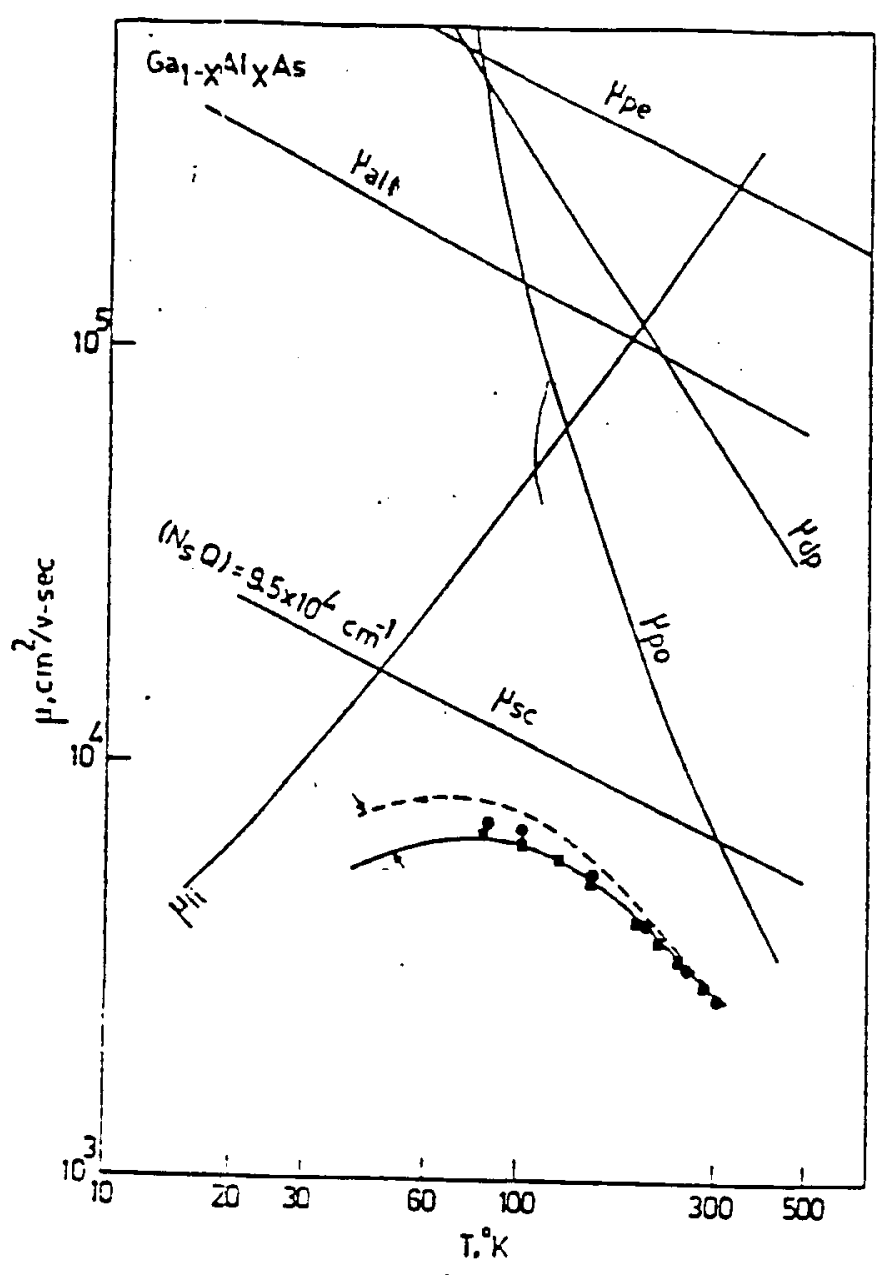

Figara 3.5 - Dependência com a temperatura da mobilidade devida a diferentes tipos de espalbamento. Círculos e quadrados - dados experimentais para composiçōes $x=0.29$ e $x=0.31$. ${ }^{39}$ $\mu_{h}$-espalhamento devido ao potencial de deformação, $\mu_{i i}$ - espaihamento devido as imporezas ionizadas, $\mu_{a l}$ - espaihamento die liga, $\mu_{\text {ac }}$ - espaihamento devido aos espaços de carga, $\mu_{n o}$ - poiar ótico 
tratamento da mobilidade devida ao espalhamento por impurezas ionizadas. A probabilidade de transição é uma função do potencial V(q), relacionado a transformada de Fourier do potencial de impureza V(r). Na análise de Brooks-Herring V(q) é dado por ${ }^{63,64}$ :

$$
|V(q)|=\frac{Z e}{\varepsilon\left(q^{2}+S_{l}^{2}\right)}
$$

onde $\mathrm{Z}$ é a carga da impureza, $\varepsilon$ é a constante dielétrica, $\vec{q}=\vec{k}-\vec{k}(\vec{k}$ - estado inicial, $\vec{k}$ ' - estado espalhado) e $\mathrm{S}_{l}$ é o comprimento inverso da blindagem, definido por :

$$
S_{l}=\frac{n e F_{-1 / 2}}{\varepsilon k_{B} T F_{1 / 2}}
$$

Na análise de Brooks-Herring, V(q) é tratado como o potencial visto pelo eletron em colisão, desprezando a deformação da nuvem de blindagem devido a campo do eletron em colisão. Na realidade o campo elétrico gerado pelo eletron em colisão vai deformar a nuvem de blindagem, diminuindo o efeito de blindagem, que será menor que aquele previsto por Brooks e Herring. Takimoto ${ }^{65}$ mostrou que a incorporação do efeito dessa polarização da nuvem de blindagem é dada por :

$$
|V(q)|=\frac{Z e}{\varepsilon\left(q^{2}+H(q)\right)}
$$

onde $\mathrm{H}(\mathrm{q})$, o parâmetro de blindagem é dado por :

$$
H(q)=S_{l}^{2} G(\zeta)
$$

onde

$$
\begin{gathered}
G(\zeta)=\frac{1}{\sqrt{\pi} \zeta} \int_{0}^{\infty} x \exp \left(-x^{2}\right) \ln \left|\frac{x+\zeta}{x-\zeta}\right| d x \\
\zeta^{2}=\frac{\hbar^{2} q^{2}}{8 m_{e} k_{B} T}
\end{gathered}
$$

onde $\hbar=h / 2 \pi, h$ - constante de Planck.

A determinação da mobilidade consiste em se avaliar a probabilidade de transição $\mathrm{P}(\vec{k}, \vec{k})$. Para uma banda parabólica e usando a aproximação de Born, obtém-se : 


$$
P\left(\vec{k}, \vec{k}^{\prime}\right)=\frac{2 \pi}{\hbar} \frac{N_{i i} e^{2}}{\Omega}|V(q)|^{2} \delta\left(E^{\prime}-E\right)
$$

onde $\mathrm{N}_{i i}$ é a concentração de impurezas ionizadas, $\Omega$ é o volume do cristal e $\delta\left(E^{\prime}-E\right)$ é a função Delta de Dirac ( $E$ '- energia do elétron em $\vec{k}$ ', E - energia do elétron em $\vec{k})$. A probabilidade de transição se relaciona com o tempo de relaxação através da relação :

$$
\frac{1}{\tau}=\frac{\Omega}{4 \pi^{2}} \int_{\vec{k}^{\prime}} \int_{s=-1}^{1}(1-z) P\left(\vec{k}, \vec{k}^{\prime}\right) k^{2} d \vec{k}^{\prime} d z
$$

e a mobilidade é finalmente obtida por :

$$
\mu=\frac{e \tau}{m_{e}^{*}}
$$

onde $\mathrm{m}_{e}^{*}$ é a massa efetiva para condutividade. Substituindo os valores do potencial de Brooks-Herring e Takimoto respectivamente e fazendo as simplificações necessárias ${ }^{64,65}$ obtém-se as respectivas mobilidades de Brooks- Herring $\left(\mu_{B H}\right)$ e Takimoto $\left(\mu_{T A K}\right)$ :

$$
\mu_{B H}=\frac{128(2 \pi)^{1 / 2} e^{2}\left(k_{B} T\right)^{3 / 2}}{Z^{2} e^{3}\left(m_{e}^{*}\right)^{1 / 2} N_{i i} \ln \left(\frac{b}{n}\right)}
$$

onde:

$$
\begin{gathered}
b=\frac{96 \pi^{2} m_{e}^{*} \varepsilon\left(k_{B} T\right)^{2}}{e^{2} h^{2}} \\
\mu_{T A K}=\frac{64(2 \pi)^{1 / 2} \varepsilon^{2}\left(k_{B} T\right)^{3 / 2}}{3 Z^{2} e^{3}\left(m_{e}^{*}\right)^{1 / 2} N_{i i}} \int_{0}^{\infty} \frac{x_{o}^{3} \exp \left(-x_{0}\right) d x_{o}}{J_{\gamma}\left(\sqrt{x_{0}}\right)}
\end{gathered}
$$

A integral na equação 3.22 tem resolução complexa, desde que a função $J_{\gamma}\left(\sqrt{x_{0}}\right)$ é também complexa. Usando-se o recurso da simulação numérica é preferível usar a aproximação de Hall ${ }^{66}$, de forma a facilitar a obtenção de $\mu_{T A K}$ :

$$
J_{\gamma}\left(\sqrt{x_{0}}\right)=\left(1-\frac{2 \gamma^{2}}{3}\right)^{-2}\left[\ln \left(\frac{3+\gamma^{2}}{3 \gamma^{2}}\right)-\frac{1-\frac{2}{3} \gamma^{2}}{1+\frac{1}{3} \gamma^{2}}\right]+\frac{\gamma^{2}}{4\left(\gamma^{2}+2 x_{o}^{2}\right)}+\frac{1}{2} \ln \left(\frac{\gamma^{2}+2 x_{o}^{2}}{2 \gamma^{2}}\right)
$$


onde:

$$
\begin{gathered}
\gamma^{2}=\frac{n e^{2} \hbar^{2}}{8 \varepsilon m_{e}^{*}\left(k_{B} T\right)^{2}} \\
x_{0}=\frac{E}{k_{B} T}
\end{gathered}
$$

Para se analizar a importância do efeito da polarização da nuvem eletrônica, são calculadas as mobilidades de Brooks-Herring e Takimoto para $\mathrm{Al}_{x} \mathrm{Ga}_{1-x} \mathrm{As}$. Um resumo dos resultados obtidos é mostrado nas figuras 3.6 e 3.7. Na figura 3.6 é variada a concentração de elétrons livres e a porcentagem de alumínio para uma temperatura fuxa de $90 \mathrm{~K}$. Conforme pode ser visto não exciste uma diferença significativa entre essas mobilidades a menos que o número de elétrons livres seja grande e a composição seja baixa em alumínio. Já a figura 3.7 é uma indicação de que a medida que a temperatura diminui, a defasagem entre essas equações torna-se surpreendente e ainda deve-se considerar que essa amostra tem $50 \%$ de alumínio, o que pela figura 3.6 não é uma composição crítica. Em amostras de AlGaAs com um dopante que forma centro DX cuja energia de captura térmica é baixa, TDPPC deve ser realizado a temperaturas mais baixas. Se a composição de alumínio é baixa, torna-se evidente que a equação de Brooks-Herring não pode ser usada para uma análise quantitativa dos dados, ou seja, o efeito da polarização da nuvem de blindagem torna-se muito importante.

\section{3 - MODELOS DE CENTROS DX PARA A SIMULAÇÃO NUMÉRICA}

O equacionamento apresentado na secção anterior é completamente geral, não dependendo do modelo de centro DX assumido para o tratamento quantitativo. Para a realização da simulação é preciso saber como equacionar $\mathrm{N}_{D X}$ (vazio), 


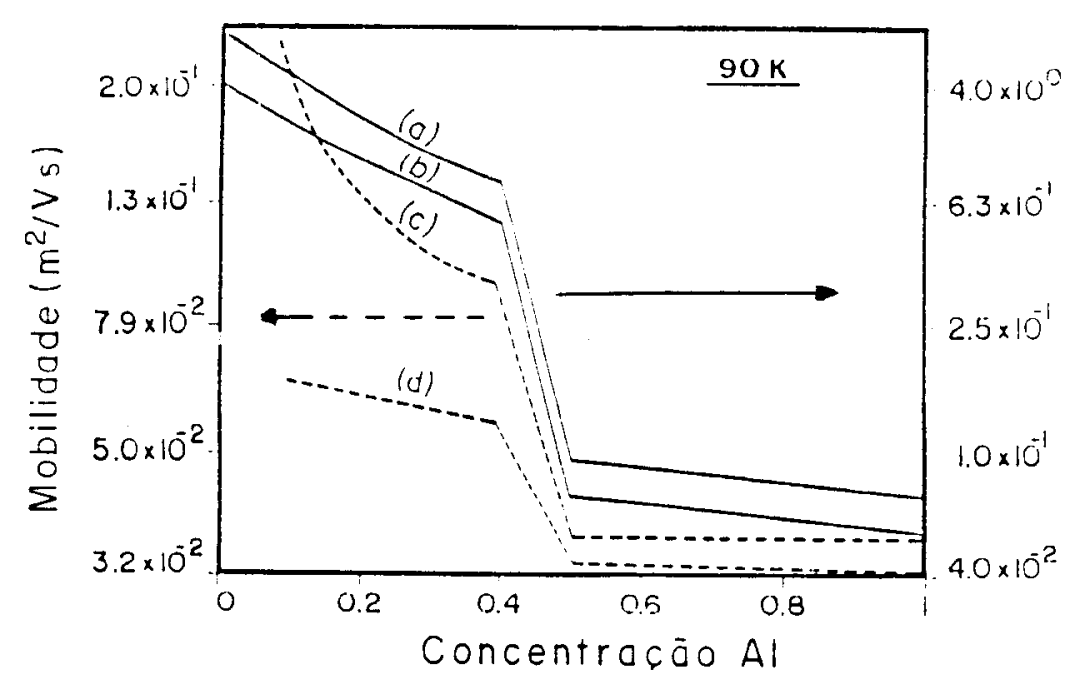

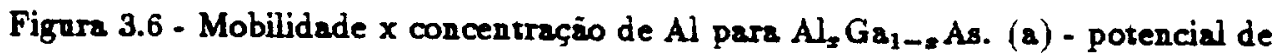
Brooks-Herring, $N_{i i}=5 \times 10^{17} \mathrm{~cm}^{-3}, n=2 \times 10^{17} \mathrm{~cm}^{-3},(b)-$ potencial de Talimoto $N_{i i}=5 \times 10^{17}$ $\mathrm{cm}^{-3}, \mathrm{n}=2 \times 10^{37} \mathrm{~cm}^{-3}$, (c) - B.H. $-N_{i i}=\mathrm{n}=1 \times 10^{18} \mathrm{~cm}^{-3}$, (d) - Takimoto $N_{i i}=n=1 \times 10^{18}$ $\mathrm{cm}^{-3}$

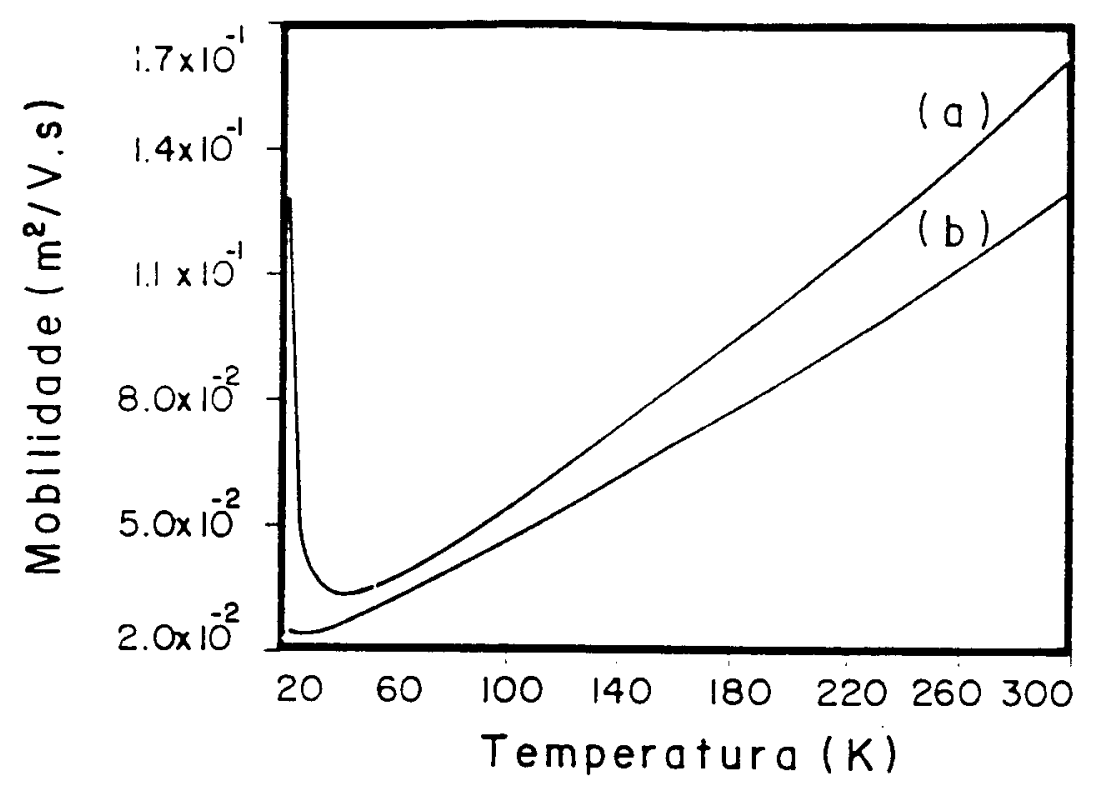

Figura 3.7 - Mobilidade $x$ temperatura para $A l_{0.8} G a_{0 . s}$ As (a) - Equação de Brooks-Herring, (b) Equação de Takimoto. $\mathrm{N}_{i i}=5 \times 10^{17} \mathrm{~cm}^{-3}, \mathrm{n}=2 \times 10^{17} \mathrm{~cm}^{-3}$ 
$N_{D X}$ (ocupado) e $N_{i i}$ e em conjunção com as equações apresentadas na secção anterior obter a simulação numérica auto-consistente. A discussão que se segue é baseada nos resultados experimentais obtidos para uma amostra de $\mathrm{Al}_{0.3} \mathrm{Ga}_{0.7} \mathrm{As}$ dopada com $\mathrm{Si}\left(1 \times 10^{18} \mathrm{~cm}^{-3}\right)$. A energia de captura é obtida pelo método descrito no apêndice A. Pode-se modelar a cinética de captura pelo centro $\mathrm{DX}$ de modo a satisfazer todas as possibilidades de balanço de carga. Assim podemos assumir o caráter doador ou aceitador do centro DX e ainda se ocorre a captura simultânea de um, dois ou tres eletrons e testar essas hipóteses. Dado ao grande sinal observado nessa amostra (veja figuras 3.1 e 3.4), pode-se desprezar o termo devido à emissão térmica, já que todo o processo de captura se dá devido aos elétrons aprisionados metaestavelmente no vale $\Gamma$ tenderem a voltar ao estado de equilíbrio termodinâmico no centro DX. Deve-se observar que a lei de conservação de carga seja respeitada e assim pode-se obter as relações para $N_{D X}$ (vazio) e $N_{i i}$. A tabela III.1 é um resumo de todas as simulaçōes realizadas para os diversos modelos assumidos. O valor de $\gamma_{\infty}$ é $5 \times 10^{-14} \mathrm{~cm}^{2}{ }^{67}$. Conforme pode ser visto, mesmo com um número maior de parâmetros ajustáveis, os modelos aonde DX envolve a captura ou emissão de um elétron simplesmente não conseguem um bom ajuste aos dados experimentais, o que pode ser visto na figura 3.8, a título de ilustração.

O modelo de Chadi e Chang ${ }^{19,23}$ apresenta um encaixe muito bom para tempos não muito longos, havendo então uma pequena defasagem, o que é mostrado na figura 3.9. A cinética de captura nesse modelo é dada por :

$$
2 d^{+}+2 e^{-}=D X^{-}+d^{+}
$$

Dessa forma em termos da cinética de captura um centro DX existe ou na forma de doador hidrogênico ionizado $\mathrm{d}^{+}$ou aprisiona dois elétrons e se transforma num centro $\mathrm{DX}^{-}$. Portanto a equação 3.26 simboliza o fato dos doadores se encontrarem em um desses dois estados. Como o número máximo de elétrons livres é igual a dopagem, então para que o estado $\mathrm{DX}^{-}$possua dois elétrons, muitos doadores rasos permanecerão no estado $\mathrm{d}^{+}$de modo que o número de centros ionizados é praticamente constante e igual a dopagem. Em têrmos da simulação de TDPPC nós assumimos que todas as impurezas ionizadas espalham elétrons da mesma forma. 


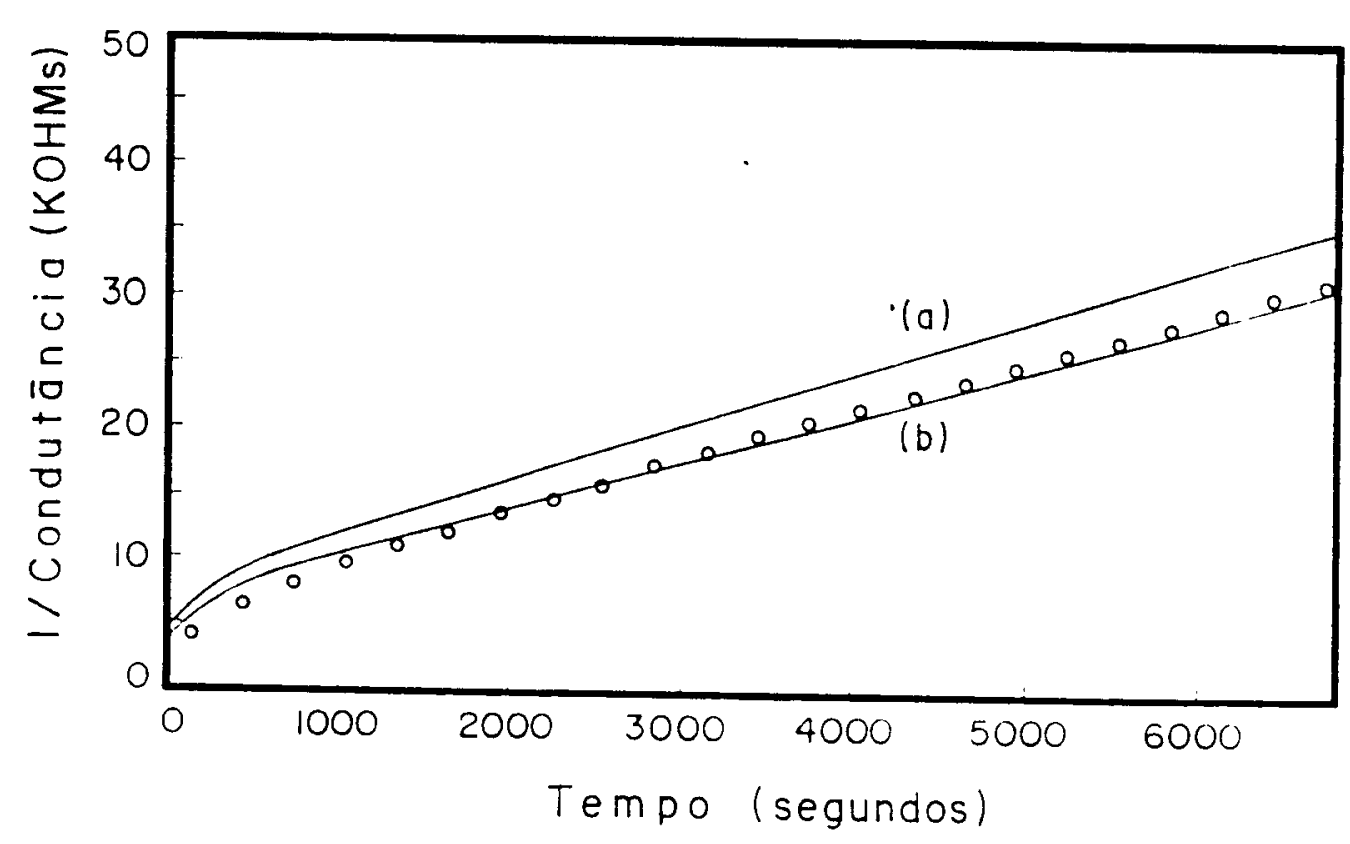

Figara 3.8 - Simulação Numérica do modelo do doador simples com uma concentração líquida de aceitadores. (*) - dados experimentais para $\mathrm{Al}_{0.3} \mathrm{Ga}_{0.7} \mathrm{As}$, temperatura $=85 \mathrm{~K}$, (a) concentração inicial de eletrons livres-n(0) $=4.5 \times 10^{17} \mathrm{~cm}^{-3},(\mathrm{~b})-\mathrm{n}(0)=4 \times 10^{17} \mathrm{~cm}^{-3}$

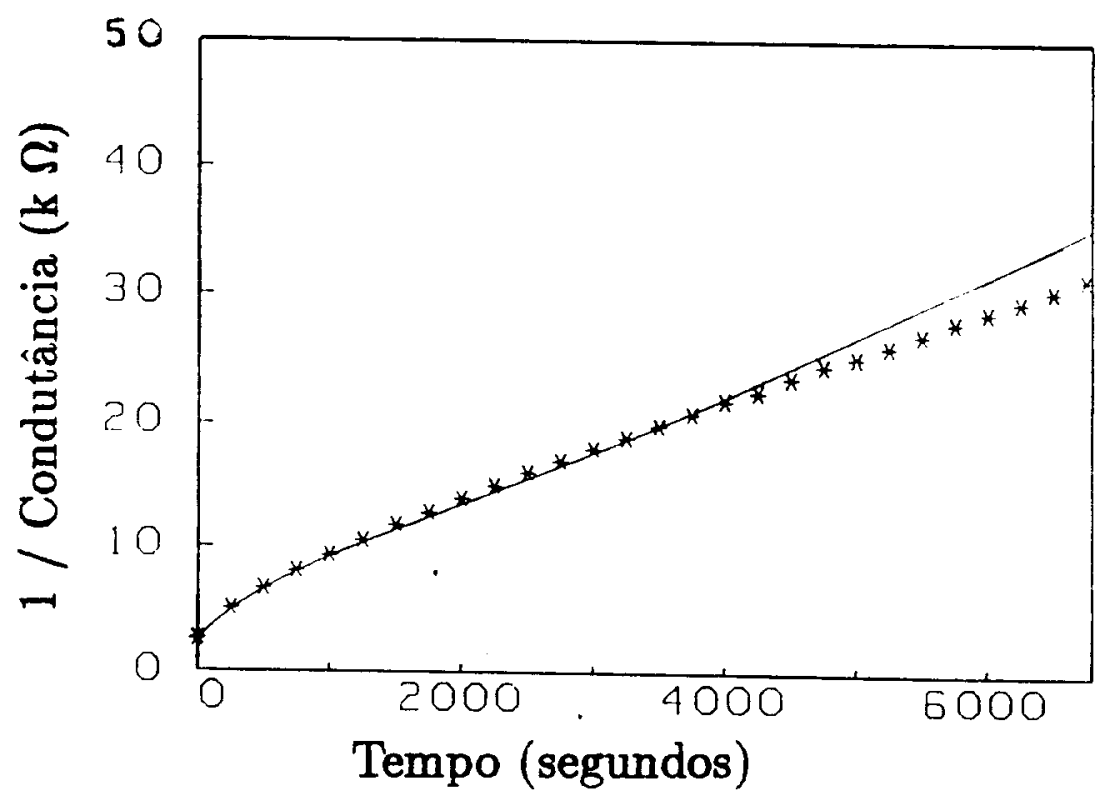

Figura 3.9 - Simulação do modelo de Chadi e Chang, (*) - dados experimentais para $\mathrm{Al}_{0.3} \mathrm{Ga}_{0.7} \mathrm{As}$, temperatura $=85 \mathrm{~K}, \mathrm{n}(0)=2.25 \times 10^{17} \mathrm{~cm}^{-3}$ 
A idéia do doador mais raso foi postulada com base na descoberta desse estado por Jia et al ${ }^{68}$. Pelo postulado da existência desse estado nós assumimos que eles são fotoionizados e permanecem ionizados durante toda a duração do experimento. Com base nessa hipótese o ajuste é perfeito, conforme mostrado na figura 3.10. Os parâmetros usados na determinação dessas curvas estão na tabela III.2.

Os cálculos de Li et al ${ }^{70}$ prevêm a existência desse doador adicional que é mais raso que o centro DX, porém ainda apresenta características de estado localizado. Dmochowski ${ }^{71}$ afirma que esse nível pode apresentar interação do tipo U-negativo assim como o centro DX. Pelo nosso postulado, não é possível dizer se o doador raso possui característica de U-negativo, porém podemos afirmar não se tratar de um nível raso hidrogênico, desde que ele permanece ionizado durante todo o tempo do experimento. Este nível mais raso poderia ser apenas um estado metaestável do próprio centro DX, no qual um átomo de As vizinho próximo do átomo de $\mathrm{Si}$ é deslocado para uma posição intersticial ${ }^{72}$. Este sistema também teria U-negativo com a diferença que o átomo de $\mathrm{Si}$ teria um deslocamento menor na direção <111> e consequentemente o sistema teria um nível mais próximo da banda de condução no gap de energia. 
Tabela III.1 - Resumo da simulação numérica para todos os modelos

\begin{tabular}{|c|c|c|}
\hline & Modelo & Qualidade do ajuste de TDPPC \\
\hline 1 & doador simples & nenhum ajuste \\
\hline 2 & $\begin{array}{l}\text { doador simples compinsado por uma concentra- } \\
\text { ção líquida de aceitadores rasos }\end{array}$ & nenhum ajuste \\
\hline 3 & $\begin{array}{l}\text { aceitador simples que compensa um concentra- } \\
\text { ção líquida de doadores rasos }\end{array}$ & ajuste fraco \\
\hline 4 & Chadi e Chang (U-negativo) & bom ajuste em tempos curtos \\
\hline 5 & $\begin{array}{c}\text { Chadi e Chang mais nível doador mais raso } \\
\text { adicional }\end{array}$ & ajuste excelente \\
\hline 6 & Van Vechten mais termo $N_{S D}$ & $\begin{array}{c}\text { bom ajuste se } \mathrm{N}_{S D} \text { é } \\
\text { variável }\end{array}$ \\
\hline
\end{tabular}

\begin{tabular}{|c|c|c|c|}
\hline & $\mathrm{N}_{D X}$ (vazio) & $\mathrm{N}_{\mathrm{ii}}$ & parâmetros ajustáveis \\
\hline 1 & $\mathrm{n}$ & $\mathrm{n}$ & $\mathrm{n}(0)$ \\
2 & $\mathrm{n}-\mathrm{N}_{D X}^{+}+\mathrm{N}_{S A}$ & $\mathrm{n}+2 \mathrm{~N}_{S A}$ & $\mathrm{n}(0), \mathrm{N}_{S A}, \mathrm{~N}_{D X}^{+}$ \\
3 & $\mathrm{n}-\mathrm{N}_{D X}^{-}+\mathrm{N}_{S D}$ & $2 \mathrm{~N}_{S D}-\mathrm{n}$ & $\mathrm{n}(0), \mathrm{N}_{S D}, \mathrm{~N}_{D X}^{-}$ \\
4 & $\mathrm{n} / 2$ & $\mathrm{~N}_{S i}$ & $\mathrm{n}(0)$ \\
5 & $\left(\mathrm{n}-\mathrm{N}_{S D}\right) / 2$ & $\mathrm{~N}_{S i}$ & $\mathrm{n}(0), \mathrm{N}_{S D}$ \\
6 & $\left(\mathrm{n}-\mathrm{N}_{S D}\right) / 3$ & $\mathrm{~N}_{d^{+}}, \mathrm{N}_{D X}$ & $\mathrm{n}(0), \mathrm{N}_{S D}$ \\
\hline
\end{tabular}

* - $N_{D X}^{+}, N_{D X}^{-}$representam concentraçöes de centros DX ionizados em equilibrio térmico 
Tabela III.2 - Parâmetros usados na simulação de TDPPC para o modelo de Chadi e Chang em conjunção com o nível mais raso

\begin{tabular}{|c|c|c|c|}
\hline Temperatura $(\mathrm{K})$ & $\mathrm{n}(0)\left(\mathrm{x} 10^{17} \mathrm{~cm}^{-3}\right)$ & $N_{S D}\left(\times 10^{16} \mathrm{~cm}^{-3}\right)$ & figura \\
\hline 80 & 3.60 & 1.3 & $3.10(1)$ \\
85 & 2.42 & 1.3 & $3.10(2)$ \\
90 & 1.97 & 1.3 & $3.10(3)$ \\
95 & 1.33 & 1.3 & $3.10(4)$ \\
100 & 1.29 & 1.8 & $3.10(5)$ \\
\hline
\end{tabular}

$O$ fato de que a concentração desse nível mais raso ser praticamente constante com a temperatura (tabela III.2) reforça a idéia da presença desse estado. Se o termo postulado como $\mathrm{N}_{S D}$ fosse devido a um estado intermediário, seria de se esperar que $\mathrm{N}_{S D}$ tivesse uma concentração variével com a temperatura, desde que a distribuição termodinâmica de elétrons entre centro DX, banda de condução e estado intermediário é uma função da temperatura ${ }^{52}$. Além disso supondo-se que esse estado intemediário fosse $d^{\circ}$, a concentração obtida para $\mathrm{N}_{S D}$ é muito maior que a prevista por Chadi e Chang e calculada na secção 1.1.1.

No modelo de Van Vechten ${ }^{8,27}$, a cinética de captura pode ser escrita em termos da seguinte reação :

$$
3 d^{+}+V_{A s}^{o}+3 e^{-}=1 d^{+} M_{A s}^{2-} V_{G a}^{-}+2 d^{+}
$$

A equação diferencial de TDPPC é :

$$
\frac{d n}{d t}=-\gamma_{n} V_{t h} \frac{n^{2}}{3}
$$

A larga relaxação da rede é simplesmente o salto do átomo de $\mathrm{Ga}(\mathrm{Al})$ para a vacância vizinha próxima de As. Para escrever a equação 3.28 nós estamos supondo que esse salto ocorre simultaneamente com a captura de 3 elétrons. No modelo de Chadi e Chang, a baixa temperatura, a concentração DX- é muito maior que a concentração de $d^{\circ}$ porque $\mathrm{DX}^{-}$é um estado muito mais estável. Portanto em nossas simulações de TDPPC, uma boa hipótese é que o transiente ocorrerá via captura de 2 elétrons para o centro DX. Já no modelo de Van Vechten, assumir a captura simultânea de 3 elétrons mais o salto atômico, sem a presença de nenhum intermediário não parece muito atraente, porém não existe nada sobre a possibilidade desse estado intermediário nos trabalhos de Van Vechten ${ }^{8,27}$. Por se tratar 

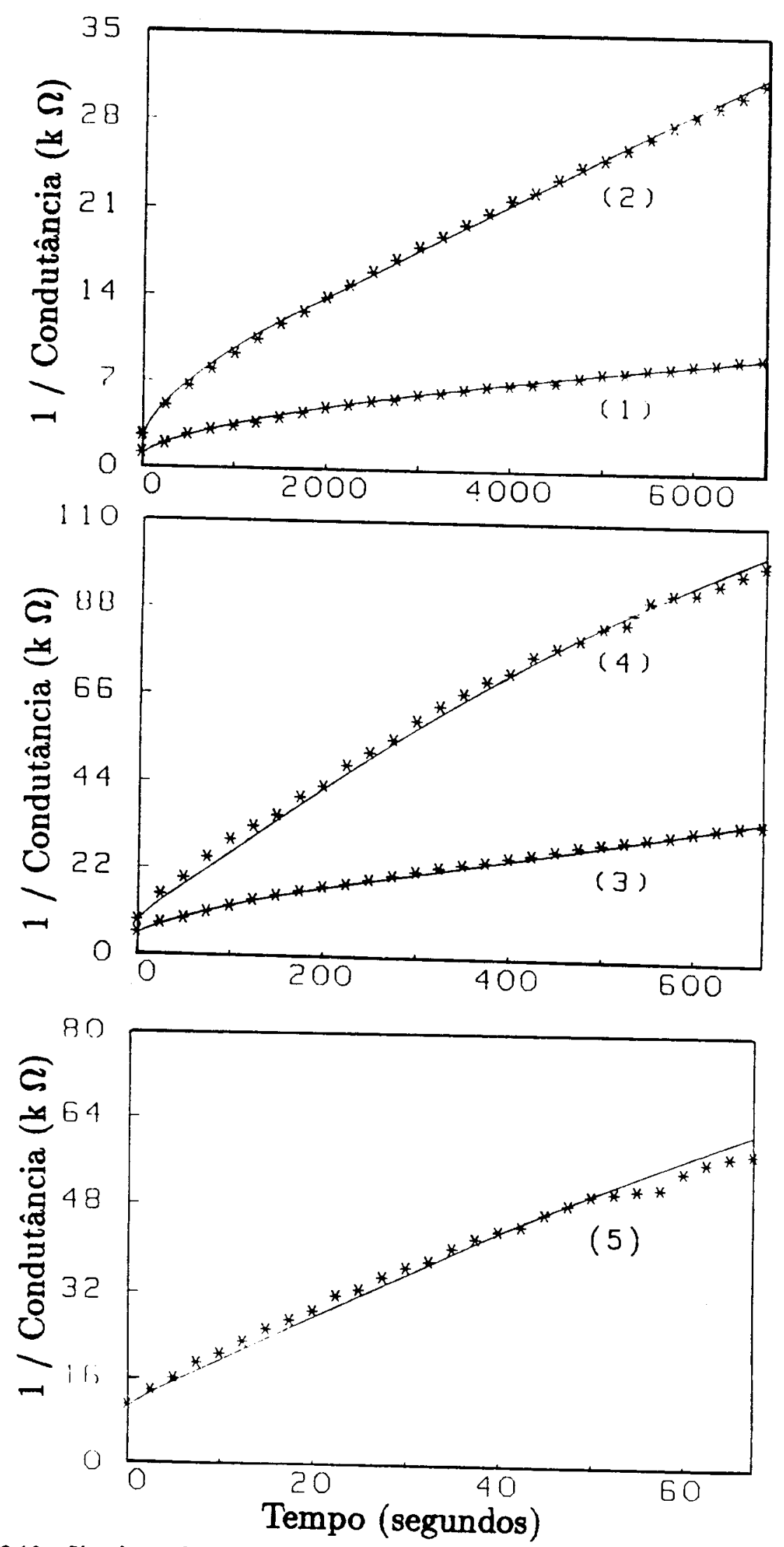

Figura 3.10 - Simulação baseada no modelo de Chadi e Chang mais doador mais raso. (1) - $80 \mathrm{~K}$, (2) $-85 \mathrm{~K},(3)-90 \mathrm{~K},(4)-85 \mathrm{~K},(5)-100 \mathrm{~K}$ 
de uma equação similar à que é usada para a cinética de captura no modelo de Chadi e Chang, a equação 3.28 também dá um bom ajuste para tempos não muito longos, desde que a mobilidade seja dividida em dois termos devida aos centros de espalhamento $\mathrm{d}^{+}$e aos centros $\left(\mathrm{d}^{+} M_{A_{s}}^{2-} \mathrm{V}_{G_{a}}^{-}\right)$. A inclusão do termo $\mathrm{N}_{S D}$ torna o ajuste perfeito, assim como aconteceu com a simulação para o modelo de Chadi e Chang, porém o valor de $\mathrm{N}_{S D}$ não é constante na temperatura (tabela III.3), de forma que seria difícil associá-lo com a presença de um nivel mais raso. A simulação numérica baseada no modelo de Chadi e Chang foi confirmada para uma amostra de $\mathrm{Al}_{0.34} \mathrm{Ga}_{0.68} \mathrm{As}$, com a presença do nível mais raso sendo realmente constante com a temperatura conforme mostrado na tabela III.4.

tabela III.3 - Parâmetros usados na simulação do modelo de Van Vechten mais um

\begin{tabular}{|c|c|c|}
\hline \multicolumn{3}{|c|}{ termo $\mathrm{N}_{S D}$} \\
\hline Temperatura $(\mathrm{K})$ & $\mathrm{n}(0)\left(\mathrm{x} 10^{17} \mathrm{~cm}^{-3}\right)$ & $\mathrm{N}_{S D}\left(\mathrm{x} 10^{18} \mathrm{~cm}^{-3}\right)$ \\
85 & 3.58 & 0 \\
90 & 2.43 & 0 \\
95 & 2.15 & 0.9 \\
100 & 1.75 & 2.1 \\
& 1.62 & 2.6 \\
\hline
\end{tabular}

Tabela III.4 - Parâmetros usados na simulação de TDPPC baseada no modelo de Chadi e Chang em conjunto com o nível mais raso para $\mathrm{Al}_{0.34} \mathrm{Ga}_{0.66} \mathrm{As}^{54}$

\begin{tabular}{|c|c|c|}
\hline $\begin{array}{c}\text { Temperatura } \\
(\mathrm{K})\end{array}$ & $\begin{array}{c}\mathrm{n}(0) \\
\left(\times 10^{17} \mathrm{~cm}^{-3}\right)\end{array}$ & $\begin{array}{c}\mathrm{N}_{S D} \\
\left(\times 10^{16} \mathrm{~cm}^{-3}\right)\end{array}$ \\
\hline 80 & 4.54 & 1.6 \\
85 & 3.43 & 1.6 \\
90 & 3.09 & 1.6 \\
95 & 2.51 & 1.6 \\
100 & 2.08 & 1.6 \\
\hline
\end{tabular}




\subsection{1 - A Inclusão do Termo de Emissão}

$O$ único valor de $\mathrm{N}_{S D}$ (tabela III.2) que é diferente dos demais é a $100 \mathrm{~K}$. Como o sinal de condutância é muito menor nessa temperatura, é possível que os termos de emissão passem a ser relevantes a partir dessa temperatura. A taxa de emissão é dada por :

$$
e_{n}^{t}=\nu_{n} V_{t h}
$$

onde $^{73}$ :

$$
\nu_{n}=\gamma_{n} \frac{N_{c}}{g} \exp \left(-\frac{\Delta E_{t}}{k_{B} T}\right)
$$

onde $g$ é a degenerescência do nível profundo e $\Delta E_{t}$ é a diferença de energia entre o nível profundo e o mínimo da banda de condução. A partir de 3.6 e $3.30, \nu_{n}$ é facilmente obtido como :

$$
\nu_{n}=\gamma_{\infty} \frac{N_{c}}{g} \exp \left(-\frac{E_{\text {emise }}}{k_{B} T}\right)
$$

onde $E_{\text {emiss }}$ é a energia de emissão do centro DX. Em termos do modelo de Chadi e Chang, a equação 3.3 , torna-se então :

$$
\frac{d n}{d t}=-\gamma_{\infty} V_{t h} \exp \left(-\frac{E_{c \mid p}}{k_{B} T}\right) \frac{n^{2}}{2}+2 \gamma_{\infty} V_{t h} \frac{N_{c}}{g}\left(\frac{N_{i i}}{2}-\frac{n}{2}\right) \exp \left(-\frac{E_{\text {emise }}}{k_{B} T}\right)
$$

Com os valores de $\gamma_{\infty}$ dados por Takikawa e Ozeki ${ }^{67}$, pode-se efetuar novamente a simulação numérica. No intervalo de temperaturas em que se trabalha $(80-100 \mathrm{~K})$, a avaliação das grandezas na equação 3.32 mostra que o segundo termo é muito pequeno quando comparado com o primeiro e portanto nenhuma emissão mensurável deveria ocorrer. Porém ao se pensar no modelo de Chadi e Chang, que envolve uma distorção da rede, a vizinhança do doador que vai capturar os elétrons e do defeito que vai emitir os elétrons são completamente diferentes, sugerindo que talvez a equação 3.32 devesse ser reescrita como : 


$$
\frac{d n}{d t}=-\gamma_{n} V_{t h} \frac{n^{2}}{2}+2 C_{1} V_{t h} N_{c}\left(\frac{N_{i i}}{2}-\frac{n}{2}\right) \exp \left(-\frac{E_{\text {emiss }}}{k_{B} T}\right)
$$

Ajustando-se os valores de $\mathrm{n}(\mathrm{o})$ e $\mathrm{C}_{1}$ na simulação, é claro que os dados experimentais podem ser encaixados e isso é mostrado na tabela III.5. Conforme pode ser visto nessa tabela, os valores de $\mathrm{C}_{1}$ para encaixar os dados experimentais não é constante, de forma que não haveria um sentido físico na equação 3.33. Além disso o valor de $\mathrm{C}_{1}$ é muito grande quando comparado com valores conhecidos de níveis profundos, o que contribui na perda do sentido físico neste tipo de modelamento. Portanto, em conclusão, não deve haver contribuição do termo de emissão nessa faixa de temperatura. O pequeno desvio observado na temperatura de $100 \mathrm{~K}$ na tabela III.2 deve ser devido a presença de luz estranha ao experimento.

Tabela III.5 - Parâmetros para análise da influência do termo de emissão na cinética de captura do centro DX pelo modelo de Chadi e Chang

\begin{tabular}{|c|c|c|}
\hline $\begin{array}{c}\text { Temperatura } \\
(\mathrm{K})\end{array}$ & $\begin{array}{c}\mathrm{n}(0) \\
\left(\times 10^{17} \mathrm{~cm}^{-3}\right)\end{array}$ & $\begin{array}{c}\mathrm{C}_{1} \\
\left(\times 10^{-11} \mathrm{~cm}^{2}\right)\end{array}$ \\
\hline 80 & 3.45 & 0 \\
85 & 2.30 & 40.0 \\
90 & 1.90 & 20.0 \\
95 & 1.24 & 3.8 \\
100 & 1.21 & 4.9 \\
\hline
\end{tabular}




\section{CAPÍTULO IV}

\section{O PROBLEMA DOS CONTATOS ÔHMICOS A BAIXA TEMPERATURA}

\subsection{CONTATO METAL SEMICONDUTOR TIPO N}

Um contato metal-semicondutor pode ser de dois tipos : retificador, como consequência de uma barreira de potencial resultante de um espaço de cargas estável no semicondutor, sendo conhecido como barreira Schottky ${ }^{74,75}$ ou, no caso do contato apresentar resistência desprezível e ser não retificador, não importando a polaridade do potencial aplicado, ele é conhecido como contato ôhmico.

Existem parâmetros relacionados com a superfície de um semicondutor e de um metal que desempenham um papel fundamental na compreensão de como é formada uma junção metal-semicondutor. São eles : a função trabalho e a afinidade eletrônica. A função trabalho de um metal $\left(\phi_{m}\right)$ é a quantidade de energia necessária para deslocar um elétron do nível de Fermi para um estado de repouso na superfície do metal (nível de vácuo). A função trabalho tem duas contribuições distintas : uma devido a potencial periódico do cristal e interação entre elétrons, e a outra contribuição é devida à formação de uma camada dipolo advinda da quebra de simetria 
da estrutura atômica na superfície do metal. A função trabalho de um semicondutor $\left(\phi_{.}\right)$é definida de forma análoga, ainda que normalmente não existam estados permitidos no semicondutor exatamente no nível de Fermi. Porém a função trabalho é um conceito estatístico e como tal pode ser vista como uma média ponderada entre bandas de valência e condução. Para um semicondutor, a afinidade eletrônica $\left(\chi_{\bullet}\right)$ é também relevante na formação da junção metal-semicondutor e é a diferença nas energias entre o nível de vácuo e o mínimo da banda de condução.

A formação da junção entre um metal e um sernicondutor é exemplificada na figura 4.1, onde um metal de função de trabalho $\phi_{m}$ é colocado em contato com um semicondutor de função de trabalho $\phi_{s}$, menor que $\phi_{m}$. A medida que os dois materiais são aproximados, existe a tendência para que os níveis de Fermi se tornem iguais, desde que a situação seja de equilíbrio térmico. Os elétrons situados nas proximidades da superfície têm sua energia mudada nos dois sólidos devido ao campo elétrico gerado pela aproximação entre eles. Os elétrons do metal repelem os eletrons na superfície do semicondutor deixando um balanço de cargas positivas, pois sendo do tipo n, os eletrons na banda de condução vêm das impurezas doadoras introduzidas propositalmente no semicondutor. A concentração de doadores no semicondutor é muito menor que a concentração de elétrons no metal de forma que os doadores não compensados ocupam uma faixa larga do material ( $\mathbf{w})$, comparável à largura da região de depleção numa junção p-n. As bandas são entortadas para cima e a diferença $V_{i}$ entre os potenciais eletrostáticos nas superfícies dos dois materiais é dada por ${ }^{76}$ :

$$
V_{i}=\delta E_{i}
$$

onde $\delta$ é a separação e $E_{i}$ é a magnitude do campo elétrico gerado. Quando os dois sólidos se encontram, $V_{i}$ vai para zero, a barreira devida ao vácuo desaparece e nós temos um contato ideal metal-semicondutor. A barreira $\phi_{b}$ é dada por ${ }^{5 B}$ :

$$
\phi_{b}=\phi_{m}-\chi_{\text {. }}
$$

Na prática é quase impossível de se obter o contato ideal mostrado na figura 4.1(d), pois sempre existe uma camada óxida fina $\left(10-20 \mathrm{~A}^{56}\right)$ na superfície do 


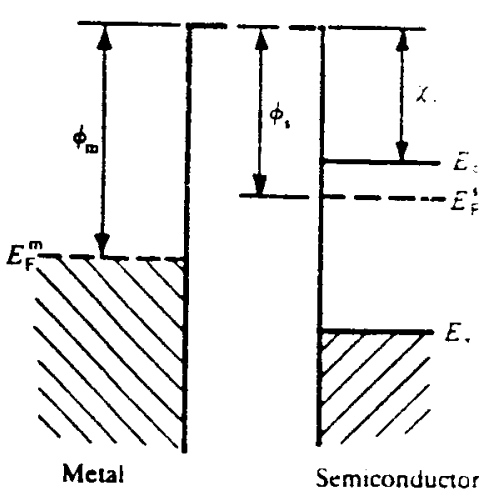

(a)

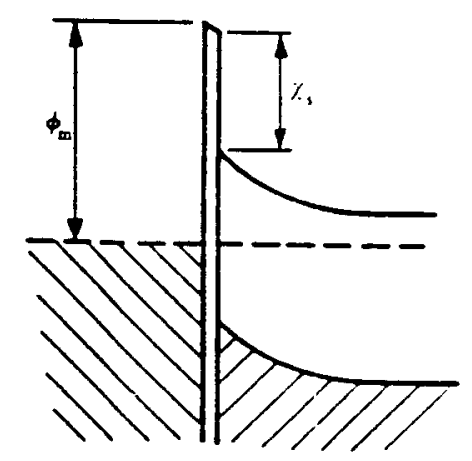

(c)

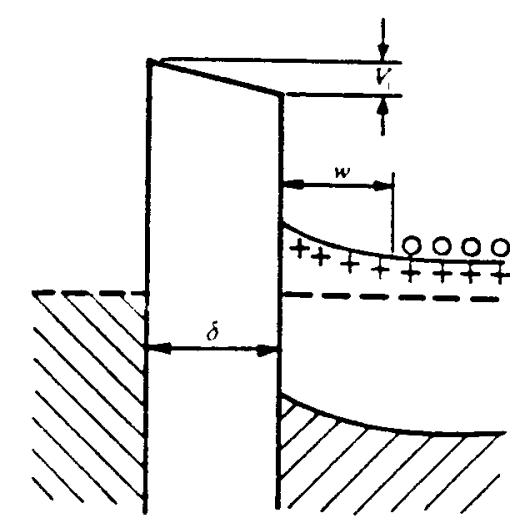

(b)

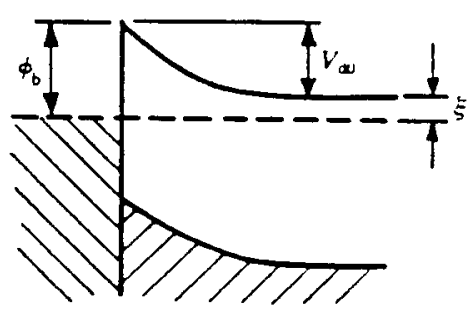

(d)

Figura 4.1 - Formação da barreira entre metal e semicondator, (a) - nentros e isolados, (b) separados por ums distância $\delta$, (c) - separados por um gap estreito, (d) - em contato perfeito ${ }^{76}$ 
semicondutor. Porém a barreira devida ao óxido é tão pequena que os eletrons podem tunelar através dela e a queda de potencial $V_{i}$ é praticamente desprezível. Na realidade a altura da barreira é uma função menos sensivel ao valor de $\phi_{m}$ do que o sugerido pela equação 4.2. A importância relativa entre os parâmetros relevantes na formação da barreira é normalmente obtida pelo modelamento com a inclusão de uma camada interfacial e ocupação dos estados superficiais do semicondutor. (Veja por exemplo Bardeen ${ }^{77}$ ou Cowley e Sze ${ }^{78}$ )

\subsection{1. - Mecanismos de Transporte}

Existem vários modos pelos quais um elétron pode ser transportado através de uma junção metal semicondutor tipo $n$, confurme exemplificado na figura 4.2 : a) emissão dos eletrons do semicondutor para o metal sobre a barreira, b) tunelamento através da barreira, c) recombinação no espaço de carga, d) recombinação na região neutra. Geralmente o processo a é o dominante, porém antes que o elétron seja emitido sobre a barreira, ele deve ser transportado do interior do semicondutor para as proximidades da barreira. Neste transporte, existem basicamente dois mecanismos em série que, combinados, devem determinar o fluxo de elétrons do semicondutor para o metal : a difusão através da região de depleção e a taxa de transporte através do contorno separando o metal e o semicondutor. Portanto o fluxo de elétrons é determinado pelo mecanismo limitante ao transporte. Existem duas teorias que se posicionam diferentemente com relação a esses mecanismos : a teoria da difusão que diz que esse é o mecanismo limitante e a teoria da emissão termoiônica que opta pela injeção de elétrons na separação metal-semicondutor como o mecanismo determinante do transporte ${ }^{76}$. O comportamento do nível de quasiFermi (energia hipotética que é introduzida parz. descrever o comportamento dos 


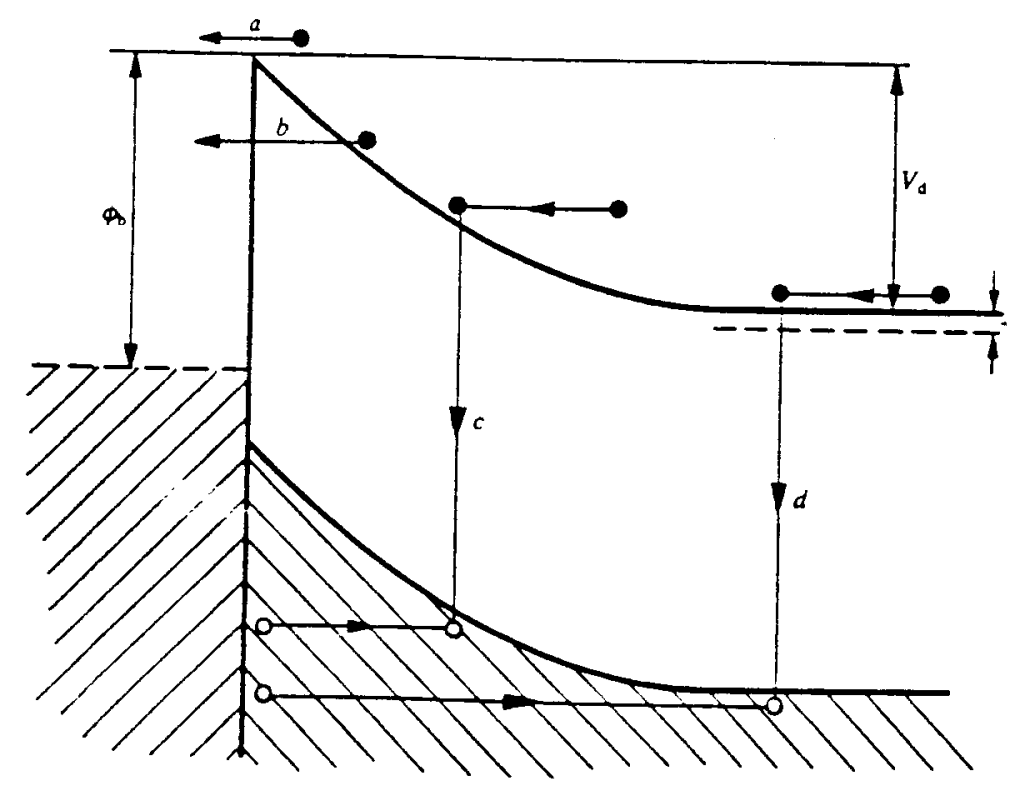

Figara 4.2 - Processos de transporte numa barreira Schottky com polarização direta is

elétrons sob condições de não equilß́brio) é o fator de diferenciação entre as duas teorias. A teoria da emissão termoiônica estabelece que quando os elétrons são emitidos do semicondutor para o metal eles têm sua energia acrescida de $\phi_{b}$ e portanto, seu valor excede o valor da energia de Fermi do metal e podem ser chamados de modo vago como elétrons quentes (o nome elétrons quentes vem do problema de transporte em semicondutores em campos elétricos altos e é associado com uma energia média eletrônica maior que o valor de equilibrio térmico da rede ${ }^{79}$ ), podendo ser descritos por seu próprio nível de quasi-Fermi ${ }^{80}$. Conforme eles penetram no metal, perdem energia devido à colisão com a rede e com os elétrons de condução, e o seu nível de quasi-Fermi cai até atingir o nível de Fermi no metal.

Por outro lado, pela teoria da difusão, a concentração dos elétrons livres no semicondutor imediatamente após a interface não é alterada pela aplicação do campo elétrico. Neste caso o nível de quasi-Fermi cai suavemente através da região de depleção e coincide com o nível de Fermi no metal. Na realidade, o transporte de elétrons numa junção metal-semicondutor deve seguir uma teoria intermediária entre esses dois extremos.

Tunelamento através da barreira pode ocorrer de dois modos diferentes. No 
caso de semicondutores degenerados altamente dopados, pode ocorrer o tunelamento de elétrons com energia próxima ao nível de Fermi (em semicondutores altamente dopados, o nível de Fermi fica acima da banda de condução), o que é conhecido como emissão de campo. Quando a temperatura aumenta, elétrons são excitados a energias mais altas e o tunelamento aumenta porque os elétrons têm que transpor barreiras cada vez mais finas e mais baixas. Isso é conhecido como emissão carapotermoiônica. Se a temperatura é aumentada ainda mais, chegará um ponto em que todos os eletrons possuem energia suficiente para ir sobre a barreira e a condução passa a ser puramente termoiônica, e o tunelamento desprezível.

Recombinação no espaço de carga se dá via estados localizados, principalmente aqueles cujo nível de energia é próximo do centro do "band gap". A componente do transporte devido a recombinação é relativamente mais importante em situações onde existem : barreiras altas, materiais aonde o tempo de vida do portador é pequeno na região de depleção, temperaturas baixas e baixa polarização direta aplicada. Nesses casos a corrente de recombinação pode causar pequenos desvios do comportamento ideal, principalmente a baixas temperaturas.

Injeção de buracos ocorre quando a barreira Schottky é maior que metade do gap de energia do semicondutor. Nesse caso uma densidade alta de buracos é formada no semicondutor na região imediatamente próxima ao metal. Quando a junção está sob polarização, esses buracos podem difundir para a região neutra, gerando recombinação (figura 4.2(d)). Injeção de buracos é muito mais significativa em materiais com pequeno gap de energia, sendo portanto, mais relevante em Ge do que Si ou GaAs.

A figura 4.3 mostra um comportamento típico de curva corrente-tensão para uma barreira Schottky.

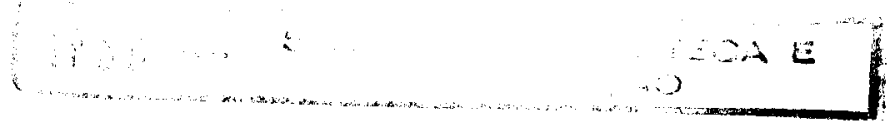




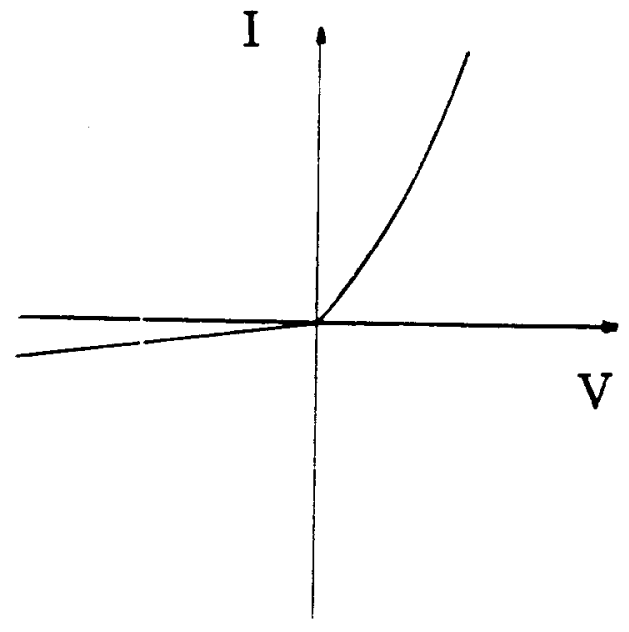

Figara 4.3 - Comportamento típico corrente-tensão de uma barreira Schottky ${ }^{81}$

\subsection{CONTATO ÔHMICO EM $\mathrm{Al}_{x} \mathrm{Ga}_{1-x} \mathrm{As}$}

Em um contato ôhmico não é essencial (porém desejável) que as características de corrente voltagem sejam lineares, mas é necessário que a resiatência de contato seja despresivel se comparada com a resistência da amostra. Existem basicamente dois modos de se fazer contatos ôhmicos em um semicondutor : diminuir a altura da barreira entre metal e semicondutor ou criar uma região altamente dopada imediatamente próxima da interface ${ }^{76}$. Pode-se diminuir a altura da barreira encontrando-se um metal cuja função de trabalho é da meama ordem ou menor que a função de trabalho do semicondutor em questão. Na prática encontrar tal material não é uma tarefa tão fácil. Em se criando uma região altamente dopada, os eletrons podem tunelar através da barreira em ambas as direções, uma vez que o nível de Fermi no semicondutor com alta dopagem está acima da banda de condução e a barreira é bem mais fina .

A liga $\mathrm{Au} / \mathrm{Ge} / \mathrm{Ni}$ tem sido amplamente usada como um contato ôhmico para GaAs e $\mathrm{Al}_{x} \mathrm{Ga}_{1-x} \mathrm{As}$ do tipo n. Apesar de existirem muitas receitas para se obter sucesso nesse problema ${ }^{82-84}$, a física dos contatos ôhmicos ainda precisa ser melhor compreendida. Além disso, o comportamento desse sistema à temperatura ambi- 
ente não assegura que ele permanecerá assim a temperaturas baixas. Conforme a temperatura é diminuida, a linha reta da curva corrente voltagem muitas vezes se desvia para um comportamento não linear. Para explicar a formação do contato ôhmico em GaAs é geralmente aceito que uma fina camada $\mathrm{n}^{+}$se forma próxima da interface ${ }^{85,86}$. Esta camada $\mathrm{n}^{+}$vem da difusão de Ge, desde que Ge ocupando um sítio de Ga em GaAs é um doador. Acredita-se que para melhorar a difusão de $\mathrm{Ge}$, a metalização deveria ser feita com ○ Au-Ge na composição eutética, de forma que a difusão no estado líquido seja possível quando se aquece acima da temperatura do eutético ${ }^{83}$.

Kim e Chung ${ }^{83}$ e Kim et al ${ }^{87,88}$ fizeram muitas investigações sobre a metalurgia do sistema $\mathrm{Au} / \mathrm{Ge} / \mathrm{Ni}$ evaporado sobre GaAs. Foi encontrado que após o tratarnento térmico, os principais compostos presentes no sistema são ligas Au-Ga tais como $\mathrm{Au}_{7} \mathrm{Ga}_{2}, \mathrm{Au}_{3} \mathrm{Ga}, \mathrm{Au}_{2} \mathrm{Ga}$ e a fase ternária $\mathrm{Au}-\mathrm{Ge}-\mathrm{As}$, entre pequenas quantidades de compostos de $\mathrm{Ni}$. De acordo com a análise desses autores, existem duas possibilidades para a formação do contato ôhmico : tanto pode ser criado algum tipo de composto que acumula o Ge (na interface $\mathrm{NiAs} / \mathrm{GaAs}$ por exemplo ${ }^{88}$ ) criando uma camada $\mathrm{n}^{+}$de germânio, ou pode ocorrer uma troca na interface entre ligas AuGa para NiAs, o que diminuiria a altura da barreira.

Microscopia eletrônica de contatos de AuGeNi após tratamento térmico foi usado por Kuan et al ${ }^{88}$ para concluir que a presença do composto $\mathrm{Ni}_{2} \mathrm{GaAs}$ melhora a difusão de Ge para dentro do semicondutor. Waldrop e Grant ${ }^{20}$ sugerem uma alternativa à explicação dos resultados de $\mathrm{Kuan}$ et $\mathrm{al}: \mathrm{Ni}_{2} \mathrm{GaAs}$ poderia ser separado de GaAs por uma camada bastante fina (ainda não observada) de Ge interfacial o que seria associado com uma barreira pequena $(\leq 0.25-0.4 \mathrm{eV})$. A presença de NiAs e $\mathrm{Ni}_{2} \mathrm{GaAs}$ foi confirmado por Ball ${ }^{81}$ através de resultados de calorimetria e raioo-X.

As hipóteses acima descritas mostram que a compreensão do que realmente acontece está longe de ser alcançada. Na próxima secção serão discutidos os resultados obtidos nas características das curvas tensão-corrente sob a luz das propostas aqui descritas. 
4.2.1. Características Corrente-Voltagem da Liga $\mathrm{Au} / \mathrm{Ge} / \mathrm{Ni}$ como um Contato Elétrico em $\mathrm{Al}_{x} \mathrm{Ga}_{1-x} \mathrm{As}$

As amostras estudadas são descritas no capítulo II. As curvas correntevoltagem são medidas em um Analisador de Parâmetros de Semicondutores da Hewlett Packard e a temperatura é controlada no mesmo sistema do experimento de TDPPC, no caso da curva corrente-tensão ser medida em função da temperatura ou simplesmente imersa em nitrogênio líquido, quando for o caso. Nas amostras testadas apenas com imersão em nitrogênio líquido, a evaporação do contato é feita através de uma máscara de sombra.

Um procedimento comum para o recozimento do contato $\mathrm{Au} / \mathrm{Ge} / \mathrm{Ni}$ em $\mathrm{GaAs}$ é manter o sistema em um forno por 4-5 minutos em uma atmosfera de gás inerte sob uma temperatura superior a $350 \mathrm{C}$. Esse procedimento foi seguido para uma amostra de $\mathrm{Al}_{0.9} \mathrm{Ga}_{0.7} \mathrm{As}$ a uma temperatura de $350 \mathrm{C}$ e os resultados otidos são mostrados na figura 4.4. Deve-se ressaltar que o experimento é realizado com as luzes comuns do laboratório ligadas. A curva perfeitamente linear da relação tensão (V) - corrente (I) a temperaturas não muito baixas dá lugar a um desvio da linearidade quando a temperatura é diminuida para valores menores que $100 \mathrm{~K}$. Com o forno a $420 \mathrm{~K}$ repete-se o procedimento para uma outra amostra de mesma composição de alumínio $e$ isso é mostrado na figura 4.5. A linha é perfeitamente reta em todo o intervalo de temperatura. A temperaturas abaixo de aproximadamente $100 \mathrm{~K}$ a resistência torna-se menor que a temperatura ambiente. Tanto a amostra da figur a 4.4 como a da figura 4.5 são processadas a partir de um pedaço de material obtido no mesmo crescimento por MBE. $O$ fato de que a resistência é maior à temperatura ambiente para a amostra da figura 4.4 comparada com a amostra da figura 4.5 não deve ser tomada necessariamente como evidência da má qualidade do contato, pois na amostra da figura 4.5 a distância entre os contatos é ligeiramente menor. Como pode ser visto na curva $4.5(\mathrm{~d})$, a $60 \mathrm{~K}$, a resistência é muito menor que à temperatura ambiente.

A tentativa do mesmo procedimento para uma amostra de $\mathrm{Al}_{0.5} \mathrm{Ga}_{0.5} \mathrm{As}$ não 


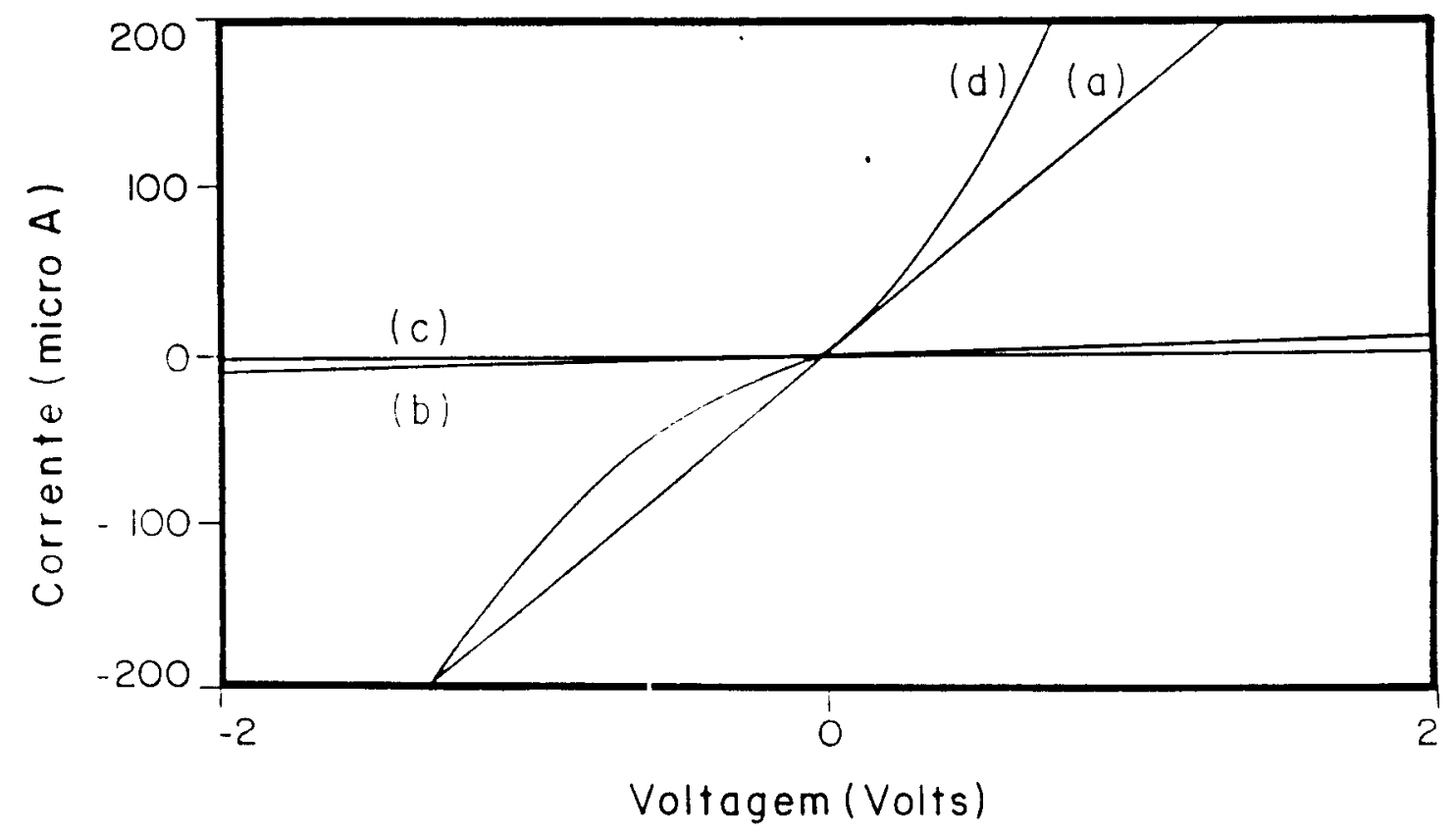

Figura 4.4 - Curvas I-V para uma amostra de $\mathrm{Al}_{0.8} \mathrm{Ga}_{0.7} \mathrm{As}$. Dopagem $=1 \times 10^{18} \mathrm{~cm}^{-3}$. Temperatura de recozimento $=350 \mathrm{C}$. (a) - temperatura ambiente, (b) $-200 \mathrm{~K}$, (c) $-100 \mathrm{~K}$, (d) $60 \mathrm{~K}$ 


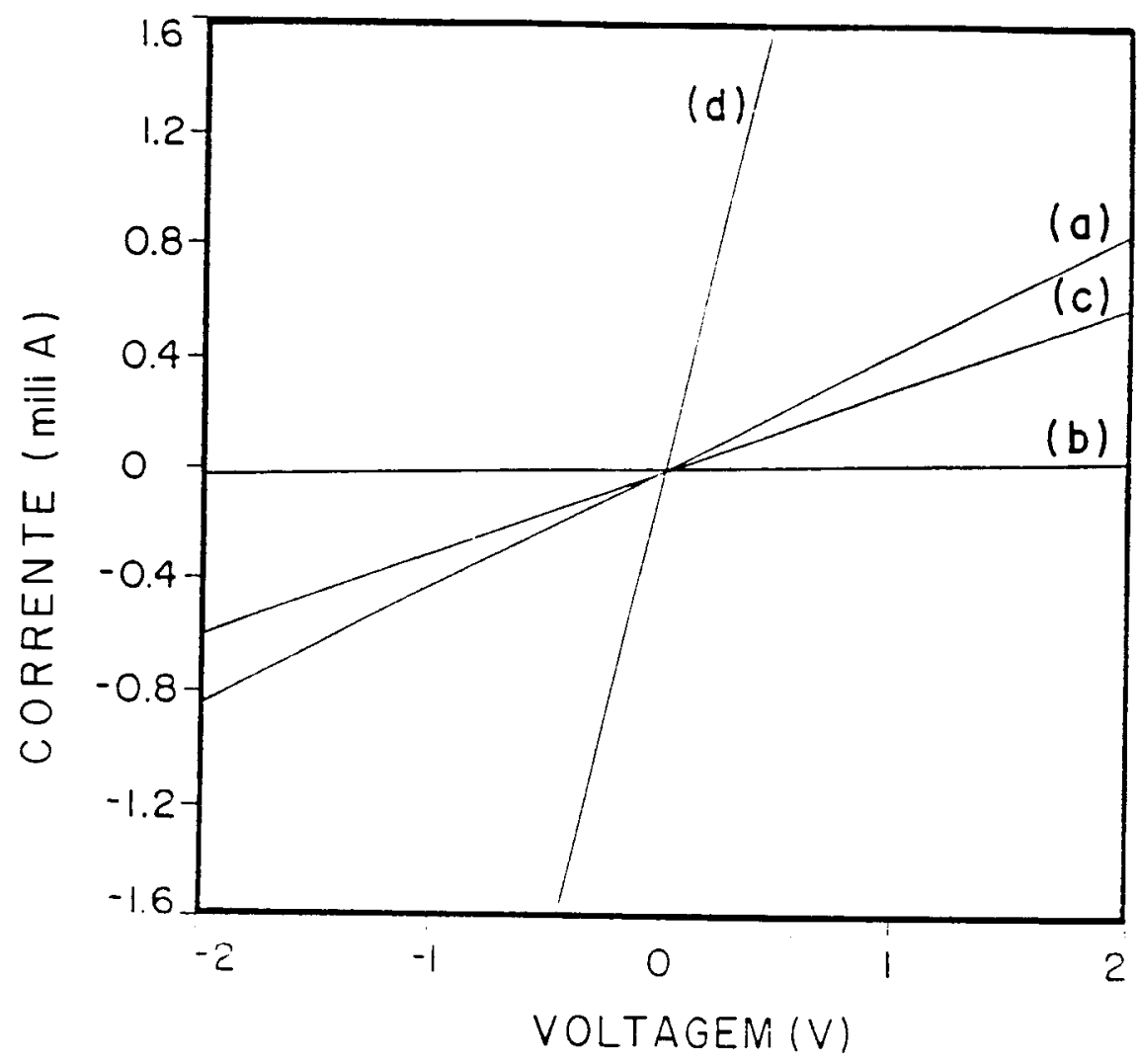

Figura 4.5 - Curvas I-V para $\mathrm{Al}_{0.3} \mathrm{Ga}_{0.7}$ As. Dopagem de $\mathrm{Si}=1 \times 10^{18} \mathrm{~cm}^{-3}$. Temperatura de recozimento $=420 \mathrm{C}$. (a) - temperatura ambiente, $(\mathrm{b})-200 \mathrm{~K},(\mathrm{c})-100 \mathrm{~K},(\mathrm{~d})-60 \mathrm{~K}$

forneceu bons resultados, conforme é mostrado na figura 4.6. Conforme a temperatura é abaixada, a linha torna-se não linear, num comportamento similar a observado na figura 4.4.

Shih e Blum ${ }^{84}$ obtiveram uma resistência mínima de contato para tratamentos térmicos no intevalo 480-540 C. Embora seus experimentos de medida de resistência sejam todos realizados à temperatura ambiente, seu trabalho sugere que seria válida a tentativa de temperaturas de recozimento naquele intervalo para amostras de AlGaAs com composições de alumínio superiores a 0.3 . A figura 4.7 mostra a evolução da curva I-V para uma amostra de $\mathrm{Al}_{0.5} \mathrm{Ga}_{0.5} \mathrm{As}$ após recozimentos sucessivos a 480 C. Esta temperatura foi escolhida porque é dentro do intervalo sugerido por Shih e Blum e não é tão alta de forma que danificasse a superfície da amostra. A amostra é tratada termicamente por tempos sucessivos de 2 minutos até um total de 


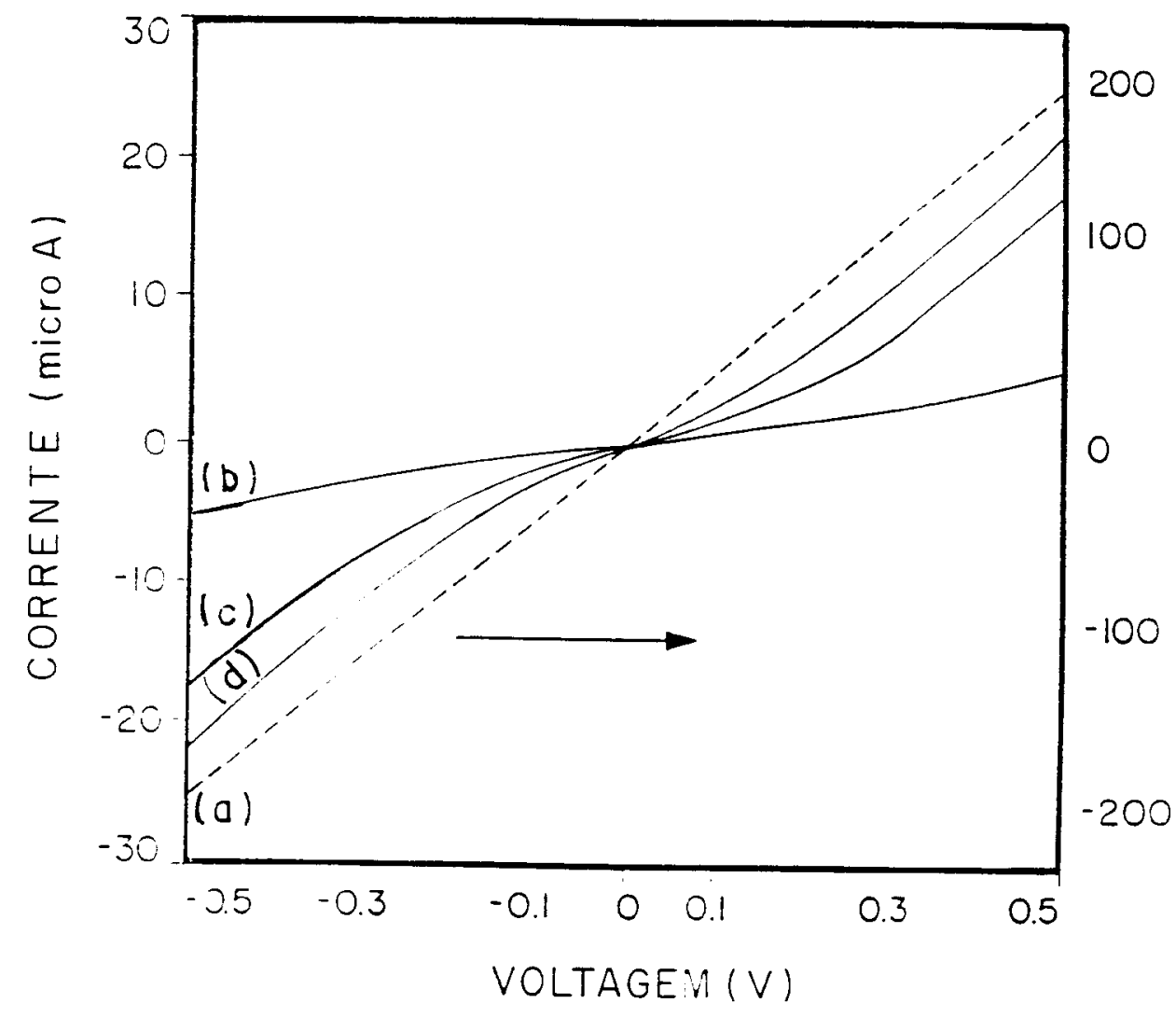

Figara 4.6 - Carvas I-V para $\mathrm{Al}_{0.8} \mathrm{Ga}_{0.5} \mathrm{As}$. Dopagem de $\mathrm{Si}=5 \times 10^{17} \mathrm{~cm}^{-3}$. Temperatura de recozimento $=420 \mathrm{C}(\mathrm{a})$ - temperatura ambiente, $(\mathrm{b})-110 \mathrm{~K},(\mathrm{c})-90 \mathrm{~K},(\mathrm{c})-80 \mathrm{~K}$. A escala do lado direito se refere a curva a, de linhas tracejadas

de 8 minutos e então por tempos de 4 minutos até um total de 20 minutos. As curvas I-V a temperatura ambiente permanecem praticamente idênticas (não mostrado na figura) e na temperatura de nitrogênio líquido elas têm uma melhoria bem razóvel, apesar de não se tornar totalmente linear.

A figura 4.8 é um gráfico da curva $\mathrm{I}-\mathrm{V}$ para uma amostra de $\mathrm{Al}_{0.4} \mathrm{Ga}_{0.6} \mathrm{As}$ a temperatura de nitrogênio líquido após recozimentos sucessivos. A amostra foi tratada inicialmente por 5 minutos a $480 \mathrm{C}$ e como seria de se esperar, o comportamento é perfeitamente ôhmico à temperatura de nitrogênio líquido (e obviamente também à temperatura ambiente, apesar de não mostrado). Após esse tratamento térmico inicial, a amostra foi tratada por períodos de 2.5 minutos até um total de 15 minutos e então por mais 5 minutos. Na temperatura ambieate a curva I-V permanece prati- 


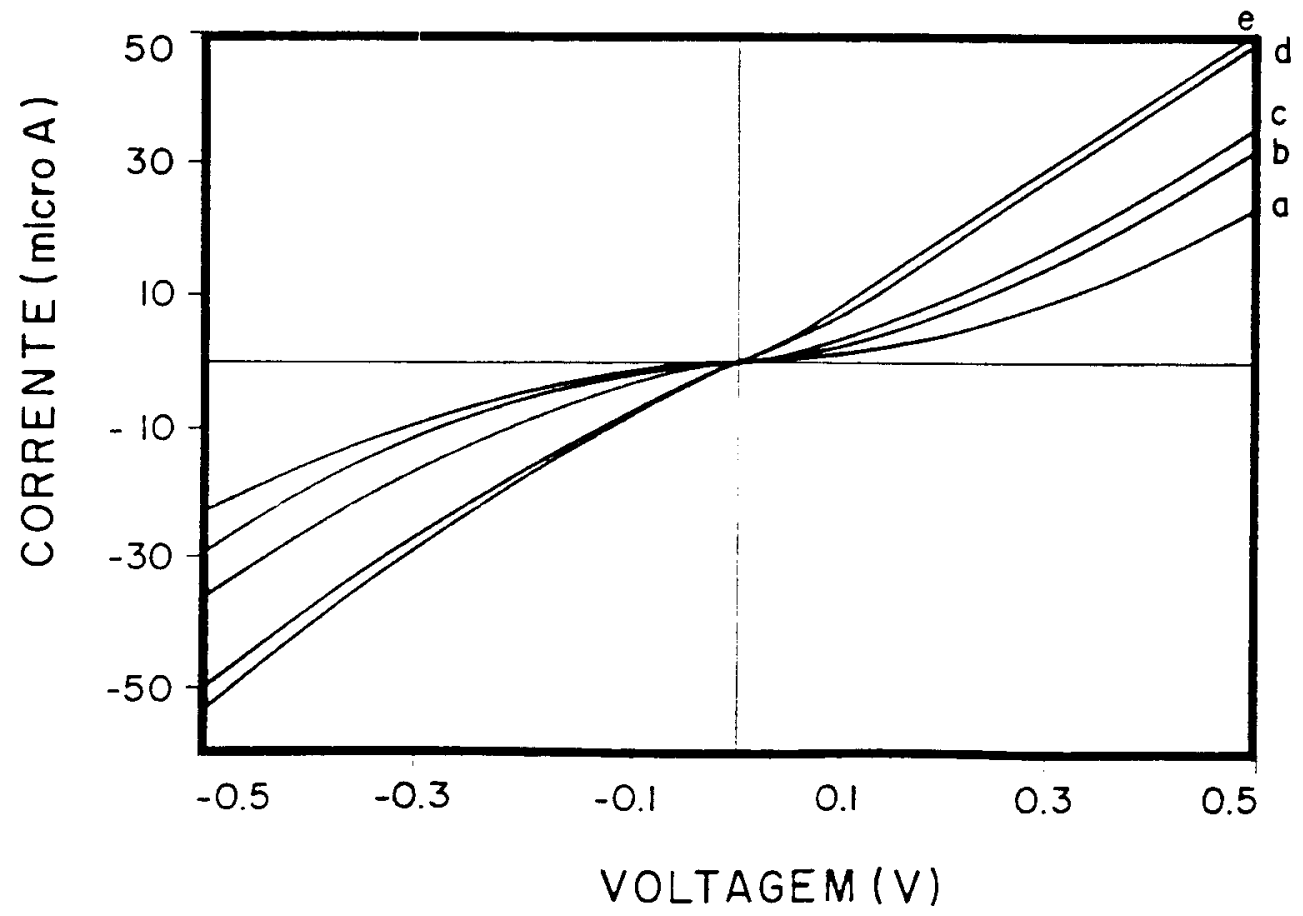

Figura 4.7 - Curvas I-V para $\mathrm{Al}_{0.8} \mathrm{Ga}$..5As. Dopagem de $\mathrm{Si}=5 \times 10^{17} \mathrm{~cm}^{-3}$. Recozimentos sucessivos a $480 \mathrm{~K}:$ (a) - $2 \operatorname{minutos,~(b)~-~} 4$ minutos, (c) -8 minutos, (d) -12 minutos, (e) - 20 minutos 


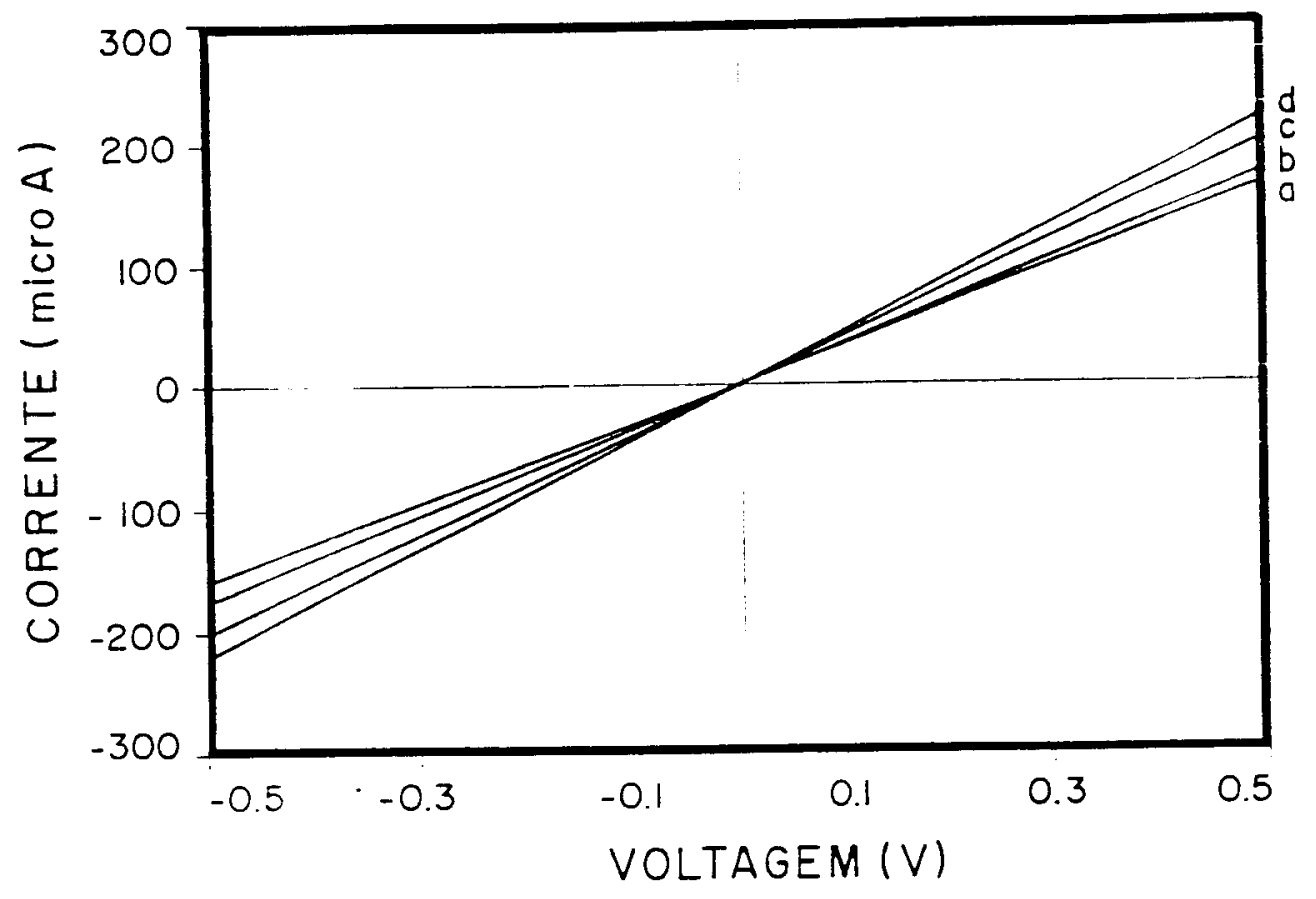

Figara 4.8 - Curvas I-V de Alo.4Ga.. As a $77 \mathrm{~K}$ para recozimentos sucessivos a $480 \mathrm{C}$. Dopagem de $\mathrm{Si}=1 \times 10^{18} \mathrm{~cm}^{-3}$. (a) $-5 \operatorname{minntos},(\mathrm{b})-10 \operatorname{minutos},(\mathrm{c})-15 \operatorname{minntos}$, (d) -20 minutos

camente constante e existe alguma melhoria à temperatura de nitrogênio líquido conforme o tempo de recozimento vai aumentando.

Os resultados obtidos nas figuras 4.7 e 4.8 informam que o procedimento comumente usado pela maioria das receitas tem o efeito único de não deteriorar a superfície da amostra e a qualidade morfológica do contato, desde que quanto mais longo o tempo de recozimento, melhor a curva I-V (menores resistências de contato). Isto está em boa concordância com aquilo que foi obtido por Kavanagh ${ }^{82}$, já que seus dados para difusão de Ge em GaAs mostram que mesmo a temperaturas tão altas como $800 \mathrm{C}$, os átomos de Ge atingem apenas uma distância de $4.5 \times 10^{-7} \mathrm{~m} \mathrm{da}$ superfície após um tratamento térmico de 30 minutos. Portanto, com uma taxa de difusão tão baixa, seria necessário um tempo muito grande para que o Ge advindo da liga $\mathrm{Au} / \mathrm{Ge} / \mathrm{Ni}$ fosse perdido pela difusão para dentro do material. 


\subsubsection{Discussão dos Resultados Obtidos a Baixa Temperatura}

De acordo com o modelo de Chadi e Chang ${ }^{18,23}$ qualquer dopante do grupo IV em AlGaAs se tornaria um centro DX, capturando 2 eletrons e relaxando a rede através de uma distorção cuja posição final teria interação com U-negativo. Isso foi confirmado por Fujisawa et al ${ }^{38,93}$, através da aplicação de pressão hidrostática em GaAs codopado com Ge e Si. Nas amostras estudadas seria de se esperar que $\mathrm{Ge}$ e Si competiriam pela captura de elétrons e o contato se tornaria fortemente não ôhmico a baixas temperaturas, desde que na ausência de luz e temperaturas baixas, os níveis profundos estão cheios de elétrons ao passo que a banda de condução está praticamente vazia. Porém, os experimentos foram realizados sob as luzes da sala. Embora a energia de fotoionização do centro DX tenha uma dependência pequena na composição da liga ${ }^{55}$, as luzes da sala são suficientemente intensas para excitar os elétrons dos centros $\mathrm{DX}$ de $\mathrm{Ge}$ e $\mathrm{Si}$ em composições $\mathrm{x}=0.3$ e 0.4 , mas não em $\mathrm{Al}_{0.5} \mathrm{Ga}_{0.5} \mathrm{As}$ aonde os centros $\mathrm{DX}$ são bastante profundos e somente uns poucos elétrons são excitados para a banda de condução. É necessário uma alta intensidade para liberar mais elétrons. Isso é confirmado na figura 4.9, onde a mesma amostra da figura 4.6 é iluminada com uma luz intensa de tungstênio e a linha I-V torna-se perfeitamente linear. Quando a luz é retirada, a resistência torna-se maior lentamente (fotocondutividade persistente) e os contatos permanecem ôhmicos 20 segundos após a remoção da luz (curva b). Este decaimento é um tanto rápido devido a nessa composição o centro DX possuir barreira de captura mais baixa que a composições em torno de $30 \%$ (capítulo III e apêndice A).

$\mathrm{Na}$ luz desses resultados, a hipótese da difusão de Ge parece razoável, mas não é possível desprezar a possibilidade do abaixamento da barreira. Pode-se imaginar a amostra como uma série de resistências contato/amostra/contato e toda a discussão acima a respeito do papel desempenhado pelos centros DX continuaria sendo válida, desde que grande quantidade de centros DX advém da própria amostra de AlGaAs. Os resultados de Ball ${ }^{81}$ mostram que as reações do estado sólido para formar $\mathrm{NiAs}$ e $\mathrm{Ni}_{2} \mathrm{GeAs}$ acontecem em torno de $220 \mathrm{C}$. Nas temperaturas normalmente empre- 


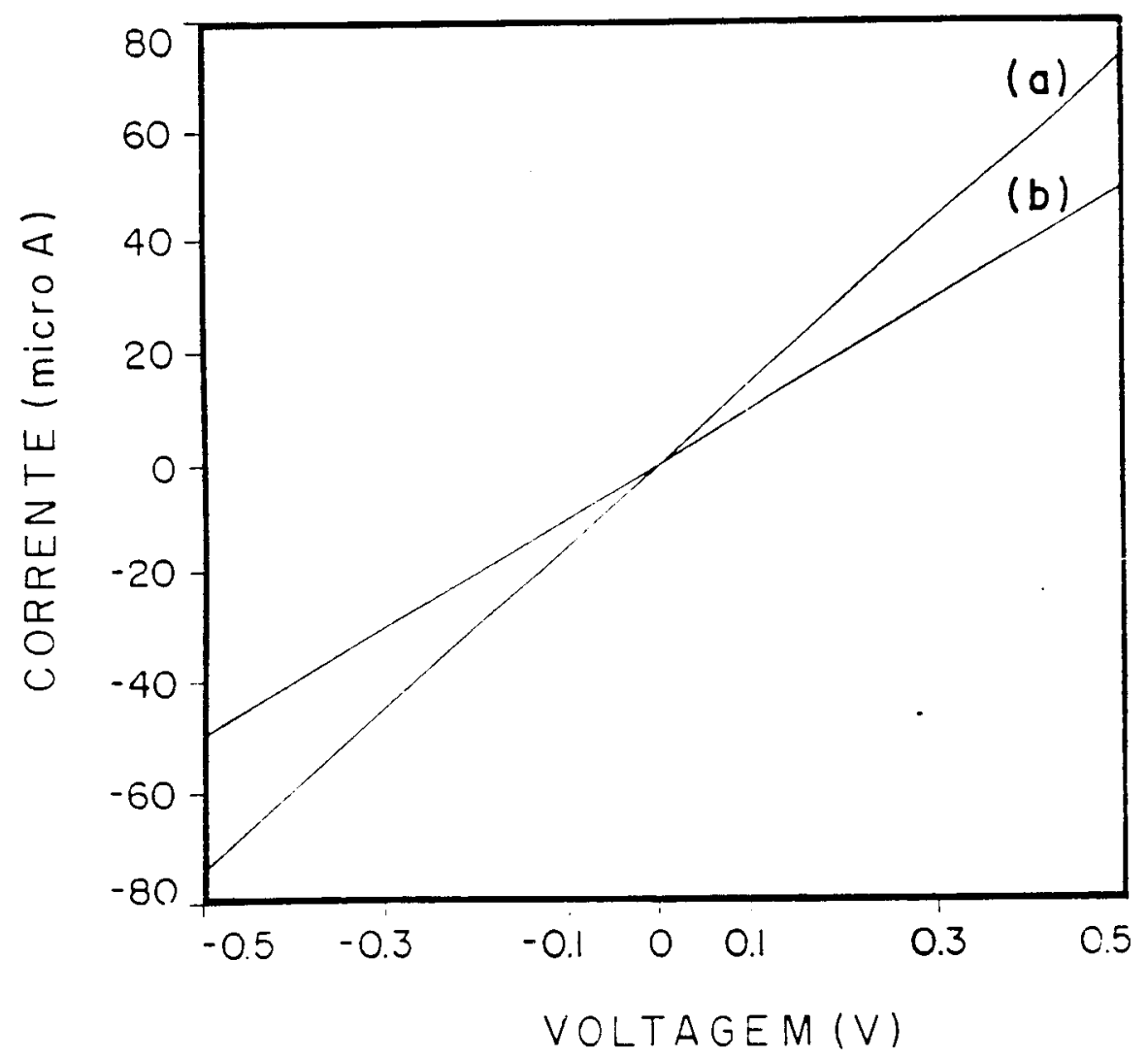

Figura 4.9 - Curvas I-V para $\mathrm{Al}_{0.8} \mathrm{Ga}_{0.8}$ As a $75 \mathrm{~K}$. (a) sob iluminação com luz intense, (b) - 20 segundos após a retirada da iluminação 
gadas para o tratamento térmico $(420-500 \mathrm{C})$ ocorre a fusão do contato resultando numa resistência de contato menor, mas também numa topografia ruim e então, o tempo de recozimento deveria ser curto. Em nosso caso, após cada recozimento, a qualidade do contato deveria deteriorar, uma vez que a temperatura é muito alta e o tempo razoavelmente longo. As reações no estado sólido deveriam ter acontecido no primeiro recozimento, mas pode-se argumentar que a liga poderia não ter tido tempo suficiente para atingir homogeinidade e então isso deve acontecer nos tratamentos subsequentes. No entanto, parece contraditório que a curva I-V vai se tornando cada vez mais linear se a topografia está se tornando cada vez pior. Um outro aspecto favorável à hipótese da difusão de Ge é a existência dos transistores de efeito de campo com dopagem $\delta^{7}$. A presença de uma dopagem residual do tipo p sugere que o único modo pelo qual o canal bidimensional de eletrons seria alcançado, é pela criação da camada altamente dopada imediatamente adjacente à interface metal-semicondutor, a qual se extenderia até o ponto de localização da dopagem $\delta$ 94,95.

Baseado nesses argumentos, vamos assumir que o transporte se dê pela formação de uma camada altamente dopada próxima da interface, de forma que os elétrons podem tunelar através da barreira Schottky. A figura 4.10 mostra um diagrama de bandas qualitativo com base na discussão apresentada, onde estão representados o comportamento a temperatura ambiente e a temperaturas baixas, ou seja, a medida que a temperatura vai diminuindo os elétrons vão sendo capturados pelos centros DX e o contato torna-se não ôhmico. A presença de luz da sala a baixa temperatura libera os elétrons para a banda de condução, de forma que o diagrama da figura 4.10(a) pode ser aproximado novamente. Quando o dispositivo é polarizado como um todo observa-se o que também é qualitativamente mostrado na figura 4.11. O nível de Fermi (quasi-Fermi - já que se trata de uma situação de não equilíbrio) no semicondutor é traçado apenas ligando os dois metais, o que nã deve ser tomado como a sua verdadeira forma no semicondutor. A verdadeira forma é complexa e deve ser obtida levando em consideração os mecanismos de transporte discutidos na secção 4.1 .1 e também a resistência relativa entre as camadas com diferentes dopagens. De qualquer forma, independente do traçado do nível de quasi 


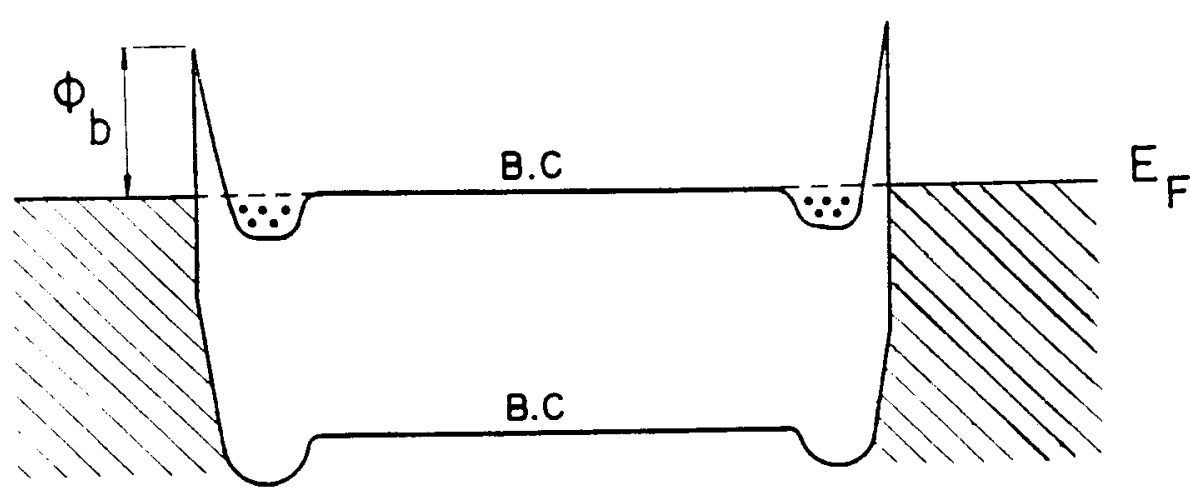

a)

$\mathrm{Au} / \mathrm{Ge} / \mathrm{Ni} \quad \mathrm{Al}_{\mathrm{x}} \mathrm{Ga}_{1-\mathrm{x}} \mathrm{As} \quad \mathrm{Au} / \mathrm{Ge} / \mathrm{Ni}$

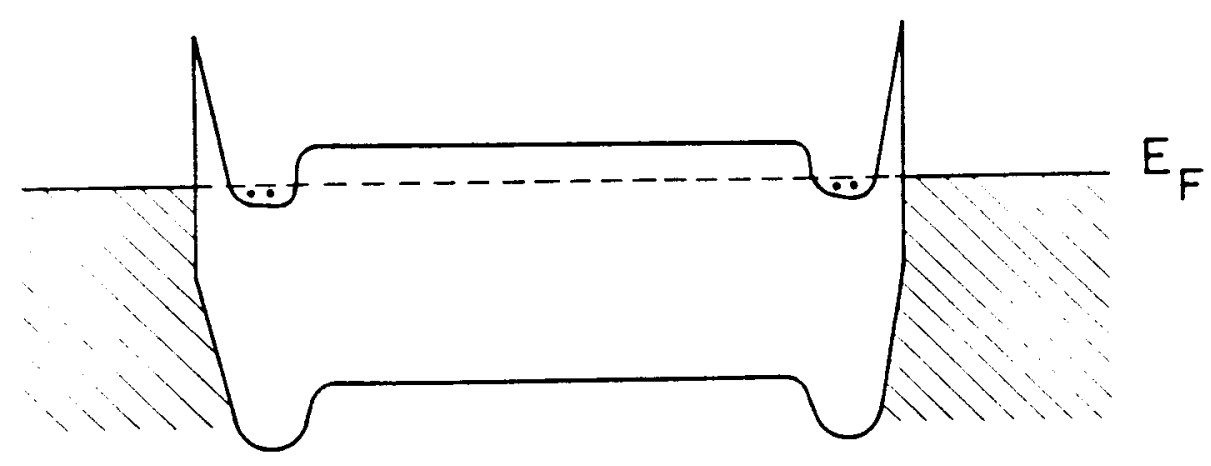

b)

Figara 4.10 - Diagrama de bandas qualitativo das amostras estudadas sem a aplicação de potencial. (a) - temperatura ambiente, (b) -temperatura de nitrogênio ĺ́quido

Fermi no semicondutor, o objetivo aqui é entender o como se dá o desvio da linearidade das amostras a baixa temperatura o que é uma função do transporte através ou sobre as barreiras de potencial. No caso do contato perfeitamente ôhmico, a barreira Schottky é transparente para o elétron e os processos dominantes são a emissão de campo e a emissão de campo- termoiônica ${ }^{26}$, ou seja o transporte não é afetado pela barreira em qualquer das direções, de forma que a curva I-V resulta linear. No caso de uma barreira Schottky ideal, a curva I-V é como mostrado na figura 4.3, aonde o transporte de elétrons se dá apenas do semicondutor para o metal praticamente. Se considerarmos o diagrama da figura 4.11 e assumirmos que a baixa temperatura as barreiras são ideais, ocorreria retificação em ambas as direções, já que o dispositivo é simétrico. 


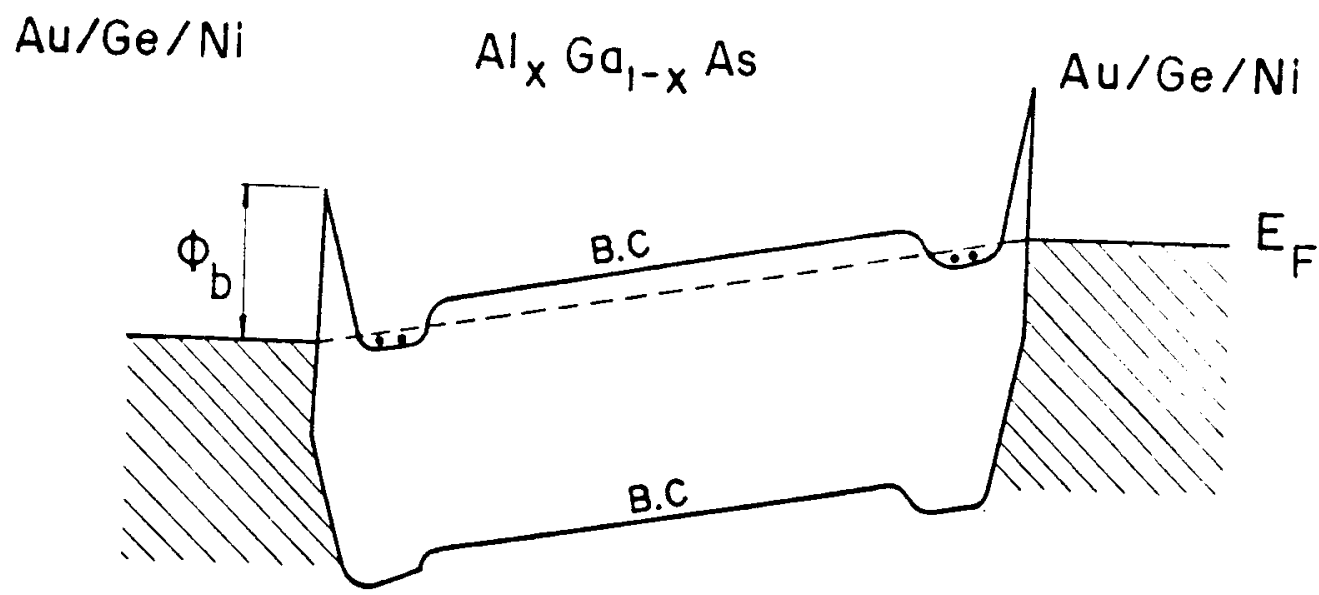

Figara 4.11 - Diagrama de bandas qualitativo com aplicação de uma diferença de potencial

A medida que o potencial é aplicado entre os dois metais, a polarização será direta para uma das barreiras e reversa para a outra, de modo que a barreira que fica sob polarização reversa domina o transporte e não permite a passagem dos elétrons através do dispositivo ( praticamente falando, já que na realidade sempre haverá um pequena corrente líquida sob polarização reversa. Devido à distribuição estatística de energia dos elétrons sempre haverá uma pequena fração em condições de transpor a barreira).

Quando o tunelamento domina o contato metal-semicondutor deve-se lançar mão do fator de idealidade do diodo para descrever o comportamento da barreira, o qual é definido como ${ }^{97}$ :

$$
f_{I}=\frac{e}{k_{B} T}\left(\frac{d v}{d \ln J}\right)
$$

A corrente fluindo através do diodo é dada por ${ }^{86}$ :

$$
I=I_{S}\left\{\exp \left[\frac{e V}{f_{I} k_{B} T}\right]-\exp \left[\left(\frac{1}{f_{I}}-1\right) \frac{e V}{f_{I} k_{B} T}\right]\right\}
$$

onde $\mathrm{I}_{S}$ é uma constante de proporcionalidade. O primeiro termo é devido a corrente na direção direta e o segundo é devido ao tunelamento na direção reversa. A 


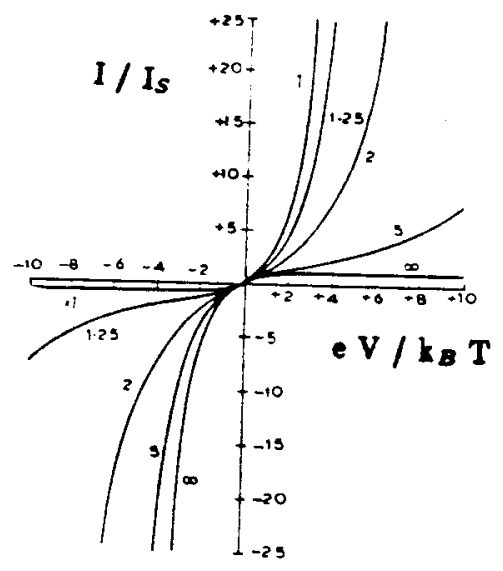

Figara 4.12 - Características corrente-voltagem normalizadas calculadas pela equação $4.4{ }^{97}$

medida que o fator de idealidade foge do valor unitário, o diodo vai revertendo suas características corrente-voltagem conforme é mostrado na figura 4.12 para valores crescentes de $f_{I}$.

Uma comparação entre as figuras 4.12 e 4.7 mostra que a razão desse comportamento pode ser agora compreendida. A captura dos elétrons pelos centros DX transforma o contato ôhmico em uma barreira Schottky. Porém dada à possibilidade da presença de luz essa barreira é ruim e o fator de idealidade deve fugir do valor unitário. $O$ empecilho ao transporte é a barreira que fica sob polarização reversa, que nesse caso não deve possuir o comportamento idealmente retificador. A simetria do nosso dispositivo faz com que a curva I-V seja simétrica, ainda que separadamente eles não necessariamente o sejam, em outras palavras o que está graficado nos quadrantes opostos da figura 4.7 (ou 4.6) é a característica reversa de cada um dos contatos. 


\section{CAPÍTULO V}

\section{OUTROS RESULTADOS ENVOLVENDO CENTROS DX}

\subsection{EXISTÊNCIA DE CENTROS DX EM $\mathrm{Al}_{x} \mathrm{Ga}_{1-x} \mathrm{As}$ DOPADO COM Pb}

Muitos trabalhos experimentais usando dopantes do grupo IV como Si, Sn e Ge têm sido realizados nos últimos anos e a existência de centros DX tem invariavelmente acontecido 5,10,39,98. Segundo Chadi e Chang a presença do centro DX é uma consequência inevitável da clopagem com dopantes substitucionais do grupo IV, pois conforme discutido no capítulo I, o centro DX é um estado do próprio átomo doador, que relaxa para uma posição intersticial através da quebra de uma das ligações com As. Apesar dessa afirmaçãs, a confirmação experimental da existência de centros DX em AlGaAs dopado corn $\mathrm{Pb}$, que seria outro elemento do grupo IV, ainda não havia sido mostrada.

Experimentos realizados em São Carlos com uma amostra de $\mathrm{Al}_{0.24} \mathrm{Ga}_{0.78} \mathrm{As}$ dopada com $\mathrm{Pb}$, crescida por epitaxia em fase de vapor metalorgânico (MOVPE) sugeriu que essa amostra poderia ter a presença de DX. OB detalhes de crescimento dessa amostra foram descritos em outro lugar ${ }^{99}$ e não serão aqui repetidos uma vez 
que não contou com minha participação (A amostra foi crescida nos laboratórios do CNRS - Valbonne - França). Passou-se então a uma análise cuidadosa para se investigar a presença de centros DX.

A estrutura da amostra é como segue : o substrato é GaAs semi-isolante e apresenta uma camada não dopada de $0.5 \mu \mathrm{m}$ de $\mathrm{Al}_{0.5} \mathrm{Ga}_{0.5} \mathrm{As}$ e uma camada ativa de $4.8 \mu \mathrm{m}$ de $\mathrm{Al}_{0.24} \mathrm{Ga}_{0.76}$ As dopada com $2.8 \times 10^{18} \mathrm{~cm}^{-3}$ de $\mathrm{Pb}$. Os contatos são do sistema usual $\mathrm{Au} / \mathrm{Ge} / \mathrm{Ni}$ e a ligação com fios é feita através de tinta prata convencional.

A figura 5.1 mostra o espectro de fotocondutividade a $77 \mathrm{~K}$ para essa amostra. Nesse espectro a flecha a $672 \mathrm{~nm}$ corresponde ao gap de energia de $\mathrm{Al}_{0.24} \mathrm{Ga}_{0.78}$ As. Existe um aumento abrupto na intensidade começando a aproximadamente $830 \mathrm{~nm}$ e continuando para um pico em torno de $950 \mathrm{~nm}$. Esta energia (aproximadamente $1.45 \mathrm{eV}$ - começo do aumento abrupto), abaixo da transição banda-banda, é devido a excitação de um nível profundo e está em boa concordância com o que tem sido publicado para a energia de fotoionização do centro DX em AlGaAs ${ }^{21,22}$. $\mathrm{O}$ alargamento pode ser causado pelo transiente de tempo para a fotoexcitação e pela seç̧ão transversal de captura termicamente ativada que impediria uma queda abrupta na intensidade devido ao fenômeno de PPC. Fotocondutividade persistente é confirmada pelo decaimento da fotoexcitação a $77 \mathrm{~K}$, o qual é mostrado no detalhe na figura 5.1. A amostra é esfriada no escuro e então iluminada com luz monocromática de $1.37 \mathrm{eV}$, abaixo portanto do gap de energia. A fonte de luz é então desligada e a condutância, muito maior que no escuro, decai para um valor menor mas não retorna ao seu valor no escuro. Uma outra explicação para o alargamento na curva de fotocondutividade da figura 5.1 é a possível presença de mais de um nivel com transição de carga fotoinduzida na liga $\mathrm{Al}_{0.24} \mathrm{Ga}_{0.76}$ As. Quando se interpreta o centro $\mathrm{DX}$ em termos do modelo com U-negativo, existem várias possibilidades para a composição da vizinhança do centro DX, de acordo com a possibilidade de zero a tres átomos de alumínio como virinhos próximos em torno da impureza intersticial ${ }^{14,15,100}$. Entã correspondente a um determinado número de átomos de $\mathrm{Al}$ há um nível diferente no gap de energia.

A figura 5.2 representa a variação da resistência dessa amostra em função da 


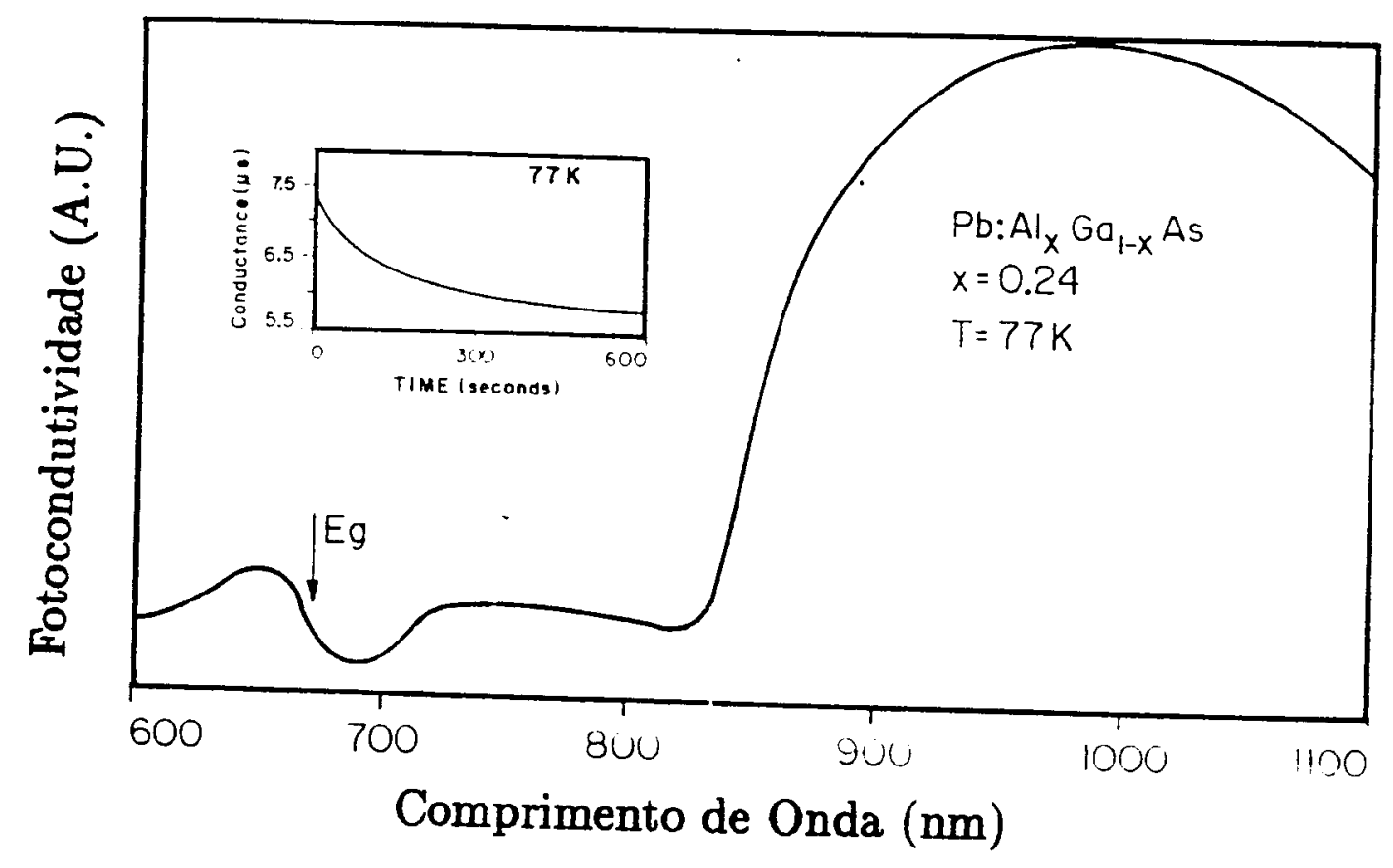

Figara 5.1 - Espectro de Fotocondatividade de $\mathrm{Al}_{0.24} \mathrm{Ga}_{0.76} \mathrm{As}$ \& $77 \mathrm{~K}$. No detalhe - decaimento da condutância após iluminação com $1.37 \mathrm{eV}$. 
temperatura. A resistência aumenta conforme a temperatura diminui. Para a diminuição de temperatura no escuro, em torno de $80 \mathrm{~K}$ existe um forte congelamento de portadores. Entre 80 e $40 \mathrm{~K}$, a resistência mantem-se praticamente constante, existindo um novo congelamento abaixo de $40 \mathrm{~K}$. Este comportamento sugere a existência de dois níveis. A iluminação da amostra a $4 \mathrm{~K}$ demonstra a existência de PPC. Conjuntamente com o que foi obłido na figura 5.1, temos uma evidência clara da existência de centros $\mathrm{DX}$ em AlGaAs dopado com $\mathrm{Pb}$. Com relação ao outro nível, é bem conhecido que níveis rasos hidrogênicos tornam-se degenerados com a banda de condução para dopagens muito altas, resultando em comportamento metálico. Portanto é provável que não se trate de um nível hidrogênico e sim de um nível localizado, mais raso no gap de energia.

As letras na figura 5.2 representam diferentes processos de iluminação, feitos para investigar a natureza do congelamento, a saber : A) Com iluminação a 4 $\mathrm{K}$, a resistência da amostra diminui de $125 \mathrm{~K} \Omega$ para $700 \Omega$ e permanece nesse valor após a iluminação ser desligada. Esse efeito de PPC pode ser atribuido à barreira de captura pelo centro DX. Aquecendo a amostra no escuro a resistência aumenta levemente, pois os elétrons vão adquirindo energia térmica para transpor a barreira de captura e retornar ao nível de energia mais estável, ligado ao centro DX. Já em torno de $40 \mathrm{~K}$, ocorre a captura mais abrupta, em bom acordo com o que foi obtido para o processo no escuro. Entre 47 e $85 \mathrm{~K}$ a curva permanece praticamente constante e paralela à curva obtida no escuro. Isso pode significar que o nível raso não captura os elétrons de volta, o que seria similar à existência do nível raso para silício, postulado no capítulo III, o qual de acordo com Zhang e Chadi ${ }^{72}$ seria um nível metaestável do próprio centro DX. Uma outra explicação é que neste intervalo de temperatura existe um compromisso entre emissão e captura pelos 2 níveis a medida que a temperatura aumenta. Em torno de $95 \mathrm{~K}$ as duas curvas convergem e o aumento de temperatura leva apenas ao processo dominante de emissã de elétrons do centro DX. $O$ aumento abrupto na resistência em torno de 40 $\mathrm{K}$ sugere que $\mathrm{Pb}$ tem menor energia de captura que $\mathrm{Si}$ ou $\mathrm{Sn}{ }^{10,98}$. B) Após aquecer a amostra para temperatura ambiente, ela é novamente esfriada no escuro para $47 \mathrm{~K}$. A variação da resistência com a temperatura é similar so que foi observado no primeiro

IFSG - SERVIGO DE BIBLIOTECA E




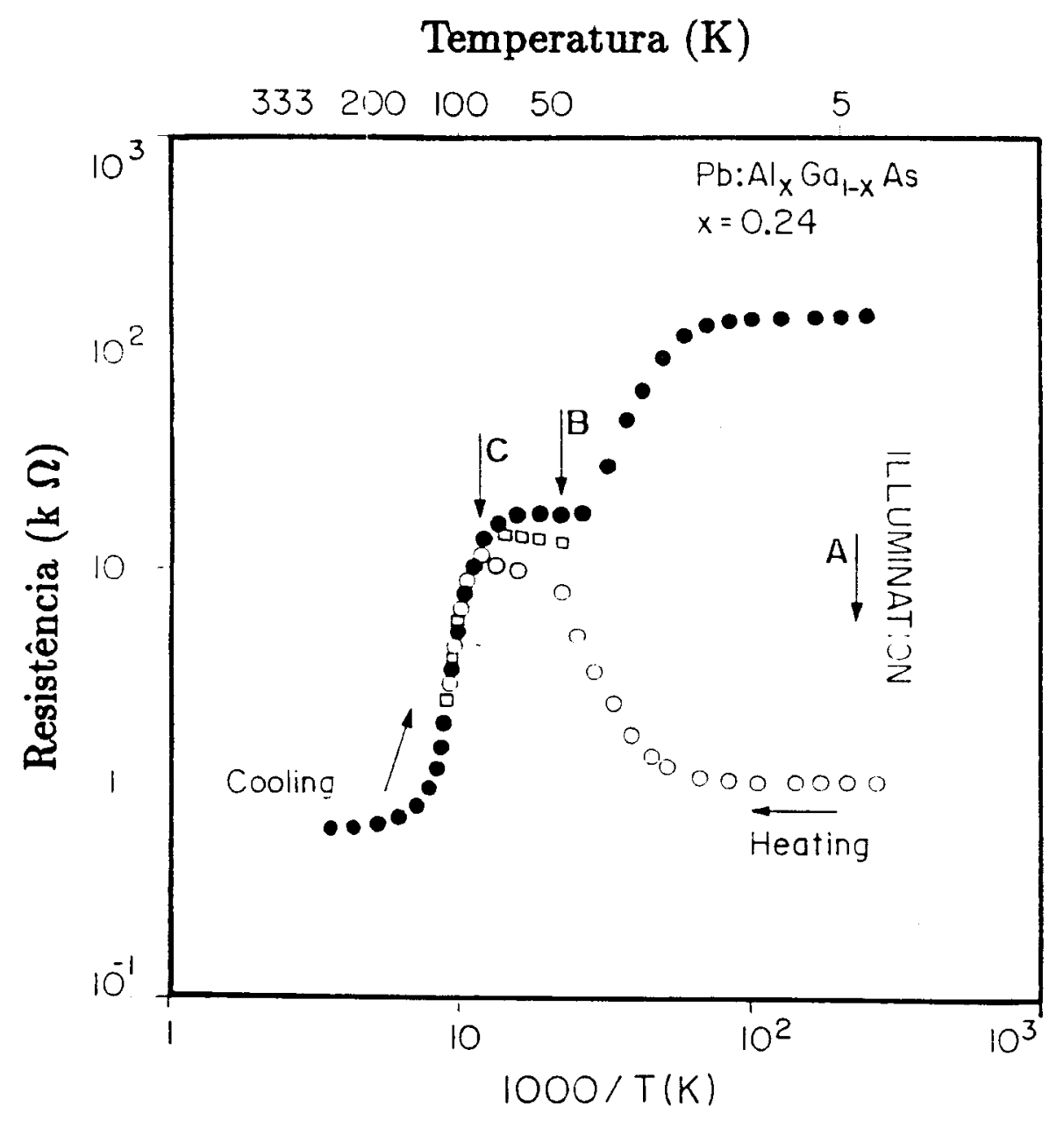

Figara 5.2 - Resistêncis $x$ temperatura para $\mathrm{Al}_{0.24} \mathrm{Ga}$. $.76 \mathrm{As}$ dopado com $\mathrm{Pb}(\bullet)$ - processo de esfriamento no escuro, (o) - prosesso de aquecimento após ilnminaça a $4 \mathrm{~K}$, (口) - aquecimento após iluminação a $47 \mathrm{~K}$ 
esfriamento. Sob iluminação com luz branca a resistência diminui de $16 \mathrm{~K} \Omega$ para 13 $\mathrm{K} \Omega$ permanecendo nesse valor após a luz ser desligada, indicando um pequeno efeito de PPC. Isso é uma outra evidência da existência e também da localização desse defeito com nível de energia mais próximo da banda de condução. C) Aquecendo-se novamente a amostra para temperatura ambiente e esfriando para $85 \mathrm{~K}$, a resistência vai a $14 \mathrm{~K} \Omega$. Após a iluminação ela é diminuída para $12 \mathrm{~K} \Omega$ e permanece nesse valor após a luz ser desligada. Pelo aquecimento ela vai se juntar com a curva anterior a aproximadamente $94 \mathrm{~K}$. A existência do centro $\mathrm{DX}$ e também de um nível de energia adicional em $\mathrm{Al}_{0.24} \mathrm{Ga}_{0.76} \mathrm{As}$ dopado com $\mathrm{Pb}$ está de acordo com o que foi obtido para AlGaAs dopado com $\mathrm{Si}$. O crescimento por MOVPE pode resultar em outros tipos de defeito advindos da presença de compostos orgânicos durante o crescimento, porém os experimentos realizados são uma clara evidência da existência de centros $\mathrm{DX}$ associados com o dopante $\mathrm{Pb}$.

\subsection{EFEITO HALL E CENTRO DX}

Os debates sobre a natureza doadora ou aceitadora do centro DX foram iniciados com os resultados de efeito Hall conflitantes de vários autores. Nelson ${ }^{101}$ e Lang et al ${ }^{8}$ observaram uma diminuição na mobilidade Hall quando o centro DX era fotoionizado a temperaturas baixas, ao contrário de Saxena ${ }^{102}$, Kunzel et al ${ }^{103}$ e Chand et al ${ }^{11}$ que viram um aumento na mobilidade sob fotoionização. A diminuição na mobilidade poderia ser interpretada como causada pelo aumento no número de impurezas ionizadas e consequentemente o centro DX teria natureza doadora. Já o aumento da mobilidade na presença de luz seria uma evidência do caráter aceitador do centro DX, já que o número de impurezas ionizadas diminuiria sob fotoionização. Já no modelo de Chadi e Chang, o número de impurezas ionizadas 
permanece praticamente o mesmo, uma vez que o dopante existe ou no estado DXou $\mathrm{d}^{+}$e a mudança na mobilidade estaria ligada apenas aos efeitos de blindagem, sendo diretamente proporcional ao número de elétrons livres. A discrepância entre esses dados experimentais está relacionada a uma má interpretação. Quando uma camada de AlGaAs é crescida sobre um substrato de GaAs, um gás bidimensional de elétrons é formado na interface ${ }^{104,105}$, consequentemente os dados de mobilidade Hall podem assumir valores mais de uma ordem de magnitude maiores que aqueles devido somente à camada de AlGaAs. Dessa forma a presença de uma camada não dopada de AlGaAs ("buffer") entre GaAs e AlGaAs é fundamental para se previnir a formação desse gás bidimensional de elétrons que mascararia os dados e levaria a interpretações errôneas. A presença da camada não dopada é uma condição necessária mas não suficiente para se evitar a presença do gás bidimensional de eletrons segundo Chand et a ${ }^{11}$, que sugerem uma estrutura mais complexa para evitar esse defeito. Essa estrutura é bastante similar à usada por nós, que foi descrita no capítulo II.

\subsection{1 - Método de Medida}

Para efetuarmos as medidas de efeito Hall, as amostras foram processadas segundo discutido no capítulo II e a medida experimental segue o bem conhecido método de Van der Pauw ${ }^{106}$, com quatro contatos colocados no canto da amostra quadrada. Os contatos foram mantidos com dimensões bastante reduzidas de modo a minimizar o erro introduzido pelos contatos finitos ${ }^{107}$. A relação entre largura do contato e largura da amostra é igual a 0.05 . Devido as perdas nos terminais gerarem voltagens indesejáveis devido aos vários efeitos termoelétricos e galvanomagnéticos, efetua-se quatro medidas d.c. da voltagem para duas direções diferentes da corrente em ordem a se obter a resistividade e também quatro medidas com inversão da 
corrente e campo magnético para a eliminação das voltagens-erro exceto a voltagem Ettingshausen ${ }^{108}$. Na figura 5.3 mostra-se a numeração dos terminais e a tabela V.1 é um exemplo de medida realizadas à temperatura ambiente.

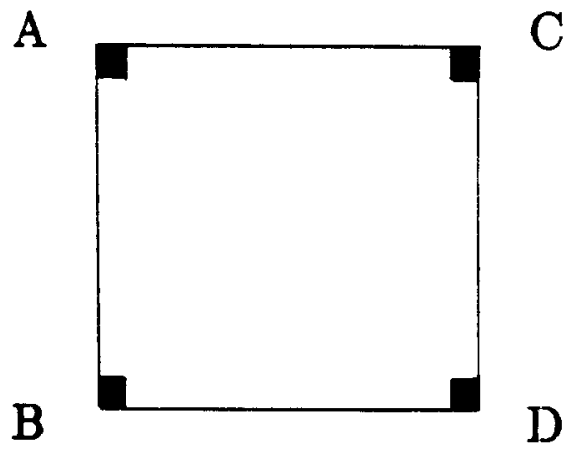

Figura 5.3 - Nomenclatura dos contatos para medidas do efeito Hall

Na tabela V.1 V(AB,CD) significa que a corrente passa pelos terminais $A B$ e a tensão é medida nos teminais CD. A resistividade é obtida através da relação :

$$
\rho=\frac{\pi d}{\ln 2} \frac{V_{1}+V_{2}}{2 I} f
$$

onde d é a espessura da camada ativa, $V_{1}$ é uma média dos quatro valores do lado esquerdo superior da tabela $V .1$ e V 2 é uma médis dos valores do lado direito superior da tabela V.1. I é a corrente e fé um fator de correção dado por ${ }^{100}$ :

$$
\cosh \left[\frac{V_{1} / V_{2}-1}{V_{1} / V_{3}+1} \frac{\ln 2}{f}\right]=\frac{1}{2} \exp \left[\frac{\ln 2}{f}\right]
$$

que é resolvida numericamente pelo bem conhecido método da secante.

Supondo-se que os contatos são suficientemente pequenos e na periferia, e a espessura uniforme, o valor do coeficiente Hall $\left(R_{H}\right)$ pode ser obtido pelas medidas realizadas com e sem a aplicação do campo magnético. Através de uma média entre todos os valores absolutos obtidos para $\Delta R$, a variação da resistência pela aplicação do campo magnético em relação ao seu valor sem o campo, pode-se obter : 
Tabela V.1 - Medidas de voltagens para determinação de resistividade e coeficiente Hall em AlGaAs:Si. Temperatura $=300 \mathrm{~K}$, sob luz branca

\begin{tabular}{|c|c|c|c|c|}
\hline$I(\mu \mathrm{A})$ & $\mathrm{V}(\mathrm{AB}, \mathrm{CD})(\mathrm{mV})$ & $\mathrm{V}(\mathrm{CD}, \mathrm{AB})(\mathrm{mV})$ & $\mathrm{V}(\mathrm{BD}, \mathrm{AC})(\mathrm{mV})$ & $\mathrm{V}(\mathrm{AC}, \mathrm{BD})(\mathrm{mV})$ \\
\hline+50 & 26.30 & 26.15 & 26.24 & 25.00 \\
-50 & -26.06 & -24.07 & -24.09 & -24.08 \\
\hline
\end{tabular}

$B=3200$ Gauss

\begin{tabular}{|c|c|c|c|c|c|c|}
\multicolumn{4}{c}{$\mathrm{V}(\mathrm{AD}, \mathrm{BC})$} & \multicolumn{3}{c|}{$\mathrm{V}(\mathrm{BC}, \mathrm{AD})$} \\
\hline $\mathrm{I}(\mu \mathrm{A})$ & $\overline{\mathrm{B}}=0$ & $\mathrm{~B}+$ & $\overline{\mathrm{B}}$ & $\mathrm{B}=0$ & $\mathrm{~B}+$ & $\mathrm{B}-$ \\
\hline+50 & 2.00 & 3.12 & 0.99 & 2.06 & 0.87 & 3.01 \\
-50 & -2.02 & -3.18 & -0.85 & -1.98 & -0.78 & -3.15 \\
\hline
\end{tabular}

$$
R_{H}=\frac{d}{B} \Delta R
$$

A partir do coeficiente Hall, duas grandezas de fundamental interesse podem ser obtidas : a concentração de portadores livres e a mobilidade. A concentração de portadores é dada por ${ }^{108}$ :

$$
n=\frac{r_{H}}{e R_{H}}
$$

$\mathbf{I}_{H}$ é o fator do coeficiente Hall e pode ser calculado usando a função distribuição obtida da solução da equação de Boltzmann para os campos elétricos e magnéticos aplicados, mais o mecanismo de espalhamento apropriado. No limite de al tos campos magnéticos e/ou degenerescência, $I_{H}$ tende a 1 não importando o mecanismo de espalhamento, Porém em muitas situącões práticas o semicondutor não é degenerado e não é prático elevar o campo para uma situação limite. Em situações práticas devese estimar o valor do fator Hall para uma determinação precisa da concentração de portadores. Blatt ${ }^{109}$ fornece o valor de $(315 \pi / 512)=1.93$ para $\mathrm{r}_{H}$ para o espalhamento por impurezas ionizadas em campos fracos. Deve-se notar que a temperaturas baixas (menores que aproximadamente $100 \mathrm{~K}$ ) o espalhamento por impurezas ionizadas é o mecanismo dominante. Os resultados para o espalhamento polar ótico, dominante em semicondutores III-V a altas temperaturas, mostram que os valores de $\mathrm{I}_{H}$ variam de 1 a 1.25 dependendo do campo magnético aplicado e 
valor da temperatura ${ }^{110}$. A mobilidade Hall $\left(\mu_{H}\right)$ é obtida de forma similar, sendo dada por ${ }^{108}$ :

$$
\mu_{H}=\frac{R_{H}}{\rho}
$$

A mobilidade para condutividade se relaciona com a mobilidade Hall por :

$$
\mu=\frac{\mu_{B}}{r_{H}}
$$

Dessa forma é fundamental sabermos o valor de $\mathrm{r}_{B}$ para uma estimativa mais precisa dos valores de mobilidade e concentração de portadores livres.

\subsection{2 - Efeito Hall em Função da Temperatura}

Baseado no que foi discutido na secção anterior, foram calculados os valores de mobilidade e concentração de eletrons de uma amostra de $\mathrm{Al}_{0.3} \mathrm{Ga}_{0.7} \mathrm{As}$ dopada com Si a partir de medidas Hall, no escuro e sob iluminação com luz branca. Os resultados encontrados estão na tabela V.2, utilizando valores de $I_{B}$ dados por Blatt ${ }^{109}$ para 80 e $100 \mathrm{~K}$ e por Stillman et al ${ }^{110}$ para as demais temperaturas. Estão mostrados também cálculos efetuados a partir de $\mathrm{r}_{H}=1$. Quando se usa o valor do fator Hall diferente de 1 , a concentração de eletrons calculada é muito maior a $80 \mathrm{~K}$ do que a $300 \mathrm{~K}$, o que é absurdo a princípio, de modo que foram graficados os resultados obtidos a partir de $\mathrm{r}_{H}=1$, conforme feito também por Chand et al ${ }^{11} \mathrm{e}$ Collins et $a^{104}$. O problema de se aceitar os valores de Stillman et al como completamente válidos para o nosso caso está no fato deles terem sido obtidos para GaAs e não AlGaAs. Com relação acs valores de Blatt, para campos magnéticos fortes $\tau_{H}=$ 1 e no limite de campo fraco $\mathrm{r}_{H}=1.93$. Para casos intermediários, o valor deve estar entre esses dois limites ${ }^{108}$, porém é de difícil determinação. Deve-se notar 
no entanto, que o campo magnético utilizado é de $3200 \mathrm{G}$, que não é tão forte, de modo que os valores graficados utilizando $\mathrm{r}_{H}=1$ certamente estão com algum fator de erro.

Tabela V.2 - Valores de concentração de eletrons e mobilidade obtidos por efeito Hall

\begin{tabular}{|c|c|c|c|c|c|}
\hline $\begin{array}{c}\text { Temperatura } \\
(\mathrm{K})\end{array}$ & $\mathrm{r}_{H}$ & $\begin{array}{c}\mathrm{n} \\
\left(\mathrm{x} 10^{16} \mathrm{~cm}^{-3}\right)\end{array}$ & $\begin{array}{c}\mu \\
\left(\mathrm{cm}^{2} / \mathrm{V} \mathrm{s}_{ }\right)\end{array}$ & $\begin{array}{c}\mathrm{n} \\
\left(\times 10^{16} \mathrm{~cm}^{-3}\right)\end{array}$ & $\begin{array}{c}\mu \\
\left(\mathrm{cm}^{2} / \mathrm{V}_{ }\right)\end{array}$ \\
\hline 80 & 1.93 & 8.37 & 245 & 5.12 & 186 \\
& 1.00 & 4.32 & 475 & 2.64 & 360 \\
\hline 100 & 1.93 & 4.89 & 178 & 4.60 & 131 \\
& 1.00 & 2.54 & 343 & 2.38 & 253 \\
\hline 150 & 1.13 & 2.03 & 256 & 1.96 & 262 \\
& 1.00 & 1.80 & 290 & 1.74 & 296 \\
\hline 200 & 1.16 & 1.95 & 262 & 1.95 & 262 \\
& 1.00 & 1.68 & 303 & 1.68 & 303 \\
\hline 300 & 1.10 & 5.61 & 275 & 5.76 & 275 \\
& 1.00 & 5.10 & 303 & 5.20 & 303 \\
\hline
\end{tabular}

Os valores tabelados para $I_{H}=1$ estão nas figuras 5.4 e 5.5. Os valores de concentração de eletrons a $300 \mathrm{~K}$ são bem menores do que os pretendidos com a dopagem de $1 \times 10^{18} \mathrm{~cm}^{-3}$. Isso pode significar uma alta compensação ou erro no próprio crescimento por MBE, já que esse valor é calibrado apenas pela temperatura da célula de efusão de silício. Além disso tratarse de uma peça de material de 2 polegadas e essa amostra foi processada a partir de um pedaço na lateral, de forma que a incorporação de silício pode ser menor devido à gradientes radiais de temperatura no bloco de molibdênio. Os valores de mobilidade bastante baixos indicam que a condução através do gás bidimensional de eletrons não está ocorrendo. A ordem de grandeza desses valores estão em ótima concordância com os valores de Collins et al ${ }^{104}$, que também utilizaram $\mathrm{I}_{H}=1$ numa amostra muito mais dopada $\left(3 \times 10^{18} \mathrm{~cm}^{-3}\right)$, cujos valores de concentração Hall também não ultrapassam $3 \times 10^{17}$ $\mathrm{cm}^{-3}$.

Quando se calcula valores de mobilidade dados pela equação de Brooks-Herring a $80 \mathrm{~K}$ (capítulo III), utilizando como concentração de impurezas a concentração eletrons livres a $300 \mathrm{~K}$, chega-se a um valor de aproximadamente $295 \mathrm{~cm}^{2} / \mathrm{V}$ s, que 


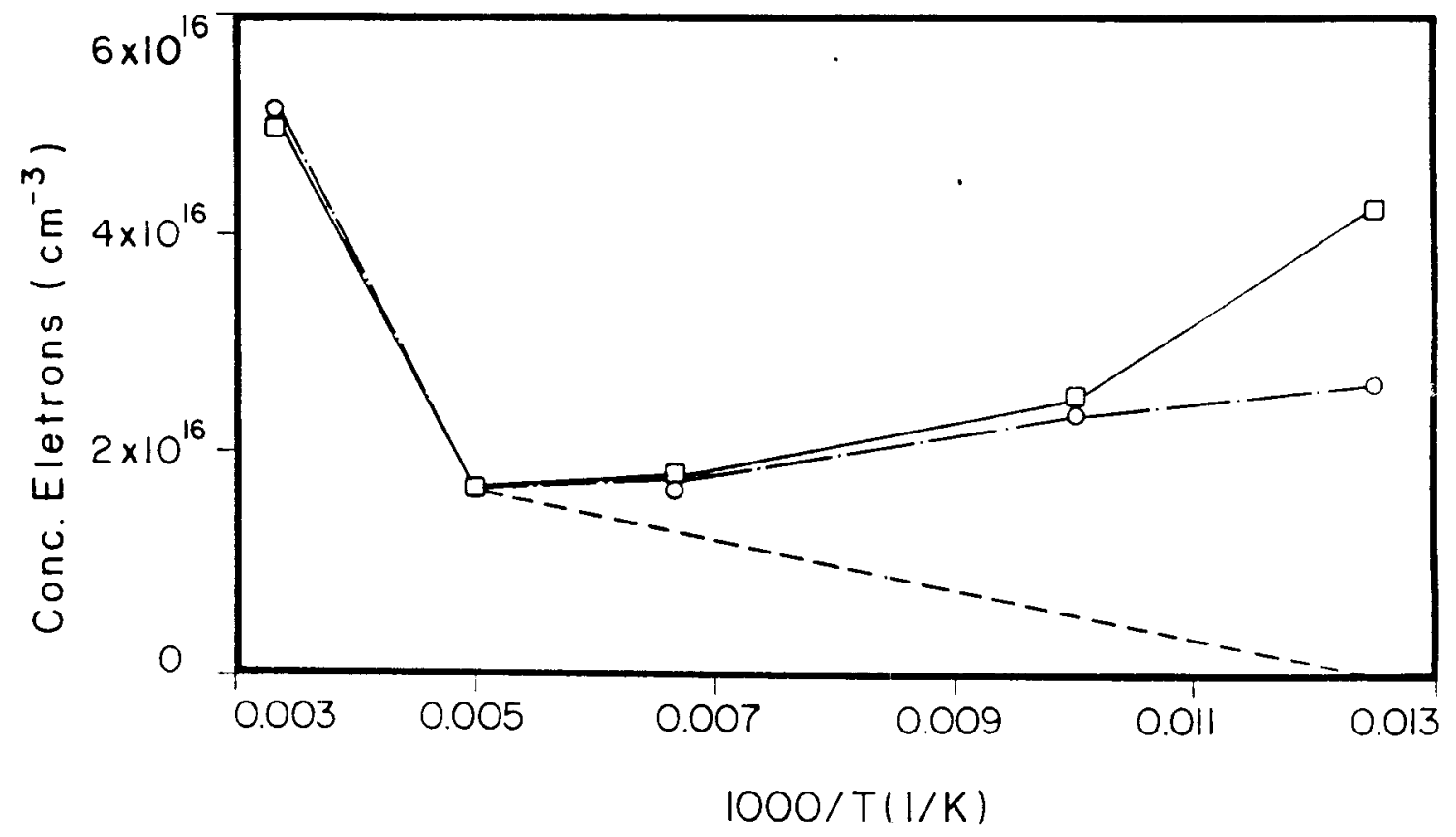

Figara 5.4 - Concentração de eletrons em função da temperatura medido por efeito Hall (ㅁ) - sob iluminação, ( o) - no "escuro"

está em boa concordância com o valor medido de $245 \mathrm{~cm}^{2} / \mathrm{V} \mathrm{s}$, obtido com $\mathrm{r}_{H}=1.93$. Isso é mais uma evidência de que o fator Hall deve ser um número intermediário entre 1 e 1.93. O fato da concentração de eletrons ser maior a $80 \mathrm{~K}$ do que a 300 $\mathrm{K}$ pode vir do erro no valor de $\mathrm{r}_{H}$ como também da possibilidade de que com luz branca, além de centros DX, pares elétrons-buracos também são excitados.

Para medidas acima de $150 \mathrm{~K}$, a concentração de portadores não apresenta variação sensível com relação à presença ou não de luz. Para as medidas realizadas a $100 \mathrm{~K}$ e $80 \mathrm{~K}$, a concentração de elétrons na amostra sob iluminação com luz branca sobe consideravelmente, como seria de se esperar, porém a concentração de elétrons no escuro também tem uma subida razoável. Uma possível explicação é que o criostato no qual o experimento foi realizado não estava totalmente vedado e havia a presença de luz não pretendida. Conforme é conhecido, a baixa temperatura a condutividade de AlGaAs é uma função muito sensivel da quantidade de luz que incide na amostra. Porém a explicação mais provável advém do modo como o experimento foi feito, no qual por dificuldades de controle na descida da temperatura, a amostra

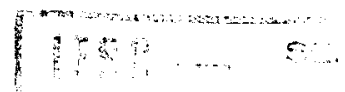




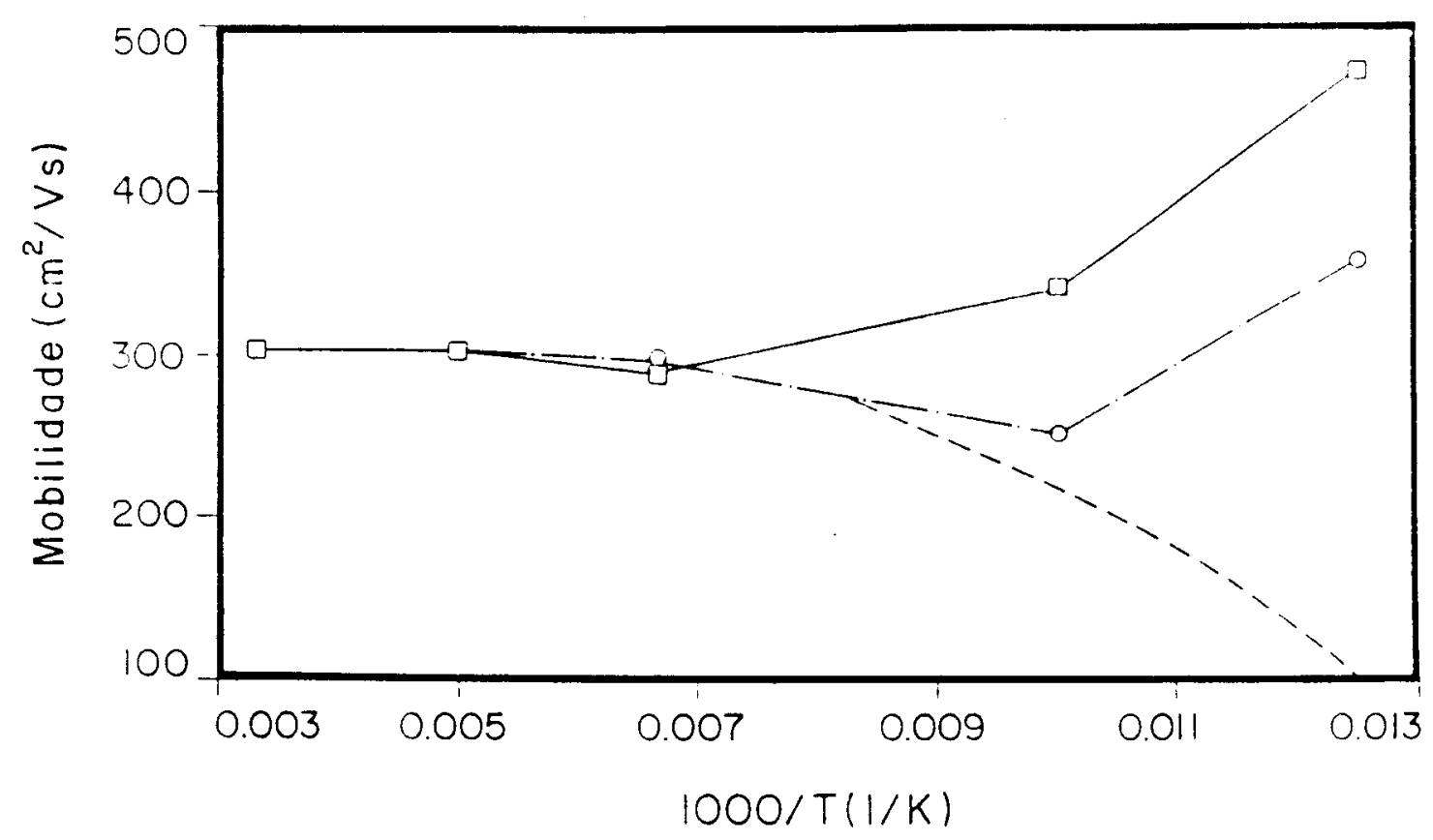

Figura 5.5 - Mobilidade em função da temperatura medido por efeito Hall (口) - sob iluminação, (o) - no "escoro"

é esfriada e depois aquecida lentamente. Este esfriamento não deve ter sido lento o suficiente para impedir o congelamento de portadores na banda de condução. Assim o aumento na concentração de elétrons com a diminuição na temperatura abaixo de $100 \mathrm{~K}$ deve ser olhado com reservas. Portanto é mostrado nas figuras 5.4 e 5.5 curvas correspondentes ao que seria qualitativamente esperado para os dados no escuro em acordo com Chand et al ${ }^{11}$ e Collins et al ${ }^{104}$ e também de acordo com os esfriamentos realizados nas medidas de TDPPC, onde o equipamento, muito mais sofisticado (capítulo III), permitia um esfriamento bastante lento de modo que os elétrons pudessem ser capturados conduzindo termodinamicamente à relaxação do defeito. A figura 5.4 é bastante similar ao que seria obtido para a concentração de elétrons em amostras expostas a diferentes tempos de iluminação ${ }^{1}$. Na região de temperatura em torno de 100 a $120 \mathrm{~K}$, ocorre a transição entre modos dominantes de espalhamento ${ }^{58,61,62}$ passando de polar ótico (temperaturas mais altas) para espalhamento por impurezas ionizadas. Nos pontos obtidos a $100 \mathrm{~K}$ e $80 \mathrm{~K}$, quanto maior a concentração de elétrons, maior a mobilidade. Ainda que o valor da concen- 
tração de elétrons livres para o experimento ieito no escuro nesse intervalo não seja - esperado, eles correspondem a medidas reais de diferentes estados de condutividade, com diferentes concentraçōes de elétrons presos metaestavelmente na banda de condução. Portanto, se a uma maior concentração de elétrons corresponde uma maior mobilidade, o centro DX não pode ser um doador simples. Conclusão similar pode ser obtida comparando-se os pontos a 100 e $80 \mathrm{~K}$ sob iluminação. Neste caso não precisaríamos comparar com os valores obtidos no escuro. $O$ fato dos dados experimentais não serem consistentes com a hipótese de um doador simples é um bom suporte acs modelos que atribuem ao centro DX um caráter aceitador, entre eles o modelo de Chadi e Chang ${ }^{19,23}$. Recentemente foram publicados ${ }^{17,111}$ dados de mobilidade em função da pressão em $\mathrm{GaAs}$, que são contrastantes com essas conclusões. Considerando-se que experimentos com pressão não foram aqui realizados, a discussão será retomada oportunamente (Conclusão), quando será discutida a validade dos resultados obtidos como um todo em função da situação atual das pesquisas sobre o centro DX. 


\section{CONCLUSÃO}

Nesse trabalho foram apresentados vários aspectos no qual se concentram atualmente a física e a tecnologia de semicondutores III-V, ou seja, desde o crescimento e processamento de amostras (dispositivcrs) de alta qualidade, até o problema do comportamento de contatos. Todo o enfoque é centrado no problema dos centros DX, o que não poderia ser diferente já que essa é a proposta do trabalho.

De uma maneira geral, os resultados apresentados são condizentes com o modelo com interação de U-negativo de Chadi e Chang. Esse modelo tem sido bem aceito pela maioria dos pesquisadores, apesar de uma boa parcela ainda tentar encontrar explicaçōes para as intrigantes particularidades do centro DX baseados em modelos que não incluem distorções da rede. No capítulo I foi citado que o modelo de Chadi e Chang não era consistente com os dados de Khachaturyan et al ${ }^{26}$ que atribuiram ao centro DX um caráter paramagnético. Recentemente Katsumoto et al 112 realizaram um trabalho similar e também encontraram a dependência com a temperatura de acordo com a lei de Curie, porém a concentração de centros paramagnéticos foi muito menor que a concentração de centros DX. Uma explicação simples é que o estado fundamental do centro DX não possui spin, ou seja, é diamagnético, daí a fraca concentração encontrada de centros com um elétron não pareado. Porém, como admitem os próprios autores, é preciso mais investigação para se encontrar a verdadeira carga do estado fundamental do centro DX. De qualquer forma o experimento de Khachaturyan et al não pode ser tomado como aquele que vai definitivamente derrubar o modelo de Chadi e Chang.

Resultados de mobilidade em GaAs sob a aplicação de pressão hidrostática ${ }^{7,111}$ mostraram que a medida que a pressão aumen:a os elétrons são capturados pelos centros DX e a mobilidade aumenta. A princípio isso seria contrário ao modelo de 
Chadi e Chang, já que a mobilidade seria proporcional a concentração de elétrons livres. Cálculos baseados em centros independentes de espalhamento $\mathrm{d}^{+}$e $\mathrm{DX}^{-}$ mostraram que essa variação de mobilidade seria mais consistente com um modelo de U-positivo, porém também não se ajusta completamente aos dados experimentais. $\mathrm{O}^{\prime}$ Reilly ${ }^{113}$ argumenta que a formação de centros $\mathrm{DX}^{-}$envolve a troca de pares $\mathrm{d}^{+}-\mathrm{d}^{+}$para dipolos $\mathrm{d}^{+}-\mathrm{DX}^{-}$e portanto, centros de espalhamento não podem ser considerados independentemente, mas sim ans pares. Com a inclusão desses fatores de correlação no cálculo de mobilidade ele conclui que tanto modelos com $\mathrm{DX}^{\circ}$ como DX - fornecem ajustes qualitativos para os dajos. Em vista disso, parece que dados de mobilidade ainda não estão fechados e devem fornecer um bom suporte para discussões futuras.

Nos trabalhos recentes, existe uma certa tendência para a inclusão de um estado intermediário para a captura de elétrons ${ }^{114}$. A idéia desse estado de transição foi primeiro argumentada por Theis e Mooney ${ }^{52,115}$ e seria uma consequência natural do estado fundamental do centro DX possuir 2 eletrons, ou seja, haveria um estado com apenas um elétron capturado que seria exatamente esse intermediário. Theis et al ${ }^{1}$ sugerem que esse intermediário seria o estado $A_{1}$ previsto pela teoria de ligações fortes ("tight binding"). Porém, como os próprios autores admitem isso é apenas uma hipótese, e portanto, necessita de investigação. Recentemente, tem sido realizados trabalhos similares ao nosso ${ }^{68}$ que confirmam o U-negativo para o centro DX e nos quais é incluída a presença desse estado intermediário ${ }^{116,117}$. Esse intermediário poderia ser uma explicação alternativa para a presença do doador mais raso que foi postulada no capítulo III para AlGaAs dopado com Si e encontrado também em AlGaAs dopado com $\mathrm{Pb}$ (capítulo $\mathrm{V}$ ). Os decaimentos suavas observados sugerem porém, que se esse intermediário existe, a transformação de $d^{+}$para $d^{\circ} e$ de $d^{\circ}$ para $\mathrm{DX}^{-}$deveriam ter velocidades comparáveis, ou que a transformação de $\mathrm{d}^{+}$para do é muito mais lenta ( se fosse muito mais rápida, a concentração cairia rapidamente no começo do experimento, o que não é observado, desde que a luz incidente na amostra seja rigorosamente mantida abaixo do gap de energia) já que num processo em série, que ocorre com a presença de intermediários, a velocidade global é determinada pelo processo mais lento. Nesse caso, a menos de nomenclatura, 
o equacionamento apresentado no capítulo III continuaria essenciaimente válido. Portanto investigações cuidadosas sobre o tempo de vida e processos de captura desse intermediário ainda precisam ser realizados.

Aproxima-se o dia em que as teorias a respeito do centro DX se unificarão e conseguirão explicar os intrigantes resultados obtidos experimentalmente, embora alguns pontos ainda estejam obscuros atualmente. Acredito que este trabalho seja uma boa contribuição nesse sentido, de entender a física dos centros DX e impedir os seus efeitos detrimentais em dispositivos ainda a serem projetados pelo avanço crescente da engenharia de semicondutores. 


\section{Apêndice A - Um método para se obter a Energia de Captura em Função dos Dados de TDPPC}

O decaimento da fotocondutividade persistente é uma função da altura da barreira para captura. Desta forma. é possível a princípio, determinar essa dependência e consequentemente avaliar o valor dessa energia de captura. A equação para captura dos eletrons pode ser escrita como :

$$
\frac{d n}{d t}=-C_{1} n^{2}
$$

onde estamos desprezando o rermo $\mathrm{N}_{S D}$, interpretado como um nivel raso para o modelo de Chadi e Chang. $C_{1}$ é dado por :

$$
C_{1}=\frac{\sigma_{n} V_{t h}}{C_{m}}
$$

onde $\mathrm{C}_{m}=1,2,3$ dependendo do modelo assumido. $\mathrm{O}$ método a ser desenvolvido deve ser completamente geral. não dependendo do valor da constante $C_{m}$. Tomando a posicão do nível de Fermi como abaixo do mínimo da banda de condução e portanto igual a zero (ver equação III.6) a equação A.1 pode ser resolvida analiticamente :

$$
n(t)=\frac{n(0)}{1+C_{n} n(0) t}
$$

Assumindo que o espalhamento por impurezas ionizadas pode ser calculado peia relação de Brooks-Herring, vem que o inverso da condutância pode ser escrito como:

onde :

$$
\frac{1}{G(t)}=\frac{\ln \left(\frac{b}{n(t)}\right)}{k_{1} T^{3 / 2} n(t)}
$$




$$
k_{1}=\frac{K_{1} 128 \sqrt{2 \pi} e^{2} k_{B}^{3 / 2}}{e^{2} m_{e}^{1 / 2} N_{i i}}
$$

De A.3 e A.4 :

$$
\frac{1}{G(t)}=\frac{\ln \left(\frac{b\left(1+C_{n} n(0) t\right)}{n(t)}\right)}{k_{1} T^{3 / 2}\left[\frac{n(0)}{\left(1+C_{n} n(0) t\right)}\right]}
$$

O valor da constante b é definido no capítulo III. Para tempos muito grandes, a parte logarítmica torna-se constante, o que pode ser visto escrevendo-se A.6 na forma :

onde :

$$
\frac{1}{G(t)}=\frac{T^{-3 / 2}}{n(0) k_{1}} P_{L I N} P_{L O G}
$$

$$
\begin{gathered}
P_{L I N}=1+C_{n} n(0) t \\
P_{L O O}=\ln \left(\frac{b}{n(0)}\left(1+C_{n} n(0) t\right)\right)
\end{gathered}
$$

derivando-se A.8 e A.9, obtém-se :

$$
\begin{gathered}
P_{L I N}^{\prime}=C_{n} n(0) \\
P_{L O G}^{\prime}=\frac{C_{n} n(0)}{1+C_{n} n(0) t}
\end{gathered}
$$

Portanto quando $t$ tende a infinito, $\mathrm{P}{ }_{L O O}$ tende a zero, o que significa que $1 / G(t)$ torna-se linear. Em outras palavras, na expressão de $[1 / G(t)] P_{\text {LOG }}$ torna-se constante. Na prática esse tempo pode ser muito longo, de modo que nosso objetivo é obter uma expressão que relacione o decaimento num determinado intervalo de tempo com a temperatura e a energia de captura, e que seja geral. Lembrando que $\mathrm{P}^{\prime}{ }_{L O O}$ é sempre uma fração de $\mathrm{P}_{L I N}$, podemos escolher dois pontos $t_{1}$ e $t_{2}$ tais que $\mathrm{P}^{\prime}{ }_{L I N}=\mathrm{kP}^{\prime}{ }_{L O O}$ e $\mathrm{P}_{L I N}=\mathrm{j} \mathrm{P}_{L O O}$ onde para efeitos de simplificação $\mathrm{k}$ e $\mathrm{j}$ são inteiros e $\mathrm{k}$ menor que $\mathrm{j}$. Substituindo em A.10 є A.11, obtém-se :

$$
t_{1}=\frac{k-1}{C_{n} n(0)}
$$




$$
t_{2}=\frac{j-1}{C_{n} n(0)}
$$

Fazendo-se uma regressão linear dos pontos experimentais entre $t_{1}$ e $t_{2}$ obtémse uma reta cujo coeficiente angular é, em boa aproximação, a tangente da reta que passa pelos pontos $1 / G\left(t_{1}\right)$ e $1 / G\left(t_{2}\right)$. ( A aproximação é cada vez meihor conforme j aproxima $k$ e ambos se distanciam da origem i. Chamando $S_{10}$ o valor obtido para a tangente da regressão linear entre $t_{1}$ e $t_{2}$, então com ajuda das expressões A.6, A.12 e A.14, pode-se obter :

$$
S_{l o} \approx \frac{\Delta(1 / G)}{\Delta t}=\frac{T^{-3 / 2} C_{n}}{k_{1}(j-k)}\left[j \ln \left(\frac{b j}{n(0)}\right)-k \ln \left(\frac{b k}{n(0)}\right)\right]
$$

Com mais algumas simplificações chega-se a :

$$
S_{l o}=\frac{T^{-3 / 2} C_{n}}{k_{1}}\left[\ln \left(\frac{b C_{j k}}{n(0)}\right)\right]
$$

onde :

$$
C_{j k}=\frac{j\left(\frac{1}{j-k}\right)}{k\left(\frac{k}{j-k}\right)}
$$

A expressão A.15 é geral, ou seja, se escolhermos $k$ e $j$ e obtivermos $t_{1}$ e $t_{2}$ para cada temperatura dados por $\mathrm{A.12}$ e A.13, temos uma expressão válida para qualquer temperatura. Aplicando-se logaritmos em ambos os lados da equação A.15 e com o auxolio da dependência com a temperatura da velocidade térmica chega-se a :

$$
k_{B} \ln \left[f(T) S_{l o}\right]=C_{F}-\frac{E_{\text {cap }}}{T}
$$

onde :

$$
\begin{gathered}
f(T)=\frac{T}{\ln \left[\frac{\left.b C_{i k}\right]}{m(0)}\right]} \\
C_{F}=k_{B} \ln \left[\frac{1}{k_{1}}\left(\frac{3 k_{B}}{m_{e}}\right)^{1 / 2} \frac{\sigma_{\infty}}{C_{m}}\right]
\end{gathered}
$$

Desta forma num gráfico de Arrhenius de $k_{B} \ln \left[f(T) S_{l o}\right]$ em função de $1 / T$, a tangente é a energia de captura. 


\section{A.1 - Cálculo do Valor Inicial da Concentração de Eletrons Livres}

Através da relação entre condutância e condutividade dada por III.2 e da mobilidade dada pela equação de Brooks - Herring, pode-se escrever :

$$
G(0)=\frac{K_{S} 128 \sqrt{2 \pi} \varepsilon^{2}\left(k_{B} T\right)^{3 / 2} n(0)}{e^{2} m_{e}^{1 / 2} N_{i i} \ln \left[\frac{b}{n(0)}\right]}
$$

que pode ser resolvida numericamente para se obter o valor de $n(0)$. O problema global de se simular as curvas de TDPPC explicado no capítulo III e a obtenção da energia de captura não pode ser resolvido separadamente ou seja, n(0) é um parâmetro ajustável na simulação numérica e o encaixe da curva depende do valor de $E_{\text {cap. }}$ Por sua vez a obtenção de $n(0)$ é uma função de $K_{S}$ que será bastante relevante na obtenção de $E_{\text {cap. }}$. Portanto o problema como um todo deve ser resolvido auto consistentemente. Valores obtidos dessa forma para algumas composiçōes de alumínio em $\mathrm{Al}_{x} \mathrm{Ga}_{1-x} \mathrm{As}$ estão listados na tabela $A .1$.

Tabela A.1 - Energia de Captura a partir de dados de TDPPC

\begin{tabular}{|c|c|c|}
\hline composição de $\mathrm{Al}$ & Dopagem $\left(\times 10^{17} \mathrm{~cm}^{-3}\right)$ & $\mathrm{E}_{\text {cap }}(\mathrm{eV})$ \\
\hline 0.30 & 10 & 0.243 \\
0.34 & 10 & 0.232 \\
0.40 & 10 & 0.195 \\
0.50 & 5 & 0.201 \\
\hline
\end{tabular}

Os valores de energia de captura listados na tabela $A .1$ são médias dos valores obtidos usando os parâmetros $k=2, j=3$ e $k=3, j=4$. As curvas correspondentes a esses valores estão na figura A.1 que mostra a excelente linearidade dos dados, assim como o paralelismo observado para diferentes $k, j$ para um mesma composição de alumínio. 


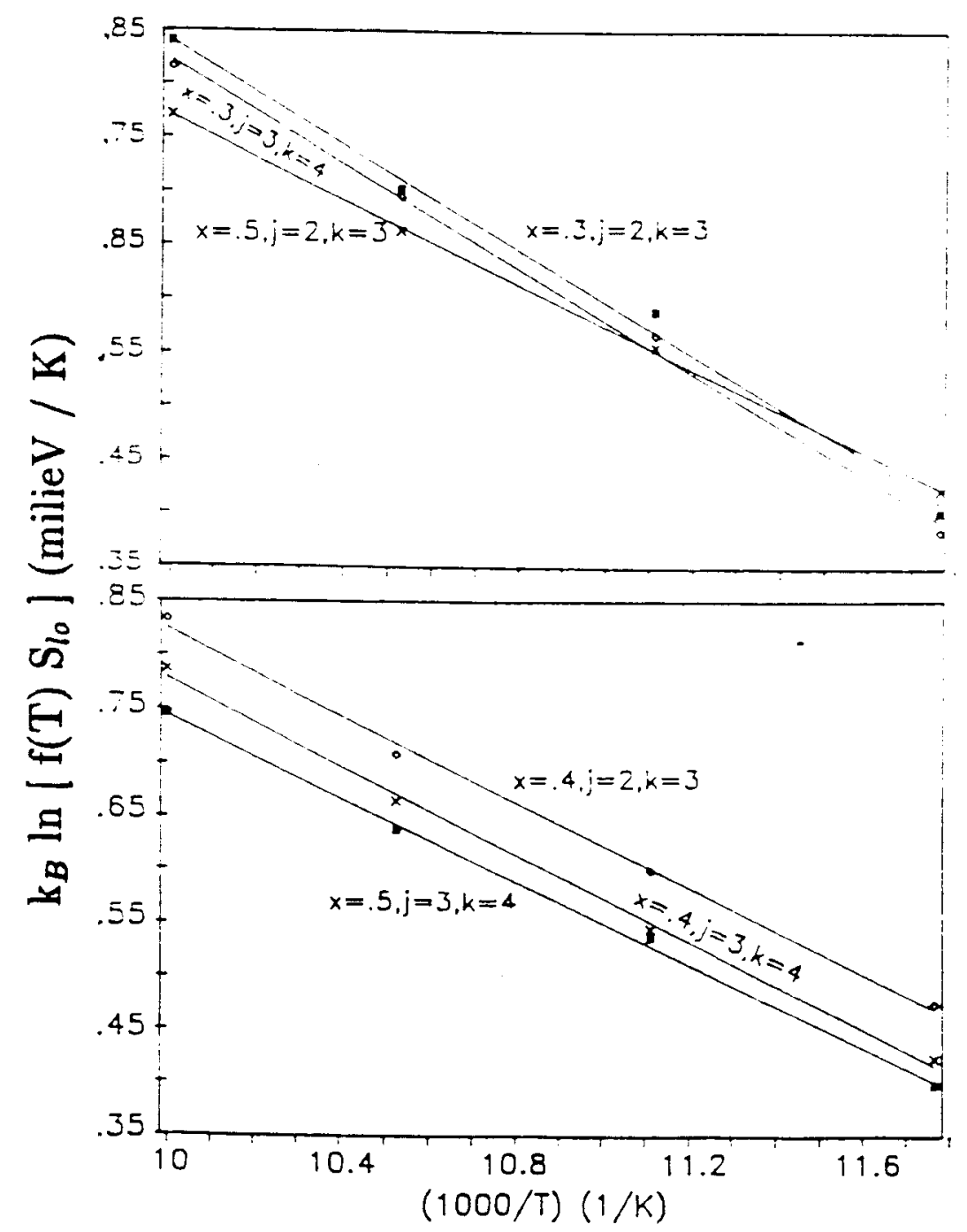

Figura A.1 - Plot de Arrhenius pars se obter a energis de capturs do centro DX. As composições e respectivos valores de $k$ e $j$ estão listados a lado da curva 


\section{REFERÊNCIAS}

1. - Theis,T.N.; Mooney,P.M.; Parker,B.D. - J. Electr. Materials 20, 35 (1991)

2. - Lannoo,M. - "Review of DX Center Models" em : Physics of DX Centers in GaAs Alloys, ed. por J.C. Bourgoin, Sci-Tech Pub., 1990, pag. 209

3. - Dmochowski,J.E.; Stradling,R.A.; Wang,P.D.; Holmes,S.N.; Li,M.; McCombe,B.D.; Weinstein,B. - Semicond. Sci. Technol. (a ser publicado)

4. - Dmochowski,J.E.; Wasilewsiki,Z.; Stradling,R.A. - Proc. 4th Int. Conf. Shallow Impurities in Semiconductors, London, 1990

5. - Mooney,P.M. - J. Appl. Phys. 67, R1 (1990)

6. - Mimura, T.; Hiyamizu,S.; Fuji, T; Nambv, K - Jpn. J. Appl. Phys. 19, L225 (1980)

7. - Schubert,E.F.; Fischer,A.; Ploog,K. - IEEE Trans. on Electron Devices EDS3, 625 (1986)

8. - Van Vechten,J.A. - J. Phys. : Condens. Mattter 1, 5171 (1989)

9. - Lang,D.V.; Logan,R.A.; Jaros,M. - Phys. Rev.B 19, 1015 (1979)

10. - Lang,D.V. - "DX Centers in III-V Alloys" em : Deep Centers in Semiconductors, ed. por S.T. Pantelides. Gordon and Breach. N.York.1986, pag. 489

11. - Chand,N.; Henderson,T; Klem,J.; Masselink,W.T.; Fischer,R.; Chang, Y.C.; Morkos,H. - Phys. Rev B 30, 4481. (1984)

12. - Mizuta,M.; Tachikawa,M.; Kukimoto,H.; Minomura,S. - Jpn. J. Appl. Phys. 24, L143 (1985)

13. - Tachikawa,M.; Fujisawa,T.; Kukimoto,H.; Shibata,A.; Oomi,G.; Minomura,S. - Jpn J. Appl. Phys. 24, L893 (1985) 
14. - Baba.T.; Mizuta.M.: Fujisawa,T.; Yoshino.J.; Kukimoto.H. - Jpn. J. Appl. Phys. 28, L891 (1989)

15. - Brunthaler,G.; Köhler,K. - Appl. Phys. Lett. 57, 2225 (1990)

16. - Pann,L.S.; Tischler,M.A.; Mooney,P.M.; Newmark,G.F. - J. Appl. Phys. $68,1674(1990)$

17. - Maude,D.K.; Portal,J.C.; Murray,R.; Foster,T.J.; Dmowsik,L.; Eaves,L.; Newman,R; Basmaji,P.; Gibart,P; Harris,J.J.; Beall,R. B. - "Studies of DX Centre Using Hydrostatic Pressure" em Physics of DX Centers in GaAs Alloys, ed. por J.C.Bourgoin, Sci-Tech Publications, Brookfield, 1990, pag. 121

18. - Jaros,M.; Brand,S. - Phys. Rev. B 14, 4494 (1976)

19. - Chadi,D.J.: Chang,K.J. - Phys. Rev. B 99,10063 (1989)

20. - Basmaji,P.; Portal,J.C.; Aulombarà,R.L.; Gibart,P. - Solid State Commun. 69, 73 (1987)

21. - Mooney,P.M.; Northroop,G.A.; Morgan,T,N.; Grimmeiss,H.G. - Phys. Rev. B 97, 8298 (1988)

22. - Legros,R.; Mooney,P.M.; Wright,S.L. - Phys. Rev. B 95, 7505 (1987)

23. - Chadi,D.J.; Chang,K.J. - Phys. Rev. Lett 61, 873 (1988)

24. - Li,M.F.; Yu,P.Y.; Weber,E.R.; Hansen,W. - Phys. Rev. B 96,4531 (1987)

25. - Anderson.P.W. - Phys. Rev. Lett. 94,953 (1975)

26. - Khachaturyan,K.A.; Awschalom,D.D.; Rozen,J.R.; Weber,E.R. - Phys. Rev. Lett. 69, 1311 (1989)

27. - Van Vechten,J.A. - Mat. Res. Soc. Symp. Proc. 46, 83 (1985)

28. - Dannefaer,K.; Kerr,D. - J. Appl. Phys. 60, 591 (1986)

29. - Chaudhuri,S.; Coon,D.D. - Phys. Rev. B 90, 3338 (1984)

30. - Bourgoin,J.C.; Maude,A. - Appl. Phys. Lett. 5s, 749 (1988)

31. - Bourgoin,J.C. - "A Critical View of DX Models" em : Physics of DX Centers in GaAs Alloys, ed. por J.C. Bourgoin, Sci-Tech, 1990, pag. 253 
32. - Foulon,Y.; Lannoo,M.; Allan,G. - "The $A_{1}-T_{2}$ Transition of Substitutional Deep Impurities" em : Pysics of DX Centers in GaAs Alloys, ed. por J.C. Bourgoin, Sci.-Tech, 1990, pag.195

33. - Mooney,P.M.; Theis,T.N.; Wright.S.L. - Appl. Phys. Lett. 59, 2546 (1989)

34. - Morgan,T.N. - J. Electron. Materiais 20,63 (1991)

35. - Morgan,T.N. - Phys. Rev. B \$4, 2664 (1986)

36. - Lang,D.V.; Logan,R.A. - Phys. Rev. Lett. 39, 635 (1977)

37. - Chadi,D.J.; Cohen,M.L. - Phys. Rev. B 8, 5747 (1973)

38. - Baldereschi,A. - Phys. Rev. B 7, 5212 (1973)

39. - Fujisawa.T.; Yoshino.J. Kukimoto.H. - Proc. 20th Int. Conf. Phys. Semicond., Thessaloniki - Grécia, 1990, pag. 509

40. - Fujisawa,T.; Yoshino,J.; Kukimoto,H. - Jpn. J. Appl. Phys. 29, L388 (1990)

41. - Wood,C.E.C. - "Molecular Beam Epitaxial III-V Compounds : Dopant Incorporation and Behavior" em : Molecular Beam Epitaxy and Heterostructures, ed. por L.L. Chang e K. Ploog, Dordrecht, 1985

42. - Monch,W. - "Some Aspects of Surface Science Related to MBE" em : Molecular Beam Epitaxy and Heterostructures, ed. por L. L. Chang e K. Ploog, Dordrecht, 1985

43. - Nicholas,R.J.; Brummell,M.A.; Portal,J.C.; Gregoris,G.; Hersee, S.; Duchemin,J.P. - Appl. Phys. Lett. 44, 629 (1984)

44. - Chand,N.; Fischer,R.; Klem,J.; Henderson,T.; Pearah; Masselink,W. T.; Chang,Y.C.; Morkoc - J. Vac. Sci. Technol. B 3, 644 (1985)

45. - Ploog,K. - "Retrospect and Prospects of MBE" em: The Technology and Physics of Molecular Beam Epitaxy, ed. por E.H.C. Parker, Plenum Press, N. York, 1985, pag. 647

46. - Heckingbottom,R.; Todd,C.J.; Davies,G.J. - J. Eletrochem. Soc. 127, 445 (1980) 
47. - Van Hove,J.M.; Cohen.P.I. - Appl. Phys. Lett. 47, 726 (1985)

48. - Ludeke,R.; King,R.M.; Parker,E.H.C. "MBE Surface and Interface Studies" em : The Technology and Physics of Molecular Beam Epitaxy, ed. por E.H.C. Parker, Plenum Press, N. York, 1985, pag. 555

49. - Jaeger,R.C. - Introduction to Microelectronic Fabrication, Modular Series on Solid State Devices,vol. 5, ed. por G.W. Neudeck e R.F. Perret, Addison-Wesley, 1989

50. - Yoo,H.; Scalvi,L.V.A. - "The VEECO Evaporation System" em : Solid State Processing Field Manual, Oregon State University, 1990, pag. 60

51. - Ebner,J.; Scalvi,L.V.A. - "The VEECO Sputtering System" em : Solid State Processing Field Manual, Oregon State University, 1990, pag. 53

52. - Theis,T.N.; Mooney,P.M. - The DX Center : Evidence for a Charge Capture via an Excited Intermediate State, Relatório Interno-Divisão de Pesquisa IBM, Yorktown Heights, 1989

53. - Scalvi,L.V.A.; Wager,J.F. - Transient Decay of Persistent Photoconductivity in AlGaAs, poster apresentado no VII Oregon Materials Science Symposium, Corvallis, 1990 (não publicado)

54. - Scalvi,L.V.A.; Wager,J.F. - "The Transient Decay of Persistent Photoconductivity in $\mathrm{Al}_{x} \mathrm{Ga}_{1-x} \mathrm{As}$ : Measurements and Simulations", Proc. 5th Brazilian School on Semiconductor Physics, World Scientific, São Paulo, 1991 ( a ser publicado)

55. - Mooney,P.M.; Caswell,N.S.; Wright,S.L. - J. Appl. Phys. 62, 4789 (1987)

56. - Sze,S.M. - Semiconductor Devices, Physics and Technology, John Wiley \& Sons, N. York, 1985

57. - Casey,H.C.; Panish,M.B. - Heterostructure Lasers, Academic Press, New York, 1978

58. - Blakemore,J.S. - Semiconductor Statistics, Dover Publications, N. York, 1987

59. - Saxena,A.K.; Mudares,M.A.L. - J. Appl. Phys. 58, 2795 (1985) 
60. - Weisberg,L.R. - J. Appl. Phys. 39. 1817 (1962)

61. - Ridley,B.K. - Quantum Processes in Semiconductors, Clarendon Press, Oxford, 1988

62. - Adachi,S. - J. Appl. Phys. 58, R1 (1985)

63. - Brooks,H. Phys Rev 89, 879 (1951)

64. - Chattopadhyay,D.; Queisser.H.J. - Rev. Modern Phys. 53, 745 (1981)

65. - Takimoto,N. - J. Phys. Soc. Japan 14, 1142 (1959)

66. - Hall,G.L. - J. Phys. Chem. Solids 2\$, 1147 (1962)

67. - Takikawa,M.; Ozeki,M. - Japan. J. Appl. Phys. 24, 303 (1985)

68. - Dobson,T.W.; Scalvi,L.V.A.; Wager,J.F. - J. Appl. Phys. 68, 601 (1990)

69. - Jia,Y.B.; Li,M.F.; Zhou,J.; Gao,J.L.: Kong,M.Y.: Yu,P.Y.; Chan,K.T. J. Appl. Phys. 66, 5632 (1989)

70. - Li,M.F.; Jia,Y.B.; Yu,P.Y.; Zhou,J.; Gao,J.L. - Phys. Rev. B 40, 1430 (1989)

71. - Dmochowski,J. - Phys. Rev. B 42, 9709 (1990)

72. - Zhang,S.B.; Chadi,D.J. - Phys. Rev. B 42, 7174 (1990)

73. - Neumark,G.F.; Kosai,K. - "Deep Levels in Wide Band Gap III-V Semiconductors" em: Semiconductors and Semimetals, vol. 19, ed. por R.K. Willardson e A.C. Beer, Academic Press, N. York, 1983, pag. 1

74. - Schottky,W.- Naturwiss. 26, 843 (1938)

75. - Mott,N.F. - Proc. Cambr. Phyl. Soc. 34, 568 (1938)

76. - Rhoderick,E.H.; Williams,R.H. - Metal-Semiconductor Contacts, segunda edição, Oxford University Press, N. York, 1988

77. - Bardeen,J. - Phys. Rev. 71, 717 (194'7)

78. - Cowley,A.M.; Sze,S.M. - J. Appl. Phy's. 36, 3212 (1965)

79. - Reggiani,L. - "General Theory" em: Hot Electron Transport in Semiconductors, ed. por L. Reggiani, Topics in Applied Physics, vol. 58, Springer Verlag, Berlin 1985, pag. 7 
80. - Gossick.B.R. - Solid State Electronics 0,445 (1963)

81. - Card,H.C.; Rhoderick.E.H. - J. Phys. D : Appl. Phys. 4, 1602 (1971)

82. - Sharma,B.L. - "Ohmic Contacts to III-V Semiconductors", em: Semiconductors and Semimetals, ed. por R.K. Willardson e A.C. Beer, Academic Press 1981, pag. 1

83. - Kim,T.; Chung,D.D.L. - Thin Solid Films 147, 177 (1987)

84. - Shih,K.K.; Blum,J.M. - Solid State Electronics 15, 1177 (1972)

85. - Popovic,R.S. - Solid State Electronics 21, 1133 (1978)

86. - Yoder,M.N. - Solid State Electronics 29, 117 (1980)

87. - Kim,T.; Chung,D.D.L.; Mahajan,S. - Mat. Soc. Symp. Proc. 77, 369 (1987)

88. - Kim,T.; Chung,D.D.L.; Mahajan,S. - Mat. Soc. Symp. Proc. 77, 749 (1987)

89. - Kuan,T.S.; Batson,P.E.; Jackson,T.N.; Rupprecht,H.; Wilkie,E.L. - J. Appl. Phys. 54, 6952 (1983)

90. - Waldrop,J.R.; Grant,R.W. - Appl. Phys. Lett. 50, 250 (1987)

91. - Ball,R.K. - Thin Solid Films 176, 55 (1989)

92. - Kavanagh,K.L. - tese de doutorado, University of Cornell 1987 (de : Impurities and Defects in Group IV Elements and III-V Compounds, ed. por M. Schulz - Crystal and Solid State Physics, vol. 22, subvol. b, Springer Verlag 1989)

93. - Fujisawa,T.; Yoshino,J.; Kukimoto,H. - J. Crystal Growth 98, 243 (1989)

94. - Schubert,E.F.; Ploog,K. - Jpn. J. Appl. Phys. 24, L608 (1985)

95. - Ploog,K. - J. Crystal Growth 81, 304 (1987)

96. - Tyagi,M.S. - "Physics of Schottky Barrier Junctions" em : MetalSemiconductor Schottky Barriers Junctions and Their Applications, ed. por B.L. Sharma, Plenum Press 1984, pag. 1

97. - Rideout, V.L. - Solid State Electron. 18, 541 (1975) 
98. - Kumagi,O.; Kawaii.H.; Mri,Y.; Kaneko,K. - Appl. Phys. Lett. 45, 5554 (1989)

99. - Basmaji,P.; Scalvi,L.V.A.; Minami.E. - Shallow and Deep DX Center in Pb-Doped $A l_{x} G a_{1-x} A s$, Phys. Rev. B (aceito para publicação)

100. - Calleja,E.; Garcia,F.; Gomez,A.; Munoz,E.; Mooney,P.M.; Morgan,T.N.; Wright,S.L.; - Appl. Phys. Lett. 56, 954 (1990)

101. - Nelson.R.J. - Appl. Phys. Lett. 31, 351 (1977)

102. - Sarena,A.K. - Solid State Electron. 25, 127 (1982)

103. - Kunzel,H.; Fischer,A.; Knecht,J.; Ploog,K. - Appl. Phys. A 92,69 (1983)

104. - Collins D.M.: Mars,D.E.; Fischer,B.; Kocot,C. - J. Appl. Phys. 54, 857 (1983)

105. - Nicholas,R.J.; Brummeil,M.A.; Portal,J.C.; Gregoris,G.; Hersee,S.; Duchemin,J.P. - Appl. Phys. Lett. 44, 629 (1984)

106. - Van der Pauw,L.J. - Philips Technical Rev. 20, 220 (1959)

107. - Chwang,R.; Smith,B.J.; Crowell,C.R. - Solid State Electron. 17, 1217 (1974)

108. - Stillman,G.E.; Wolfe,C.M. - Thin Solid Films \$1, 96 (1976)

109. - Blatt,F.J. - "Theory of Mobility of Electrons in Solids", em: Solid State Physics : Advances in Research and Applications, vol. 4, ed. por F. Seitz e D. Turnbull, Academic Press 1957, pag. 199

110. - Stillman,G.E.; Wolfe,C.M.; Dimmock,J.O. - J. Phys. Chem. Solids 31, 1199 (1970)

111. - Oelgart,G; Grummt,G; Lippold,G; Pickenhain; Schwabe,L - Semicond. Sci. Technol. 5, 894 (1990)

112. - Katsumoto,S.; Matsunaga,N; Yoshida,Y.; Sugiyama,K.; Kobayashi,S. Proc. 20th Int. Conf. Phys. Semicond., Thessaloniki - Grécia 1990, pag 481

113. - O'Reilly, O.P. - Appl. Phys. Lett. 55, 1409 (1989) 
114. - Mooney, P.M. - conferência no XIV Encontro Nacional de Física da Matéria Condensada, Caxambu 1991 (não publicado)

115. - Theis,T.N.; Mooney,P.M. - Mat. Res. Soc. Symp. Proc. 16\$, 729 (1990)

116. - Sampaio,J.F.; Chaves, A.S.; Ribeiro,G.M.; Guimarães,P.S.S., Carvalho,R.P.; Oliveira,A.G. - Transient and Steady Decay of Persistent Photoconductivity in Si-doped AlGaAs (a ser publicado)

117. - Mosser,V.; Contreras,S.; Robert,J.L.; Piotrzkowski,R.; Rochette,J.F.; Phys. Rev. Lett. 66, 1737 (1991) 